Linköping University Medical Dissertation No. 1706

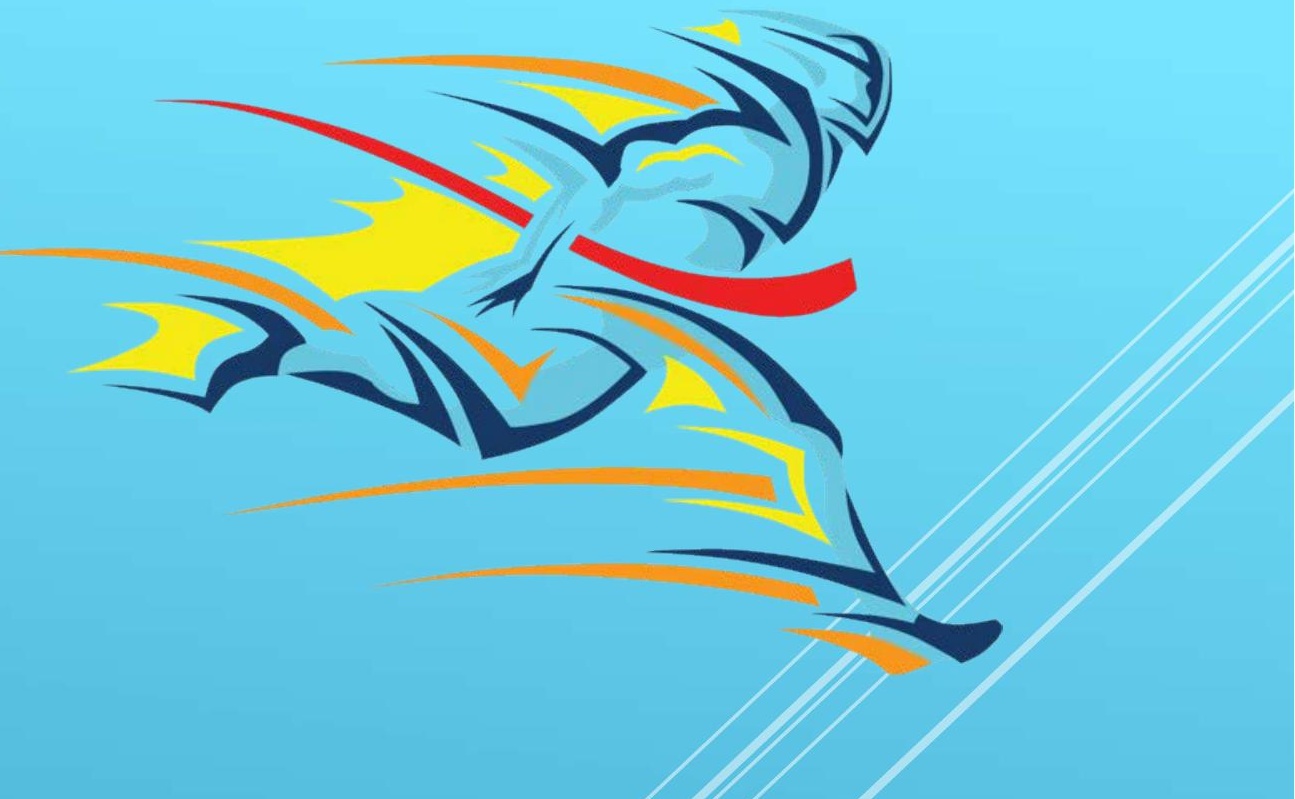

Treatment Decision after Anterior

Cruciate Ligament Injury, and Evaluation of Measurement Properties of a Patient Reported Outcome Measure

Hanna Tigerstrand Grevnerts
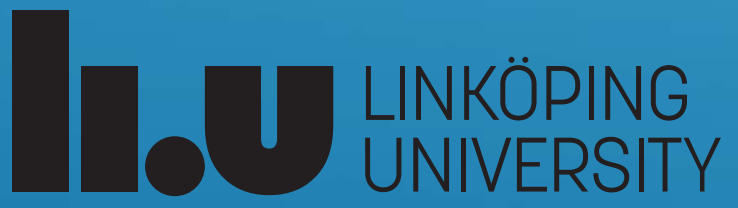
Linköping University Medical Dissertations No. 1706

\section{Treatment Decision after Anterior Cruciate Ligament Injury, and Evaluation of Measurement Properties of a Patient Reported Outcome Measure}

Hanna Tigerstrand Grevnerts

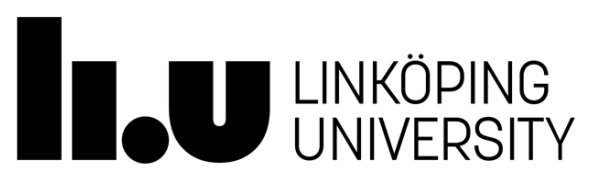

Department of Medical and Health Sciences

Linköping University, Sweden

Linköping 2019 
(C) Hanna Tigerstrand Grevnerts, 2019

Cover design: Free Logo Service

Published articles has been reprinted with the permission of the copyright holder

Printed in Sweden by LiU-Tryck, Linköping, Sweden, 2019

ISBN 978-91-7929-990-3

ISSN 0345-0082 
Till mina älskade barn och man!

"If your dreams don't scare you, they are not big enough" - Ellen Johnson Sirleaf 



\section{CONTENTS}

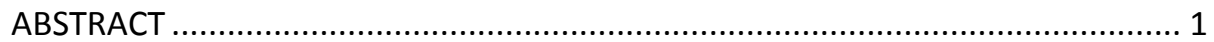

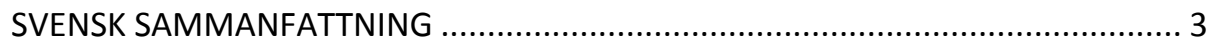

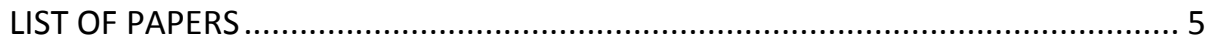

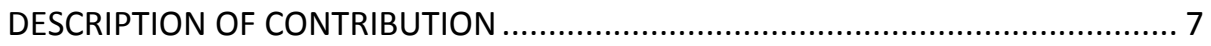

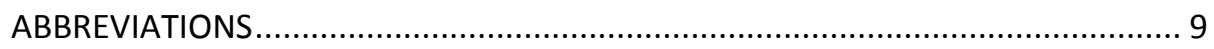

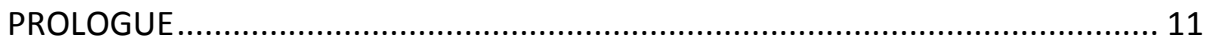

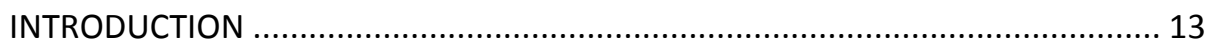

Treatment decision- from evidence to recommendation........................ 13

Treatment decision- patient contribution .............................................. 15

Choice of treatment after ACL injury ................................................... 16

Little knowledge of patient's perspective of important reasons for choice of

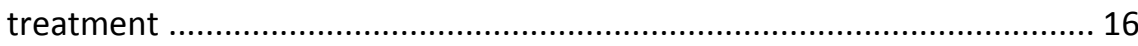

Short- and long-term consequences after ACL injury ............................. 16

Rehabilitation after ACL injury and after ACLR ................................... 16

Evaluation after $\mathrm{ACL}$ injury ................................................................ 17

Patient-reported outcome measures ................................................. 17

Measurement properties of a patient-reported outcome measure............ 18

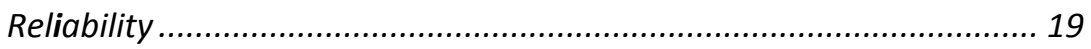

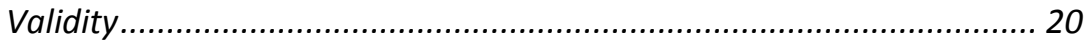

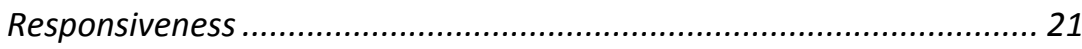

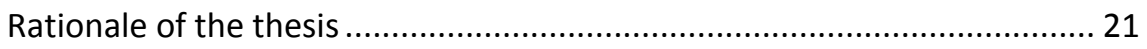

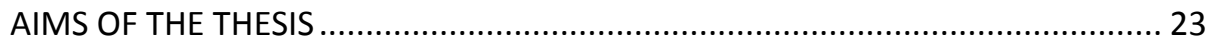

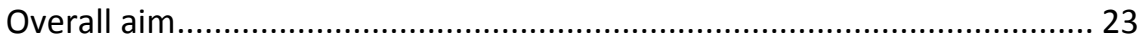

Specific aims ............................................................................... 23

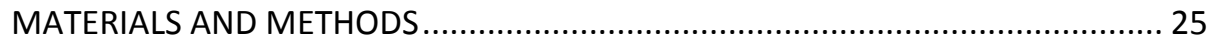

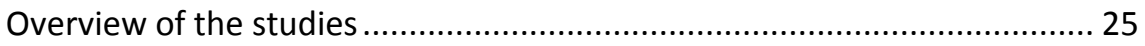

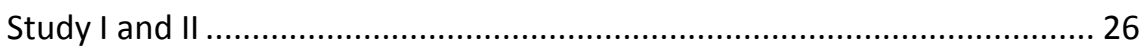

Systematic review ...................................................................... 26

Update of the systematic review .................................................. 27 


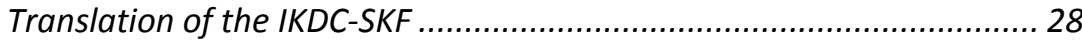

Participants and data collection ...................................................... 28

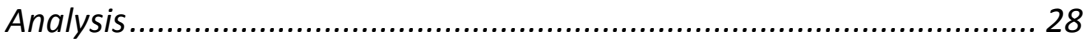

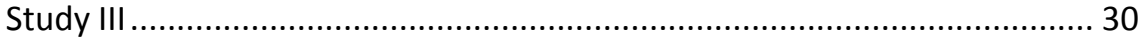

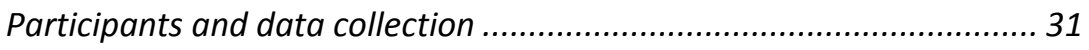

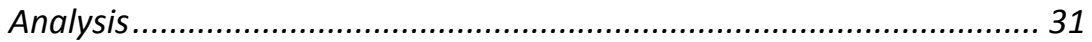

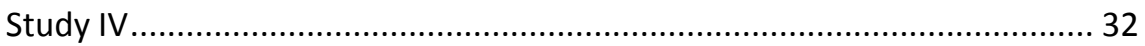

Participants and data collection ......................................................... 32

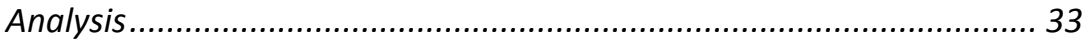

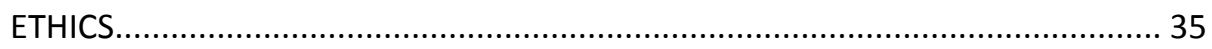

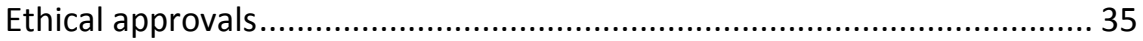

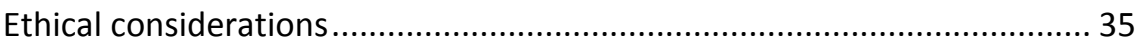

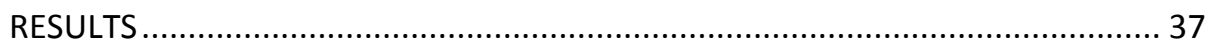

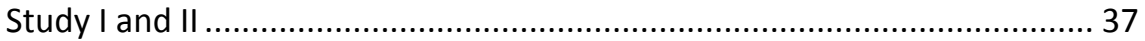

Systematic review of the measurement properties of the IKDC-SKF ...... 37

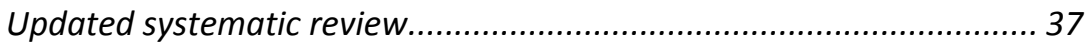

The measurement properties of the Swedish version of the IKDC-SKF... 40

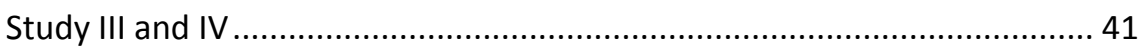

Factors that orthopaedic surgeons and physiotherapists rate as important to recommend ACLR ............................................................... 41

Open-ended question for factors considered important to recommend

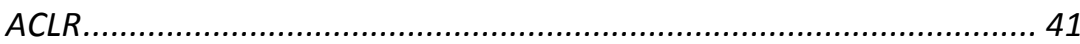

Orthopaedic surgeon's, physiotherapist's and patient's contributions to

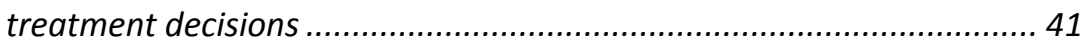

Compliance to rehabilitation; communication about treatment decision

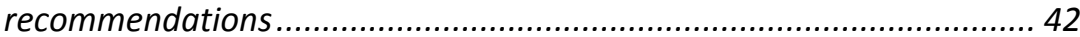

Treatment decision after an ACL injury; what decision was made and

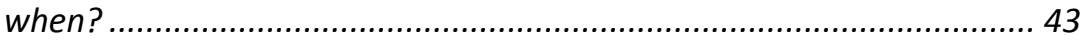

Reasons for treatment decision ........................................................ 43

Comparisons of patient-reported factors between ACLR and nonoperative groups ................................................................................... 43

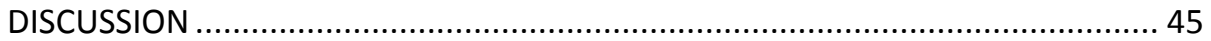

Measurement properties of patient-reported outcome measures ............. 45 


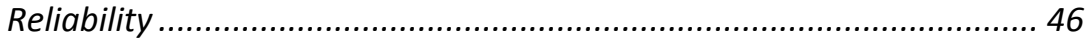

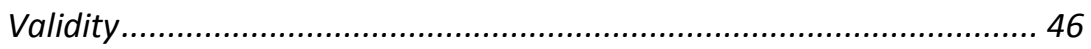

Responsiveness ............................................................................. 49

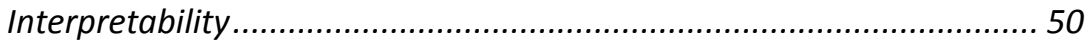

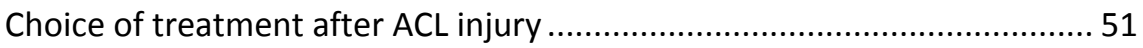

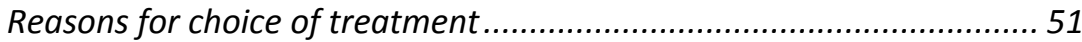

Treatment decision process: patient's, physiotherapist's and orthopaedic

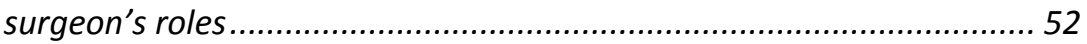

Patient-reported factors in relation to choice of treatment................... 54

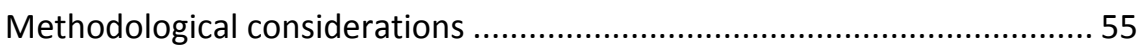

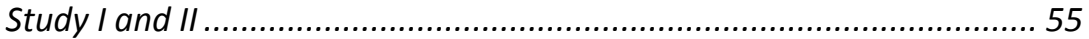

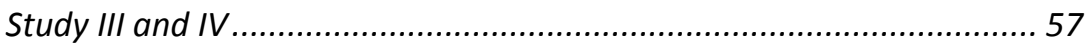

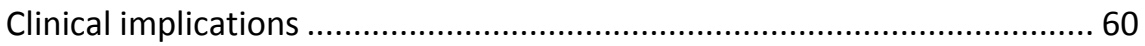

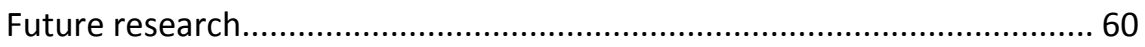

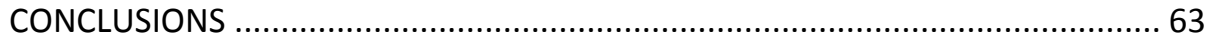

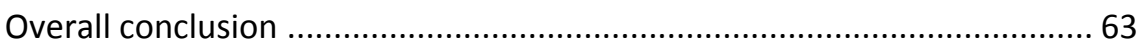

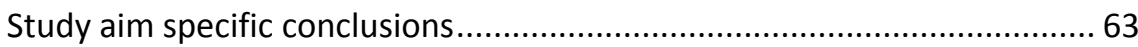

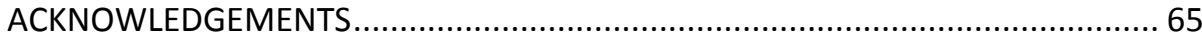

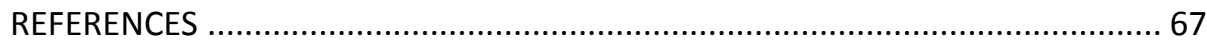

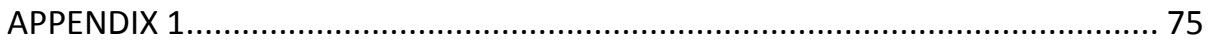





\section{ABSTRACT}

Background: After an ACL injury, treatment aims to restore knee function. Evaluation of treatment progress is important, and adequate measurement methods are necessary. The International Knee Documentation CommitteeSubjective Knee Form (IKDC-SKF) is a common patient-reported outcome measure (PROM) used after ACL injury. It evaluates symptoms, function and physical activity. The IKDC-SKF had not been translated to Swedish language for use in Swedish clinical and research settings. The measurement properties of the IKDC-SKF had been tested, but no assessment of methodological quality of the studies investigating it, nor compiling of results, was published.

Sooner or later after an $A C L$ injury, a treatment decision must be made. Treatment options are either $A C L$ reconstruction (ACLR) plus rehabilitation, or rehabilitation alone. There are guidelines stating that a decision for ACLR should be made if the patient has high activity demands and/or knee joint instability. It is unclear which factors orthopaedic surgeons and physiotherapists prioritise when recommending ACLR. It is also unclear when the decision for treatment is taken, on what grounds, and how treatment decision correlates to patients reported symptoms and function.

Aims: The overall aim of this thesis was to evaluate the measurement properties of a patient-reported measure for evaluation of function after ACL injury and treatment, and to overview the treatment decision process after an ACL injury.

Methods: A systematic review was conducted to assess the measurement properties of the IKDC-SKF. The IKDC-SKF was translated from English to Swedish, and the Swedish version was tested for reliability, validity, responsiveness and interpretability.

A survey study was conducted, where 98 orthopaedic surgeons and 391 physiotherapists rated 21 predefined factors based on importance to the decision for ACLR. Orthopaedic surgeons and physiotherapists rated how important they considered their own and each other's assesments and patient's wishes for treatment decision making.

In a prospective cohort study, patients with an $A C L$ injury were followed from within 6 weeks up to 12 months after injury. Data regarding treatment chosen, 
when and why, were described and compared to patient-reported pre-injury activity level, knee joint instability and function.

\section{Results:}

The English and Swedish version of the IKDC-SKF had good measurement properties and interpretability.

Swedish orthopaedic surgeons and physiotherapists considered young age, high activity demands, knee-demanding occupation, and knee joint instability despite adequate rehabilitation indications to recommend ACLR.

An early decision for ACLR was primarily based on high activity demands. A later decision was mainly due to knee joint instability and high activity demands. A decision taken later than five months after injury was based mainly on knee joint instability.

A decision for non-operative treatment taken and maintained during the first 12 months after injury was mainly due to sufficient function or no knee joint instability problems, and non-operatively treated patients were older than the other groups.

\section{Conclusions:}

The patient-reported outcome measurement IKDC-SKF is suitable for evaluation and assessment in patients with ACL injury.

ACLR as treatment after an ACL injury was recommended for young patients, patients with high activity demands (i.e. knee demanding occupation and/or knee joint instability despite adequate rehabilitation) and/or patients suffering from knee joint instability

An early decision for ACLR was more often based on high activity demands, while later decisions were more often based upon knee joint instability. Non-operative treatment decisions were often based upon lack of knee joint instability problems or sufficient knee function.

Self-reported knee joint instability and function during the first three months after ACL injury were no different in patients who chose ACLR treatment or who chose non-operative treatment.

Keywords: anterior cruciate ligament injury, $A C L, A C L$ reconstruction, $A C L R$, choice of treatment, IKDC, measurement properties, evaluation

ISBN: 978-91-7929-9 


\section{SVENSK SAMMANFATTNING}

Bakgrund: Efter en främre korsbandsskada syftar behandlingen att återställa knäfunktionen. Utvärdering av framstegen är av vikt, och adekvata mätmetoder för detta är nödvändigt. International Knee Documentation Committtee Subjective Knee Form (IKDC-SKF) är ett patientskattningsformulär som är välanvänt över hela världen vid främre korsbandsskador. Det utvärderar symptom, funktion och fysisk aktivitet. Det har inte funnits tillgängligt på svenska tidigare och det har heller inte funnits någon sammanställning över formulärets mätegenskaper.

Efter en främre korsbandsskada måste förr eller senare beslut om behandling fattas, om patienten ska genomgå en rekonstruktionsoperation för främre korsbandet, med efterföljande rehabilitering, eller enbart rehabilitering. Det finns riktlinjer som gör gällande att en korsbandsrekonstruktion kan vara ett adekvat alternativ när patienten har höga aktivitetskrav eller lider av instabilitet i knäleden. Det är dock ej fastställt vilka faktorer ortopedläkare och fysioterapeuter anser viktiga för att rekommendera rekonstruktionsoperation. Det är inte heller klargjort när efter skada och på vilka grunder faktiska behandlingsbeslut fattas, och hur orsaken till beslutet hänger samman med patientens självrapporterade symptom och funktion.

Syfte: Det övergripande syftet med avhandlingen var att utvärdera mätegenskaper för ett patientskattningsformulär som utvärderar funktion efter en främre korsbandsskada, samt att överblicka beslutsprocessen för behandling efter en främre korsbandsskada.

Metod: En systematisk genomgång utfördes av studier som utvärderat mätegenskaper för IKDC-SKF. Studierna värderades avseende metodologi och resultat. IKDC-SKF översattes till svenska, och den svenska versionens mätegenskaper prövades.

En enkätstudie utfördes där 98 svenska ortopedläkare och 391 svenska fysioterapeuter fick skatta 21 faktorers betydelse för valet att rekommendera rekonstruktionsoperation av främre korsbandet. Ortopedläkare och fysioterapeuter fick även skatta vikten av sin egen och varandras bedömning samt patientens önskan, i valet av behandling. 
I en prospektiv kohortstudie följdes 219 patienter med en främre korsbandsskada, från 6 veckor och upp till 12 månader efter skadan. Data om vilken behandling patienten genomgått, när behandling valdes och grunder för behandling samlades in från patient och ortopedläkare och jämfördes med patientskattad aktivitetsnivå innan skada, knäledsinstabilitet och funktion.

Resultat: Den systematiska genomgången av IKDC-SKF och prövningen av den svenska versionens mätegenskaper visade att IKDC-SKF uppvisar goda mätegenskaper och tolkningsbarhet.

Svenska ortopedläkare och fysioterapeuter anser att ung ålder, höga aktivitetskrav, knäkrävande arbete och knäledsinstabilitet trots adekvat rehabilitering är faktorer som indicerar behov av rekonstruktionsoperation av främre korsbandet.

Ett tidigt beslut för rekonstruktionsoperation efter främre korsbandsskada fattas i hög grad på grund av höga aktivitetskrav. Ett senare beslut för rekonstruktionsoperation fattas i hög grad på grund av knäledsinstabilitet och höga aktivitetskrav, medan ett sent beslut fattas i hög grad på grund av knäledsinstabilitet. Ett beslut att enbart behandla med rehabilitering fattas i hög grad på grund av att patienten har tillräckligt god funktion eller inte har några besvär från knäledsinstabilitet. Det var inga skillnader i patientskattad funktion och knäledsinstabilitet mellan de patienter där rekonstruktionsoperation valdes och de som valde att behandla med enbart rehabilitering.

Sammanfattning: IKDC-SKF visar goda mätegenskaper och kan rekommenderas för användning hos patienter med en främre korsbandsskada och andra knärelaterade diagnoser.

Efter en främre korsbandsskada fattas ett tidigt beslut för rekonstruktionsoperation på grund av höga aktivitetskrav. Ett senare beslut för rekonstruktionsoperation fattas när patienten lider av knäledsinstabilitet och nedsatt knäfunktion, medan ett beslut för enbart rehabilitering valdes när funktion och knästabilitet var god. Det var inga skillnader mellan patienter där man valt rekonstruktionsoperation och enbart rehabilitering, avseende skattad funktion och knäledsinstabilitet. Både ortopedläkarens och fysioterapeutens bedömning samt patientens önskan är viktig i valet av behandling.

Nyckelord: främre korsbandsskada, främre korsbandsrekonstruktion, val av behandling, IKDC, mätegenskaper, utvärdering

ISBN: 978-91-7929-990-3 


\section{LIST OF PAPERS}

I. Hanna Tigerstrand Grevnerts, Caroline Terwee, Joanna Kvist. The measurement properties of the IKDC-subjective knee form. Knee Surg Sports Traumatol Arthrosc. 2015 Dec;23(12):3698-706. doi: 10.1007/s00167-014-3283-z. Epub 2014 Sep 6.

II. Hanna Tigerstrand Grevnerts, Karin Grävare Silbernagel, Sofi Sonesson, Clare Ardern, Annika Österberg, Håkan Gauffin, Joanna Kvist. Translation and testing of measurement properties of the Swedish version of the IKDC subjective knee form. Scand J Med Sci Sports. 2017 May;27(5):554562. doi: 0.1111/sms.12861. Epub 2017 Mar 19.

III. Hanna Tigerstrand Grevnerts, Anne Fältström, Sofi Sonesson, Håkan Gauffin, Siw Carlfjord, Joanna Kvist. Activity demands and instability are the most important factors for recommending to treat $\mathrm{ACL}$ injuries with reconstruction Knee Surg Sports Traumatol Arthrosc. 2018 Aug;26(8):2401-2409. doi: 10.1007/s00167-018-4846-1. Epub 2018 Feb 6.

IV. Hanna Tigerstrand Grevnerts, Sofi Sonesson, Håkan Gauffin, Clare Ardern, Anders Stålman, Joanna Kvist. Decision-making for surgical or nonsurgical treatment after an ACL injury: acute and subacute treatment decision is based upon expected future activity demands and later decision on current knee function. Manuscript in process. 



\section{DESCRIPTION OF CONTRIBUTION}

\section{Study 1}

Study Design: Hanna Tigerstrand Grevnerts, Joanna Kvist

Data Collection: Hanna Tigerstrand Grevnerts, Joanna Kvist

Data Analysis: Hanna Tigerstrand Grevnerts, Joanna Kvist

Manuscript Writing: Hanna Tigerstrand Grevnerts, Joanna Kvist

Manuscript Revision: Hanna Tigerstrand Grevnerts, Joanna Kvist, Caroline Terwee

Study 2

Study Design: Hanna Tigerstrand Grevnerts, Joanna Kvist, Karin Grävare Silbernagel, Sofi Sonesson, Clare Ardern,

Data Collection: Hanna Tigerstrand Grevnerts, Joanna Kvist

Data Analysis: Hanna Tigerstrand Grevnerts, Henrik Hedevik

Manuscript Writing: Hanna Tigerstrand Grevnerts

Manuscript Revision: Hanna Tigerstrand Grevnerts, Joanna Kvist, Karin Grävare Silbernagel, Sofi Sonesson, Clare Ardern, Annika Österberg, Håkan Gauffin

Study 3

Study Design: Joanna Kvist, Hanna Tigerstrand Grevnerts, Anne Fältstöm, Sofi Sonesson, Håkan Gauffin, Siw Carlfjord

Data Collection: Gunilla Leidelöf, Joanna Kvist

Data Analysis: Hanna Tigerstrand Grevnerts

Manuscript Writing: Hanna Tigerstrand Grevnerts

Manuscript Revision: Hanna Tigerstrand Grevnerts, Anne Fältström, Joanna Kvist, Sofi Sonesson, Håkan Gauffin, Siw Carlfjord 
Study 4

Study Design: Hanna Tigerstrand Grevnerts, Joanna Kvist, Sofi Sonesson, Håkan Gauffin, Clare Ardern, Anders Stålman

Data Collection: Hanna Tigerstrand Grevnerts

Data Analysis: Hanna Tigerstrand Grevnerts

Manuscript Writing: Hanna Tigerstrand Grevnerts

Manuscript Revision: Hanna Tigerstrand Grevnerts, Sofi Sonesson, Håkan Gauffin, Clare Ardern, Anders Stålman, Joanna Kvist 


\section{ABBREVIATIONS}

$\mathrm{ACL}$

ACLR

ANOVA

AUC

COSMIN

ES

GRC

GRADE

ICC

IKDC-SKF

KOOS

MCS

$\mathrm{MCIC}$

PCS

PROM

ROC

SD

SDC

SDCgroup

SDCind

SF36

SRM
Anterior cruciate ligament

Anterior cruciate ligament reconstruction

Analysis of variance

Area under the curve

COnsensus-based Standards for the selection of health Measurement INstruments

Effect Size

Global rating of change

Grading of Recommendations Assessment, Development and Evaluation

Intraclass correlation coefficient

International Knee Documentation Committee Subjective Knee Form

Knee injury and osteoarthritis outcome score

Mental component summary (of SF36)

Minimal Clinical Important Change

Physical component summary (of SF36)

Patient Reported Outcome Measure

Receiver operator curve

Standard deviation

Smallest detectable change

Smallest detectable change group

Smallest detectable change individual

Short Form 36

Standardized response mean 



\section{PROLOGUE}

As a child, I was not interested in sports. I loved to read. I used to beg my mother to tell kids who rang on the doorbell asking to play, that I was sick. I just wanted to be left alone with my books.

As a child I also loved to plan and make lists. I used to make Christmas lists in February, for the presents I would make myself to my family. But I always had a hard time to focus and structure when things were boring. My childhood room was a mess, I've lost plenty of house keys in my life and I can't remember the times I forgot to bring clothes for gymnastics class or forgot an apple or banana in my schoolbag- resulting in having to throw everything in the bag and clean it from rotten fruit...

When I was about 14 year old, a gymnastics teacher in school had a lecture about the importance of strengthening the body with physical activity. It really made me understand that I needed to be more physically active. Since I didn't like team sports, I just felt clumsy and awkward, I begun to work out at the gym. I loved it. I wanted to know everything about the muscles and the body. I wanted to become a body builder.

A natural step to "knowing everything" about the body, I thought, was to become a physiotherapist. I studied in Linköping, and loved it. While writing my bachelor thesis, I had an inspiring supervisor that asked if I wanted to write some further and turn the essay in to a scientific article. I liked the writing, and I liked to challenge myself, so we wrote a manuscript for a scientific journal. It was published.

Some years later, I decided to do the master programme, and quite early into the programme I realised how much I had missed the university world, and the structure. I thought that PhD studies must be the greatest challenge I could ever imagine. So, that was what I wanted to do!

I had the same supervisor for both bachelor and master thesis, and I found that she had a way of mentoring that motivated me in to doing my best. I had the fortune that she agreed to be my PhD supervisor too. 
During these years of PhD studies, I have learned so much. I have challenged myself. I have been nervous so many times. I have been full of endorphins and joy when I have overcome my fears. I have developed new sides of myself.

I have had the fortune to co-examine more than 250 patients with an acute knee injury together with two great orthopaedic surgeons. The experience I bring from these sessions will be useful for me for the rest of my career as a physiotherapist.

I have loved (almost) every moment of my years as a PhD student, and I am so grateful that I have had the opportunity to do this. The experiences during these years, are of the kind that money cannot buy.

I quote Forrest Gump; "life is like a box of chocolates". I think that the years as a $\mathrm{PhD}$ student are too. There are some chocolates that go down easily with joy, and some that are bitterer to chew on. But you need the bitter ones to appreciate the most delicious ones, and all together the box is perfectly balanced.

Enjoy reading my box of chocolate! 


\section{INTRODUCTION}

For as long as people have participated organized sports, there have been reports of sports injuries. There have also been attempts to heal injuries, in one way or another. Since Hippocrates sought to treat sports related injuries ${ }^{66}$, we have sought to evaluate and improve the treatment methods. To find the best way to help the patient to heal as safely and quickly as possible and to return to sport.

An Anterior Cruciate Ligament ( $A C L$ ) injury is a serious sports injury ${ }^{59,96}$. The late nineteenth century saw the first attempts to reconstruct the torn ligament ${ }^{66,109}$. Techniques for surgical repair of the ACL have varied ever since ${ }^{109}$. Regardless how a torn ACL is replaced, it seems that function and motor control is not restored to the preinjury state ${ }^{99,128}$.

In the early eighties, Noyes described the ACL injury and corollary. Approximately one third of an $A C L$ injured cohort requires reconstructive surgery, one third seems to manage without surgery, and one third manages with a modification of activity ${ }^{93,94}$. Today, the two major treatment options are $\mathrm{ACL}$ reconstruction plus rehabilitation, or rehabilitation alone (non-operative treatment). Patients report satisfactory outcomes following non-operative treatment ${ }^{40,74}$. However, in many countries, ACLR is the standard treatment after ACL injury. We lack evidence about how treatment is chosen. In all medical care approaches, the best treatment possible is desirable.

\section{Treatment decision- from evidence to recommendation}

Evidence Based Medicine (EBM) is the foundation of modern health care systems, and the basis for empirical practice of medicine ${ }^{25}$. EBM is often divided into two branches: one with more emphasis on clinical experience and judgement, and one with more emphasis on research evidence ${ }^{108}$. Critics of EBM are concerned that research is emphasized too much, and clinical expertise and patients preferences are ignored ${ }^{123}$. With constant updates of clinical guidelines and publication of new research, it may be a challenge for clinicians to stay up-to-date and utilize the latest evidence ${ }^{21}$. The core message of EBM is that good clinical practice should be based upon valid and reliable research. Although, in practice 
there is often a gap between the available research and its use in clinical decision making ${ }^{33,111 .}$

Evidence Based Practice (EBP), was developed as a response to growing demands in health care organizations for professional practice to be based on research and treatment decisions based on evidence of effectiveness ${ }^{18}$. EBM is the theoretical framework and foundation to EBP, and the result of improving how researchers conduct and clinicians use research ${ }^{39}$. Clinical practice and recommendations should be based on up-to-date, valid and reliable evidence from research. However, the disparity between the production of research and the use of research findings in clinical practice -the research-practice gap ${ }^{89}$ - is hard to bridge.

Researchers have attempted to bridge the gap between research and practice by developing guidelines that include information about the strength of recommendations for different treatments. Several factors impact on clinical recommendations. The more complex the decision, the more important it is that the recommendations are clear, and can lead to clinical guidelines or policies ${ }^{80}$. The Grading of Recommendations Assessment, Development and Evaluation (GRADE) is a theoretical framework for assessing the quality of guidelines. GRADE aims to ease the translation from evidence to clinical recommendations ${ }^{50}$. Clinical recommendations can be assessed as "strong" or "weak". Strong recommendations imply (i) evidence is strong for that treatment, (ii) most patients will want and should receive the treatment, and (iii) recommendations can often be adopted as a policy. Weak recommendations imply (i) evidence is lacking, (ii) many patients should not receive the treatment, and (iii) policies cannot be made without considerable discussions ${ }^{50}$. After rating the quality of the evidence (considering design and potential biases), there are four key factors that are important to assess whether a recommendation is strong or weak (figure 1) ${ }^{50}$ :

1. There should be a balance between desirable and undesirable consequences (i.e. a valuation of potential adverse effects of the treatment).

2. There should be strong evidence for treatment method and effect (i.e. research of high methodological quality). 
3. Values and preferences; the more variation in preferences, or high uncertainty in values and preferences, the greater chance of a weak recommendation.

4. Cost-effectiveness; higher costs might cause a recommendation to lose impact.

\begin{tabular}{|c|c|c|c|c|c|c|}
\hline \multirow{7}{*}{ 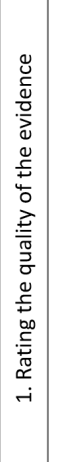 } & \multicolumn{2}{|c|}{$\begin{array}{c}1 . \\
\text { Establish initial } \\
\text { level of confidence }\end{array}$} & \multirow{2}{*}{\multicolumn{3}{|c|}{$\begin{array}{l}2 . \\
\begin{array}{l}\text { Consider lowering or raising } \\
\text { level of confidence }\end{array} \\
\begin{array}{c}\text { Reasons for considering lowering } \\
\text { or raising confidence }\end{array}\end{array}$}} & $\begin{array}{c}3 . \\
\text { Final level of } \\
\text { confidence rating }\end{array}$ \\
\hline & \multirow[t]{2}{*}{ Study design } & \multirow{2}{*}{$\begin{array}{l}\text { Initial } \\
\text { confidence } \\
\text { in an estimate } \\
\text { of effect }\end{array}$} & & & & \multirow{2}{*}{$\begin{array}{c}\text { Confidence } \\
\text { in an estimate of effect } \\
\text { across those considerations }\end{array}$} \\
\hline & & & \multicolumn{2}{|c|}{$\downarrow$ Lower if } & $\uparrow$ Higher if & \\
\hline & Randomized trials $\rightarrow$ & $\begin{array}{c}\begin{array}{c}\text { High } \\
\text { confidence }\end{array}\end{array}$ & \multirow{4}{*}{\multicolumn{2}{|c|}{$\begin{array}{l}\text { Risk of Bias } \\
\text { Inconsistency } \\
\text { Indirectness } \\
\text { Imprecision } \\
\text { Publication bias }\end{array}$}} & \multirow{4}{*}{$\begin{array}{l}\text { Large effect } \\
\text { Dose response } \\
\text { All plausible } \\
\text { confounding \& bias } \\
\text { - would reduce a } \\
\text { demonstrated effect } \\
\text { or } \\
\text { - would suggest a } \\
\text { spurious effect if no } \\
\text { effect was observed }\end{array}$} & $\begin{array}{l}\text { High } \\
\oplus \oplus \oplus \oplus\end{array}$ \\
\hline & & & & & & $\begin{array}{c}\text { Moderate } \\
\oplus \oplus \oplus O\end{array}$ \\
\hline & \multirow[t]{2}{*}{ Observational studies $\rightarrow$} & \multirow[t]{2}{*}{$\begin{array}{l}\text { Low } \\
\text { confidence }\end{array}$} & & & & $\begin{array}{l}\text { Low } \\
\oplus \oplus \bigcirc \bigcirc\end{array}$ \\
\hline & & & & & & $\begin{array}{l}\text { Very low } \\
\oplus 000\end{array}$ \\
\hline \multirow{2}{*}{ 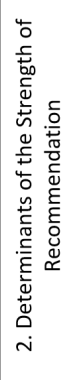 } & \multirow[t]{2}{*}{$\begin{array}{c}\text { Quality } \\
\text { (certainty) } \\
\text { of evidence }\end{array}$} & \multirow[t]{2}{*}{$\begin{array}{l}\text { Balance } \\
\text { between } \\
\text { benefits, harms } \\
\text { \& burdens }\end{array}$} & \multirow{2}{*}{ 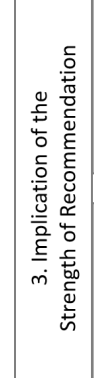 } & 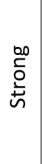 & \multicolumn{2}{|c|}{ 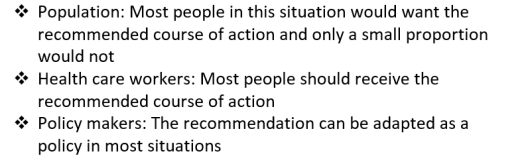 } \\
\hline & & & & $\sum_{3}^{\frac{2}{0}}$ & $\begin{array}{l}* \text { Population: The } n \\
\text { want the recomm } \\
\text { Health care work } \\
\text { decision that is cc } \\
\text { and shared decisi } \\
* \text { Policy makers: Th } \\
\text { involvement of st }\end{array}$ & $\begin{array}{l}\text { ople in this situation would } \\
\text { of action, but many would not } \\
\text { ed to help people to make a } \\
\text { their own values/decision aids } \\
\text { for substantial debate and }\end{array}$ \\
\hline
\end{tabular}

Figure 1. Factors affecting decision making according to GRADE. Reprinted with permission from the U.S. GRADE Network.

\section{Treatment decision- patient contribution}

Patient's preference is an important factor and a key component in shared decision making. Shared decision making aims to enhance patients' involvement in the treatment decision. In sports medicine, efforts should be made to consider long-term outcome, especially for young athletes. Cost-effectiveness and risk assessment must be considered, and an assessment of the appropriateness of the stakeholders to make the decision, as well as the appropriateness of the decision itself $^{6,10}$. 


\section{Choice of treatment after ACL injury}

There are no internationally-accepted guidelines on how to treat an ACL injury. There are several guidelines and recommendations ${ }^{9,78,84,112}$ stating that knee joint instability and high activity demands are indications for ACLR. However, nonoperative treatment can be an effective treatment also ${ }^{40,48}$. Although there is uncertainty about which patient is a candidate for ACLR and which patient can be managed with non-operative treatment, there have been attempts to develop decision rules to ease the decision for choice of treatment ${ }^{74,88}$. Studies of these decision rules show that patients who are initially classified as copers (able to manage without surgery) might need ACLR later, and some patients who have surgery might have been able to cope without it.

\section{Little knowledge of patient's perspective of important reasons for choice of treatment}

There are few studies of patient's perspective regarding choice of treatment after an $A C L$ injury ${ }^{116,120}$. Patients state that fear of not being able to participate in sports to the same extent as before the injury, disbelief in the ability to perform in physical activity/sports, and knee joint instability/giving way episodes or impaired knee function are important reasons for choosing ACLR treatment ${ }^{116}$. We lack knowledge of patient's reasons for choosing a non-operative treatment.

\section{Short- and long-term consequences after $\mathrm{ACL}$ injury}

The $\mathrm{ACL}$ is an important structure in the knee, controlling rotation and anteroposterior displacement of the tibia on the femur ${ }^{77}$. Patients experience swelling and pain early after $A C L$ injury ${ }^{17}$. Knee joint instability or giving way symptoms often occur after swelling has reduced and the knee is exposed to more strenuous activity ${ }^{97}$. Giving way episodes can contribute to new injuries. When a decision for ACLR is taken later after $A C L$ injury, the risk for further injuries until the surgery is performed is significantly raised ${ }^{5,16,43}$. Associated injuries (e.g. meniscus injuries) are important risk factors for developing osteoarthritis ${ }^{22}$. ACLR does alter the risk of early onset of osteoarthritis, compared to non-operative treatment ${ }^{22,122 .}$

\section{Rehabilitation after ACL injury and after ACLR}

Patients benefit from starting knee rehabilitation early after injury, irrespective of the final treatment choice ${ }^{127}$. Pre-surgical rehabilitation to regain full range of 
motion, control swelling and to regain strength in quadriceps are factors that enhance the likelihood of good outcome after surgery ${ }^{127}$. The pre-surgical rehabilitation period can also serve as education of the patient about how the post-operative treatment will be and the amount of effort that is required. For patients who undergo rehabilitation, the physiotherapist's role is important. Physiotherapists assess functional outcome, inform and educate patient about the nature of the injury and recognize psychological issues that might arise during the process ${ }^{79,127}$.

The first rehabilitation phase aims to "quiet" the knee - reduce swelling and improve range of motion. Balance, neuromuscular control and muscle strength also need to be addressed. Sport-specific exercises are added in a later phase depending on functional progress and the goals of the patient ${ }^{34,127}$.

\section{Evaluation after $\mathrm{ACL}$ injury}

Evaluation of treatment is a cornerstone in health care ${ }^{24,34,127}$. Assessments of function are useful in the treatment decision process, to seek to predict who may be able to manage without $A C L R^{11,29}$ and to evaluate function ${ }^{38}$. Assessing range of motion, swelling, muscle strength and other quantitative measures provide important information to allow physiotherapists to adjust and progress rehabilitation ${ }^{1}$.

Among patient-reported outcome measures (PROMs), the International Knee Documentation Committee Subjective Knee Form (IKDC-SKF) measures symptoms, function and sports activity, and is developed for use in knee injuries and symptoms ${ }^{56}$. The IKDC-SKF is the third most used patient-reported outcome in $\mathrm{ACL}$ injuries ${ }^{130}$. It has been translated into 20 different languages ${ }^{119}$ and consists of 18 items that gives a total score a 0-100 scale, where 100 equals full knee function ${ }^{56}$.

\section{Patient-reported outcome measures}

PROMs identify non-observable characteristics such as confidence in own ability, fears to return to sport and ability to perform ${ }^{23}$. The use of PROMs in clinical practice and research, as well as health-care policies, has increased during the last two decades ${ }^{42}$. Clinicians seem to be positive about the use of PROMs to improve quality of care, but the time for administration and collection can be a barrier for the use of PROMs in clinic ${ }^{100}$. Using PROMS means: 
- Information that cannot be obtained from clinical measures (e.g. how the knee functions in daily life) can be gained ${ }^{42}$.

- Monitoring changes and effects of treatment in non-observable characteristics can lead to further possibilities to improve and tailor the treatment ${ }^{42}$.

- Behavioural changes might occur due to addressing unobservable characteristics such as health related quality of life (i.e. patients might become aware of problems and be more adherent to treatment) ${ }^{44}$.

- Opening a discussion between patient and health care provider about topics that might be sensitive to address ${ }^{71}$.

- Patients can facilitate important questions to be raised in the clinical encounter ${ }^{71}$.

- Improved patient engagement ${ }^{71}$.

- Patients being integrated in clinical care ${ }^{71}$.

- Enhanced shared decision making ${ }^{71}$.

\section{Measurement properties of a patient-reported outcome measure}

To successfully use a measurement instrument, it is important to examine its design, and make sure it is appropriate for use in the patient population. The measurement properties should be tested and evaluated, with appropriate methodology 24 .

The COnsensus-based Standards for the selection of health care Measurement INstruments (COSMIN) panel is a team of scientists in the Netherlands. They have developed a checklist with a scoring system for evaluation of the methodological quality and result of studies assessing measurement properties of health carerelated PROMs. The scoring system and their work aims to improve research and simplify evaluation of PROMs ${ }^{86}$. The COSMIN group has also defined and described the taxonomy of measurement properties of a health-related patientreported outcome (HR-PRO) (Figure 2). They have defined reliability, validity and responsiveness for evaluation of PROMs ${ }^{87}$ and the quality criteria that should be met for a PROM to show good measurement properties, and developed a standardized way to summarize the methodological score and valuation of results 117 . 


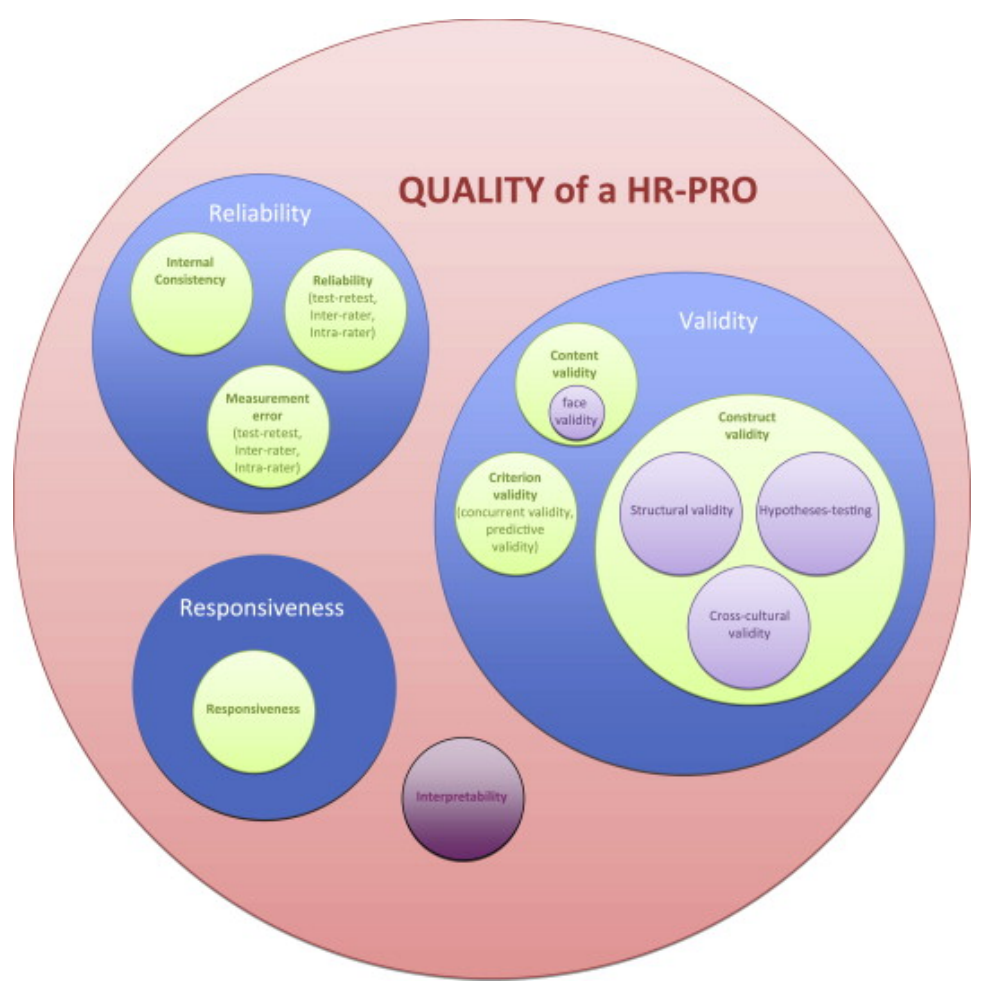

Figure 2. The taxonomy of measurement properties defined by the COSMIN panel ${ }^{87}$. Reprinted with permission from the COSMIN group.

\section{Reliability}

Reliability is "the degree to which the measurement is free from measurement error". Testing of reliability includes test-retest reliability, measurement error and internal consistency. Test-retest reliability is important to evaluate whether the outcome replicates the same measure when it is tested repeatedly, with the same test surroundings and in the same study population ${ }^{24}$. Test-retest reliability for a PROM involves patients completing out the form twice, with a short gap (typically 2 weeks) between measurement occasions. The interim time should be appropriate, ensuring that no change in condition has occurred, and that the patient does not recall the answers from last time. Correlations between the first and second score are made, and a high correlation is a sign of good test-retest reliability ${ }^{117}$. An ICC or Kappa test result for test-retest reliability of $>0.7$ is considered good ${ }^{117}$. Measurement error is the systematic and/or random error of a patient's score that is not due to true changes in the construct that will be 
measured. Internal consistency measures the internal relationship among the items included in the score ${ }^{87}$, and is often tested with a Cronbach's alpha, where a value of 0.7-0.95 is considered good ${ }^{117}$.

\section{Validity}

Validity is "the degree to which an instrument measures the construct(s) it purports to measure". Content validity, including face validity, is assessed by testing that the items are fit for the construct to be measured, for the study population and for the purpose of the measurement instrument. It also includes the comprehensibility of the items ${ }^{87}$. One simple yet effective way to examine face validity of a PROM is the "eyeball test" - simply to look at the questions. Does it look professional? Are the questions too basic or too advanced for the population intended? Are the instructions clear? Is there a good flow in the questions? Does the questionnaire look sloppy or do the questions appear in an unstructured way? ${ }^{24}$.

Construct validity includes structural validity, hypothesis testing and crosscultural validity. Structural validity for a PROM can be assessed using factor analysis, exploring or confirming whether the score is a reflection of the dimensionality of a construct ${ }^{117}$.

Hypothesis testing involves testing pre-defined hypotheses (e.g. correlations between the measurement instrument and another measurement instrument). Hypotheses should be well-defined and set a priori, and $>75 \%$ confirmed hypothesis is a good result for hypothesis testing ${ }^{117}$. Cross-cultural validity refers to translating and culturally-adapting PROMs into another language. Testing cross-cultural validity includes assessing that the translated version reflects the construct to be measured and adequately reflects the original version, and assessing if any cultural changes need to be made in the new version ${ }^{24}$.

When testing criterion validity, the measurement instrument can be compared to another measurement that reflects the same construct - a "gold standard". It is difficult to find an adequate "gold standard" for a HR-PRO. If another HR-PRO is too well correlated to the HR-PRO in question, the use of the HR-PRO being tested can be questioned. Low correlation between two HR-PROs makes the use of the "gold standard" comparison meaningless. The use of a "gold standard" in testing PROMs has been debated ${ }^{24}$, but is often used as a way to test criterion validity. 


\section{Responsiveness}

Responsiveness to change is a measurement property linked to validity and reliability. In an instrument with poor reliability, a patient must report a large improvement for a change to be visible. An instrument with poor validity (i.e. does not measure the construct intended) will also have low responsiveness, because the construct that has improved is not the one being measured ${ }^{24}$.

\section{Rationale of the thesis}

After an $\mathrm{ACL}$ injury, treatment aims to restore knee function. Early after injury, patients are often shocked, upset and worried about their future knee function ${ }^{97}$. To assess the main goal - restoration of function, regardless of treatment evaluation with outcome measures with good measurement properties is important. The outcome measure should be suitable for the patient population and detect changes in state. The IKDC-SKF is the third most used PROM in ACL populations worldwide ${ }^{130}$, but there has been no summary of the measurement properties of the IKDC-SKF. There was no Swedish language version for use in Swedish clinics and research settings. A systematic review with assessment of methodological quality and synthesis of results from studies that have tested measurement properties would help clinicians and researchers. Translating and testing the measurement properties of the Swedish IKDC-SKF would be useful in Swedish clinical settings and research.

Sooner or later, patients will, together with orthopaedic surgeon and physiotherapist, decide how their injury should be treated. We lack knowledge about how to help patients make the best treatment decision. To be able to offer patients the best treatment, we must investigate how the treatment decision is taken, when the decision is taken and how the reasons for a decision match patient's activity demands, knee joint instability and function. To map the important factors for treatment choice after ACL injury, a first step is to investigate the factors orthopaedic surgeons and physiotherapists consider important when they recommend treatment, and how they value the importance of their own and each other's assessment, as well as patient's wishes.

To further map how the treatment decision after an $\mathrm{ACL}$ injury is taken, extended information about patient's reasons for choice of treatment is needed plus information about how patient-reported symptoms and function are related to 
these reasons. By adding clinician's reasons for chosen treatment, we will clarify the picture of the treatment process and reasons for treatment choice. 


\section{AIMS OF THE THESIS}

\section{Overall aim}

The overall aim of this thesis was to evaluate the measurement properties of a patient- reported measure for evaluation of function after $A C L$ injury and treatment, and to overview the treatment decision process after an $A C L$ injury.

\section{Specific aims}

1; To evaluate the methodological quality and results of studies reporting on the measurement properties of the IKDC-SKF following the COnsensus-based Standards for the selection of health status Measurement INstruments (COSMIN) guidelines and the Preferred Reporting Items for Systematic Reviews and Metaanalyses (PRISMA) guidelines (Study I).

2; To perform translational and cross-cultural adaption for the Swedish version of the IKDC-SKF and to test the validity, reliability, responsiveness, and interpretability (floor and ceiling effect and Minimal Clinical Important Difference) of the IKDC-SKF in patients with an ACL injury undergoing reconstruction surgery, from before reconstruction to up to 1-year follow-up (Study II).

3; To (1) study and compare the factors Swedish orthopaedic surgeons and physiotherapists consider important for recommending ACLR, and (2) to assess how important orthopaedic surgeons and physiotherapists consider their own and each other's, as well as patients', roles are in the treatment decision (Study III).

4; To (1) describe the key characteristics of treatment decisions for patients with an ACL injury; what treatment was chosen, when was the decision made, which reasons do patients and orthopaedic surgeons state that the treatment decision was based upon, and (2) compare key patient reported function measures (preinjury activity level, knee joint instability and function at baseline, 4 weeks and 3 months after an ACL injury) between patients who had ACLR and those who had non-operative treatment (Study IV) 



\section{MATERIALS AND METHODS}

\section{Overview of the studies}

The four papers included in this thesis are based on four studies (table 1): one systematic review (study I), one methodological study (study II), one crosssectional survey study (Study III) and one prospective cohort study (study IV).

Table 1. Overview of the studies in the thesis

Study 1

Study 2

Study 3

Study 4

\begin{tabular}{|c|c|c|c|c|}
\hline Design & Systematic review & Methodological study & $\begin{array}{l}\text { Cross-sectional } \\
\text { survey study }\end{array}$ & Prospective cohort study \\
\hline $\begin{array}{r}\text { Material/ } \\
\text { Participants }\end{array}$ & $\begin{array}{l}\text { Previously published } \\
\text { studies with } \\
\text { methodological } \\
\text { evaluation of the } \\
\text { measurement } \\
\text { properties of the } \\
\text { IKDC-SKF }\end{array}$ & $\begin{array}{l}\text { Patients, } 16-40 \text { years } \\
\text { old, with an ACL } \\
\text { injury, that had or } \\
\text { would undergo ACLR }\end{array}$ & $\begin{array}{l}\text { Orthopaedic surgeons } \\
\text { and physiotherapists } \\
\text { treating ACL } \\
\text { deficient patients }\end{array}$ & $\begin{array}{l}\text { Patients, } 15-40 \text { years old, } \\
\text { with an ACL injury less } \\
\text { than seven weeks ago }\end{array}$ \\
\hline Methods & $\begin{array}{l}\text { Systematic assessment } \\
\text { of the methodological } \\
\text { quality and results of } \\
\text { articles published on } \\
\text { measurement } \\
\text { properties of the } \\
\text { IKDC-SKF, using the } \\
\text { COSMIN guidelines }\end{array}$ & $\begin{array}{l}\text { Translation to } \\
\text { Swedish, cross-cultural } \\
\text { adaption and testing of } \\
\text { measurement } \\
\text { properties of the } \\
\text { Swedish version of } \\
\text { IKDC-SKF }\end{array}$ & $\begin{array}{l}\text { Questionnaire to } \\
\text { orthopaedic surgeons } \\
\text { and physiotherapists } \\
\text { active in treating } \\
\text { patients with ACL } \\
\text { injury. Ranking the } \\
\text { importance of reasons } \\
\text { for recommending } \\
\text { ACLR }\end{array}$ & $\begin{array}{l}\text { Choice of treatment, } \\
\text { reason for it and timing, } \\
\text { was collected from } \\
\text { medical charts and } \\
\text { questionnaires to } \\
\text { patients and orthopaedic } \\
\text { surgeons. Reasons for } \\
\text { treatment was compared } \\
\text { to patient-reported } \\
\text { preinjury activity level, } \\
\text { knee joint instability and } \\
\text { IKDC-SKF, at } 4 \text { weeks } \\
\text { and } 3 \text { months after injury }\end{array}$ \\
\hline Data analysis & $\begin{array}{l}\text { Analysis by two } \\
\text { independent } \\
\text { researchers, using the } \\
\text { COSMIN guidelines to } \\
\text { assess methodological } \\
\text { quality and compile the } \\
\text { results }\end{array}$ & $\begin{array}{l}\text { Test for face validity } \\
\text { and cross-cultural } \\
\text { validity, internal } \\
\text { consistency } \\
\text { (Cronbach's alpha), } \\
\text { test retest reliability } \\
\text { (ICC } 2,1 \text { ), measurement } \\
\text { error (based on } \\
\text { reliability measures), } \\
\text { correlations for } \\
\text { structural validity and } \\
\text { construct validity, } \\
\text { correlations and ROC- } \\
\text { analysis for } \\
\text { responsiveness and } \\
\text { MCIC, and descriptive } \\
\text { statistics }\end{array}$ & Descriptive statistics & $\begin{array}{l}\text { Descriptive statistics and } \\
\text { comparisons between } \\
\text { acute, subacute and late } \\
\text { ACLR decision and non- } \\
\text { operative decision, using } \\
\text { Chi-Square test, } \\
\text { independent sample T- } \\
\text { tests and one-way } \\
\text { Analyses of variance } \\
\text { (ANOVAs), with a post } \\
\text { hoc Tukey test. }\end{array}$ \\
\hline
\end{tabular}

ACL: Anterior Cruciate Ligament, ACLR: Anterior Cruciate Ligament Reconstruction, ANOVA: Analyses of variance, COSMIN: COnsensus-based Standards for the selection of health status Measurement Instruments, IKDC-SKF: International Knee Documentation Committee Subjective Knee Score, ICC: Intra-Class Correlation, ROC: Receiver Operating Characteristic, MCIC: Minimal Clinical Important Change 


\section{Study I and II}

The COSMIN manual and 4-point checklist was used to assess the methodological quality of studies that evaluated measurement properties of the IKDC-SKF ${ }^{85-87}$, specifically for study I, but also as criteria for the design and conduct of study II.

\section{Systematic review}

A search strategy was developed in consultation with a librarian. A filter developed for searching articles evaluating the measurement properties of patient-reported outcomes was also used ${ }^{118}$. The search terms were "IKDC" AND "knee" together with the search filter for PubMed, and without the filter for search in Scopus and CINAHL. The search was conducted on March 24, 2013. The search and abstract screening was completed by one researcher (HTG). Full text screening and data extraction was completed by two independent researchers (HTG and JK), with comparison of result and consensus discussion if required.

The inclusion criteria were:

1. The study should aim to develop IKDC-SKF or to evaluate measurement properties of the IKDC-SKF.

2. Studies that aimed to evaluate measurement properties of another measurement instrument, and used IKDC-SKF to compare to (e.g. correlations or hypothesis).

3. Studies should be peer-reviewed publication written in English or Swedish.

The included articles were assessed with the COSMIN 4-point checklist for methodological quality. The methodological score was given according to "worse score counts" system, meaning that the lowest score in any section was the overall score given to the measurement property assessed. The results of the findings of the study were assessed with guidance from the quality criteria proposed by Terwee et al ${ }^{117}$ :

- Strong positive scoring (+++): Consistent positive findings in multiple studies of good methodological quality OR in one study of excellent methodological quality

- Moderate positive scoring (++): Consistent positive findings in multiple studies of fair methodological quality OR in one study of good methodological quality 
- Strong negative scoring (---): Consistent negative findings in multiple studies of good methodological quality OR in one study of excellent methodological quality

- Moderate negative scoring (--): Consistent negative findings in multiple studies of fair methodological quality OR in one study of good methodological quality

- Limited findings (+/-) Positive or negative findings in one study of fair methodological quality

- Indeterminate scoring (?): Results only from studies of poor methodological quality

- Conflicting findings (+/-): conflicting findings

An overall score, based on both methodological score and result for each measurement property, was presented. Further information about the methodology is described in study ${ }^{46}$.

\section{Update of the systematic review}

The systematic review was updated in June 2019 and covered the time frame from March 24, 2013 to June 2, 2019. The COSMIN 4-point checklist for methodological quality was used as in the original systematic review, with some methodological adjustments for the updated systematic review:

- The increase in studies evaluating measurement properties for the last few years led to an exclusion of the second inclusion criterion (to limit the search and narrow the material, and include the most important data).

- The update was conducted by one researcher (HTG), and the search filter was not used because the search terms "IKDC" AND "knee" were estimated to be specific enough to retrieve all relevant articles.

- For responsiveness, studies with only reports of effect size, standardized response means, minimal detectable change were graded as "poor" due to "other important methodological flaws in the design or execution of the study". A correct evaluation of responsiveness should include a construct or criterion approach ${ }^{24}$, thus, if that was not assessed, the methodological assessment was considered insufficient. In the original systematic review, the same studies were assigned a score for methodology, but the results were interpreted as inconclusive because the assessment method was inappropriate. 


\section{Translation of the IKDC-SKF}

The translation process of the IKDC-SKF (study II) was completed according to the guidelines by Guillemin et al ${ }^{49}$ and the recommendations by the COSMIN group. After the translation process, cross-cultural validity was evaluated and minor changes in terminology when describing activities were made ${ }^{121}$.

\section{Participants and data collection}

The Swedish version of the IKDC-SKF was tested in 10 patients with ACL injury who evaluated face validity by commenting on relevance, comprehensibility and similarity between the English and Swedish versions.

In total, 179 patients, waitlisted for ACLR, participated in the study. Participants completed a questionnaire package (IKDC-SKF, KOOS, ACL-RSI and study-specific questions) before ACLR and at 6, 15, 24 and 52 weeks after ACLR. A complementary population of 514 patients from the Swedish Knee Ligament Register were invited, and 203 (39\%) agreed to participate. Participants completed the questionnaire package once at 6-8 months after ACLR. The second recruitment ensured that the number of participants was sufficient to power the test of measurement properties, strengthening the methodological quality. Data from participants in the additional recruitment were used for the internal consistency, structural validity and criterion validity analyses, thus fulfilling the criterion for excellent score on sample size, according to the COSMIN checklist ${ }^{85-}$ 87.

\section{Analysis}

Test-retest reliability was calculated based on data from patients at 6 months after ACLR. The questionnaire was sent out the second time by mail, at five days after the initial questionnaire had been completed and returned. A maximum of 21 days between test and retest was considered adequate. Patients reported whether they considered their knee-related condition had changed since the last time they completed the questionnaire. If so, their answers were excluded. The correlation between the test and retest was analysed with $\mathrm{ICC}_{2,1}$.

Measurement error was analysed using the change scores from the test-retest analysis, and the formula SDdiff/V2, and calculations for smallest detectable change (SDC) was completed for individuals (SDCind $=1,96 \times \sqrt{ } 2 \times \mathrm{SEM}$ ) and groups $(\mathrm{SDCgroup}=\mathrm{SDCind} / \mathrm{Vn})^{7,117}$. 
Internal consistency of the items was analysed with Cronbach's alpha, where a result of 0.7-0.95 was considered good internal consistency ${ }^{117}$.

Construct validity was tested with structural validity, hypothesis testing and criterion validity testing. Structural validity was tested using factor analysis. The IKDC-SKF had been tested using factor analysis in three previous studies ${ }^{56,110}$, supporting a one-factor solution twice and the possibility for a two-factor solution once ${ }^{52}$. The two factor solution was "symptom and knee articulation" (14 items) and "activity level" (4 items), leaving three items that failed to fit either factor in the model. Because of the few studies that had evaluated structural validity using factor analysis, we used exploratory factor analysis to explore how the score should be interpreted.

For hypothesis testing, ten predefined hypotheses were developed, with a predefined direction and magnitude for confirmation definitions. For good measurement properties in hypothesis testing, at least $75 \%$ of hypothesis should be confirmed ${ }^{117}$. The hypotheses can be found in table 3 in study ${ }^{121}{ }^{121}$.

Criterion validity was analysed using the Short Form 36 (SF-36) as a gold standard. We hypothesised that the IKDC-SKF would have a stronger correlation to the physical component summary (PCS) of the SF-36 ( $r>0.5)$ than to the mental component summary (MCS) $(r<0.5)$.

For responsiveness, we used the change score from baseline (preoperative) to 4 months post ACLR. Both a construct and a criterion approach were used to analyse responsiveness.

For the construct approach to responsiveness, correlations between change scores from baseline and 4 months and baseline to 12 months were calculated between IKDC-SKF and the five subscales of KOOS and the PCS of the SF-36. Effect size (ES) and standardized response mean (SRM) was calculated for change scores from baseline to 12 months. ES and SRM are measures of the magnitude of a change score, not measures of the validity of the change score ${ }^{24}$. To calculate the validity of the change score, a comparison to other instruments or strongly grounded hypothesis should be made. We chose to analyse responsiveness using several methods, including reporting ES and SRM because they are commonly used measures, and ES and SRM were complementary results to the responsiveness testing. 
For the criterion approach to responsiveness, a global rating of change (GRC) question was used. Responses were dichotomized into two groups: "no change" and "improved". The change score of the IKDC-SKF between baseline and 4 months post ACLR was used, a time frame considered to be sufficient for a change (improvement in most cases) in condition to have occurred. A receiver operating characteristics (ROC) curve was plotted, and the Youden index was used to estimate the most sensitive and specific change value ${ }^{133}$, which is the minimal clinical important difference (MCID) value. The area under the curve (AUC) was used to interpret the result, and $>0.7$ was considered appropriate ${ }^{117}$.

Interpretability is not a measurement property. Although, it is important to evaluate, not the least for clinical implications. Floor and ceiling effects were investigated, with $<15 \%$ respectively, considered adequate ${ }^{117}$.

\section{Study III}

In this survey study, the questionnaire used was developed by researchers well experienced in ACL injury research, and based on research by Swirtun et al ${ }^{116}$. The questionnaire was tested for content validity by orthopaedic surgeons and physiotherapists, who reviewed the questions for content, relevance and clarity.

The final questionnaire contained 21 factors that were to be graded on a 0-3 scale, with a higher grade corresponding to higher likelihood to recommend ACLR. Each factor had the heading; "How do the following factors affect your judgement of whether a patient should undergo ACLR?". The 0-3 grade scale was anchored $0=$ "no surgery" and 3 = "surgery" for orthopaedic surgeons. For physiotherapists, $0=$ "little probability that I would recommend $A C L$ reconstruction" and $3=$ "great probability that I would recommend $\mathrm{ACL}$ reconstruction".

An open question was included; "Are there any more factors you consider important in the recommendation for ACLR?" Participants could add comments or additional factors they believed to be important to recommend ACLR. Orthopaedic surgeons and physiotherapists were asked "To what extent do you believe the decision for ACLR is based on orthopaedic surgeon's assessment, physiotherapist's assessment, and patient's wishes". Respondents graded the three alternatives from 0 (not important at all) to 3 (very important). 


\section{Participants and data collection}

More than $90 \%$ of orthopaedic surgeons who are active in performing ACLR procedure in Sweden, register data in the Swedish national knee ligament register ${ }^{132}$. All orthopaedic surgeons listed in the register were contacted by email, with information about the study and asked to participate. Of the 235 invitations sent to orthopaedic surgeons, 130 responded and 98 participated. One email address was incorrect. The number of surgeons who were performing ACLR during the time of the survey study was 152-160, according to the Swedish $A C L$ register ${ }^{132}$, which indicates that some email addresses could have reached surgeons who were not performing ACLR. Among the 32 who declined participation, 25 declined because they did not treat patients with ACL injury, and 7 declined without explanation.

Physiotherapists who could have been active in treating patients with ACL injury were identified through the Swedish Society for Physical Activity and Sports medicine, Swedish Football Physiotherapists Association, at orthopaedic clinics and through professional contacts. They were contacted by email, with information about the study and an invitation to participate. After the first send out, physiotherapists who accepted to participate recommended colleagues who were active in the area of rehabilitation, leading to two complementary rounds of questionnaires. A total of 947 emails were sent to physiotherapists. Of the 595 physiotherapists who responded, 391 participated (205 women and 186 men). Of the physiotherapists who declined participation, 166 were not treating patients with an ACL injury, and 38 declined without explanation.

Up to two reminders were sent to orthopaedic surgeons and physiotherapists. The questionnaire was administered via a secure web-based system (Esmaker version 3.0, Entergate ${ }^{\circledR} A B$ ). All data were registered anonymously.

\section{Analysis}

Data were analysed after dichotomizing the response options to a combination of $0-1$ and of 2-3. A rating of 2-3 indicated that the factor had an important impact on the decision to decide for or recommend surgery.

Responses for each factor were analysed to determine if clinical agreement was reached. Clinical agreement was defined as when $80 \%$ of respondents had chosen the same response option (after dichotomizing the answer options) ${ }^{78}$. 
The answers to the open-ended question of which factors that were the most important for choosing ACLR were categorized into six categories; knee joint instability, patient focus, activity demands, other injuries, sociodemographic factors and objective measures). For each category, we examined whether it was described as a sole factor in the decision to recommend ACLR, or part of a cluster of factors that were considered to be important together.

\section{Study IV}

A prospective cohort study where patients with $A C L$ injury were included early (06 weeks) after ACL injury and followed up to 12 months after injury. If a decision for ACLR was taken, patients were followed until the surgery was performed.

\section{Participants and data collection}

The patients were participants of the NAtural COrollorary X (Nacox) study ${ }^{69}$, a prospective cohort study that aims to describe the natural collorary after an ACL injury. The patients who at the time for data analysis had undergone ACLR or had chosen non-operative treatment at 12 months after injury were included.

Patients were included from six different orthopaedic clinics in cities of various size, in urban and rural environments in Sweden, during June 2016 to October 2018. Patients were recruited consecutively ${ }^{69}$.

Information about the treatment, reason and timing for chosen treatment was derived from medical charts and questionnaires to orthopaedic surgeons and patients. All medical charts regarding the $A C L$ injury were reviewed by the first author, and data about which treatment was decided, when, and why were obtained.

When a treatment decision was made, the orthopaedic surgeon answered a question about which treatment was chosen and described why in free text.

Patients answered electronically-administered questionnaires, distributed via short message service (SMS), about treatment choice and reason for the choice. Patients answered the questionnaires after the visit at the orthopaedic surgeon. When a decision for non-operative treatment was made, patients still received questionnaires with questions about treatment decision at 3, 6, and 12 months after injury to ensure the decision had not changed. If the decision was unchanged at 12 months after injury, the decision was considered to be final. 
Analysis

All final reasons for each patient were categorized according to previous research 45, guidelines 78, 84, 112 and clinical experience within the research group. Categories were:

ACLR treatment

- knee joint instability/giving way

- high activity demands

- knee joint instability/giving way and high activity demands

- patients' wishes

Non-operative treatment

- lack of knee joint instability/giving way

- low activity demands

- sufficient knee function

- other reasons

The timing for decision of ACLR treatment was categorized as "acute phase decision" when the decision was made between injury day and 31 days after injury, "subacute phase decision" when a decision was made between 32 days and 5 months after injury and "late phase decision" when the decision was made between 5 and 12 months after injury.

Patients-reported data were collected regarding:

- activity participation before the injury (categorized in the Tegner activity scale ${ }^{76}$ according to definitions by Fältström et al ${ }^{36}$ )

- knee joint instability in everyday living and in rehabilitation training, recreational activities or sports activities

- knee function (using the IKDC-SKF)

Group comparisons were made between (i) patients who chose ACLR and patients who chose non-operative treatment, and between (ii) acute phase decision ACLR, subacute phase decision ACLR, late phase decision ACLR and the non-operative group. Variables analysed were age, sex, preinjury Tegner Score, knee joint instability in daily living (baseline, 4 weeks, 3 months), knee joint 
instability in rehabilitation physical activities or sports (3 months), and IKDC-SKF (4 weeks, 3 months). 


\section{ETHICS}

\section{Ethical approvals}

Study ethics, where required, was approved by the Ethical Review board in Linköping, Sweden.

Study I: No ethical approval was needed.

Study II: 2011/ 450-31

Study III: 2014 71/31

Study IV: 2016/44-31

\section{Ethical considerations}

The general ethical principles for medical research, stated in the Declaration of Helsinki were followed. All study participants received written study information, and approved participation either in writing (study IV) or electronically (study II and III). All participants in all studies were informed that the results would be coded and handled anonymously, that they had the possibility to retrieve information collected about them, and how to retrieve the information collected.

In study II and IV, patients were informed that they could decline or withdraw participation at any time during the study, and that participation or declining to participate would not have any impact on their health care. There is a possibility that patients believed they would receive better care by participating in the study, and would not have otherwise participated.

It is possible that patients in study II and IV could have been affected by replying to questions about their knee, that it could cause both an extended feeling of severeness about the condition, and possibly exaggerate fear. However, no patient made any written or verbal comments about fear. 



\section{RESULTS}

\section{Study I and II}

Systematic review of the measurement properties of the IKDC-SKF

Twenty-six studies were assessed for methodological quality and scored from poor to excellent. Several studies tested more than one measurement property, and there were four studies that had poor methodological quality for all

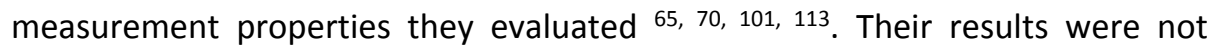
included in the assessment of the results of the testing of measurement properties. For some other studies ${ }^{4}, 54,58,62,67,121,124$, we assigned a poor methodological score one or more measurement properties, but fair to excellent methodological score for the other measurement properties. Thus, these studies were included in the assessment of the results, for the measurement properties where they had a fair to excellent methodological score. Based on the results of 22 studies, IKDC-SKF has good internal consistency, test-retest reliability, content and structural validity, responsiveness and interpretability (no floor and ceiling effects). Further evaluation of measurement error, MCID, and hypothesis testing is recommended.

\section{Updated systematic review}

There were 14 additional full text articles for evaluation (figure 3 ), and 4 articles that evaluated interpretability only ${ }^{90,91,104,107}$ (appendix 1 ).

There was stronger evidence of good measurement properties of the IKDC-SKF. There was new evidence for hypothesis testing, translation validity and criterion validity (table 2). Interpretability in terms of floor and ceiling effects was consistently low, except in two studies ${ }^{32,91}$, in a population that had undergone ACLR 2-4 years ago and a population of "children with a history of knee surgery". Muller et al ${ }^{90}$ defined the threshold for patient acceptable symptoms score as 75.9 points. 


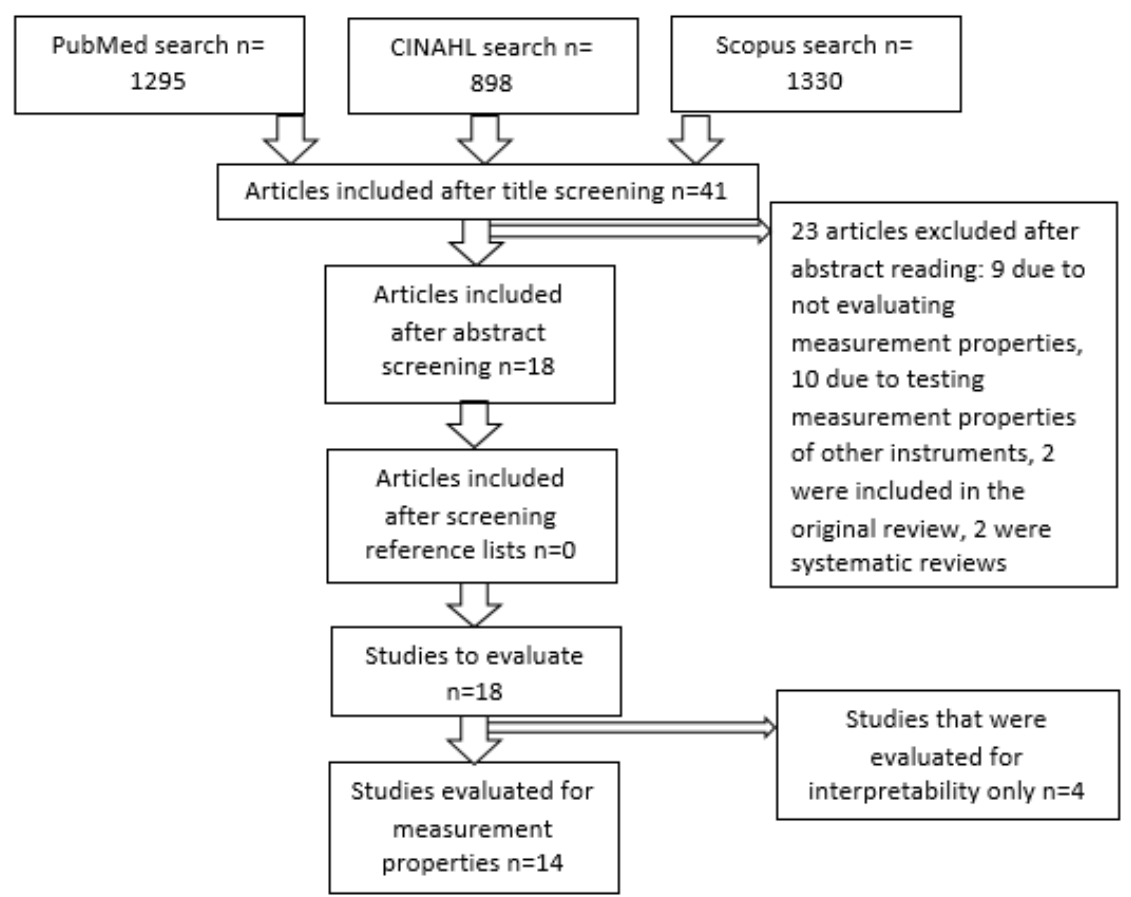

Fig 3. Flow chart over the literature search process in the updated review. 


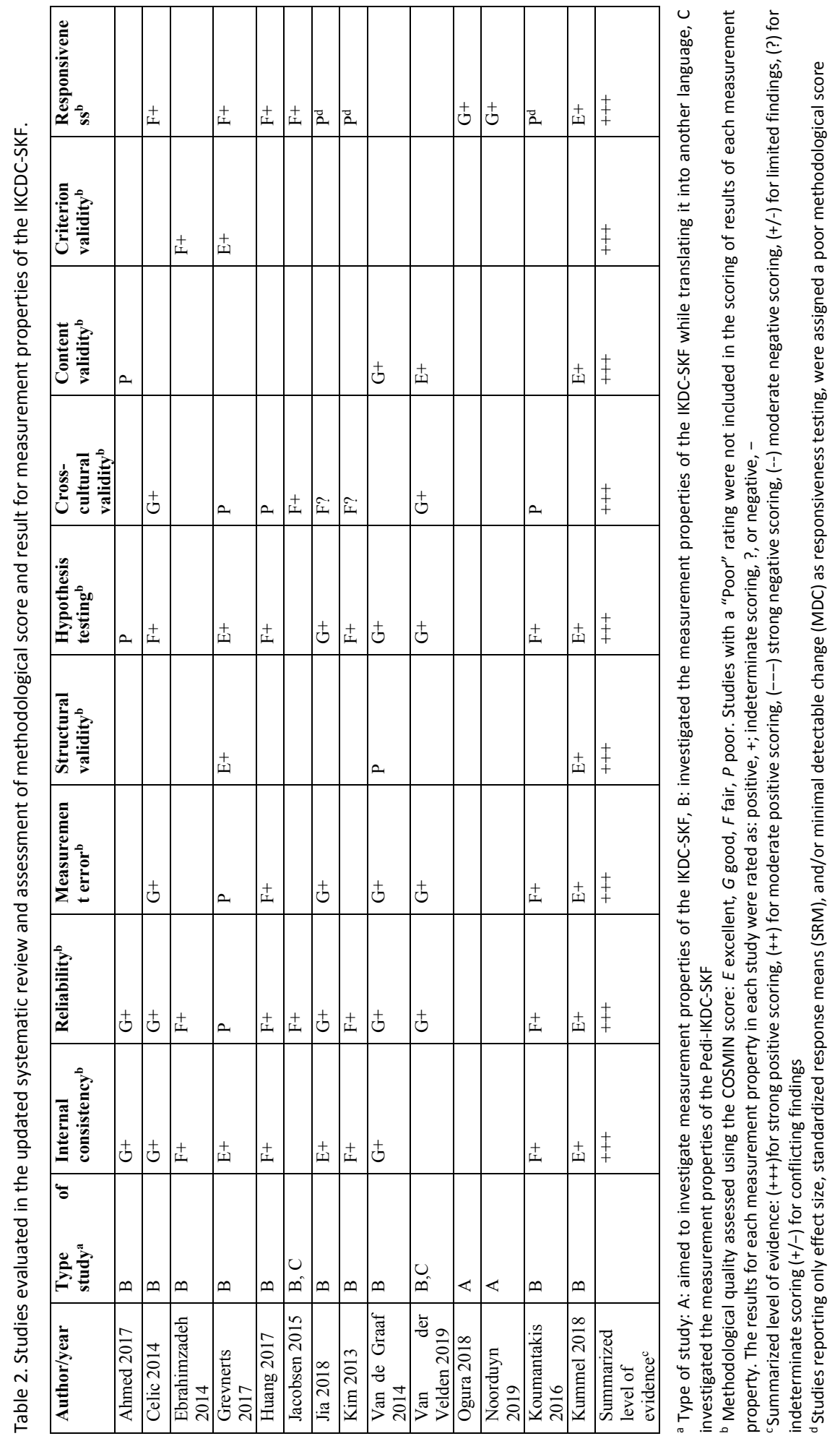


The measurement properties of the Swedish version of the IKDC-SKF

The Swedish version of the IKDC-SKF had good measurement properties in reliability, validity and responsiveness.

Reliability:

- Internal consistency: good, Cronbach's alpha: 0.9.

- Test-retest reliability: excellent, $\mathrm{ICC}_{2,1}: 0.92$ (95\% Cl: 0.81- 0.97, $\left.\mathrm{P}<.001\right)$.

- SEM: 5.7 points, SDC $_{\text {group: }} 2.4$ points and $\mathrm{SDC}_{\text {ind: }} 15.8$ points.

Validity:

- Structural validity: A single factor solution accounted for $46.1 \%$ of the variance in an exploratory factor analysis. Factor loadings were $>0.4$ for 17 out of 18 items. The factor loading for item 6 ("during the past 4 weeks, or since your injury, did your knee lock or catch?") was 0.349 .

- Criterion validity; the correlation between the IKDC-SKF and the Physical Component Summary of the SF36 was strong, $r=0.73(p<0.001)$. The correlation between the IKDC-SKF and the Mental Component Summary of the SF36 was weak, $r=0.32(p<0.001)$. Both results were as hypothesized, confirming the hypothesis for criterion validity.

- Hypothesis testing; the ten hypotheses ${ }^{121}$ were confirmed.

Responsiveness:

- Construct approach to responsiveness: The IKDC-SKF change score (baseline to 4 months after ACLR) was positively correlated with the global rating of change $(G R C)$ question $(r=0.62, p<0.01)$. The ROC analysis had an AUC of 0.79 .

- Criterion approach to responsiveness: The six hypotheses for change scores from baseline to 4 months and baseline to 12 months ${ }^{121}$, were confirmed.

Interpretability:

- There were no floor or ceiling effects $(<15 \%)$ at any occasion.

- $\mathrm{MCID}$ at 4 months was 13.9 points (sensitivity: 65.2\%, specificity: $95.5 \%$ ). 
- Patients who reported "great improvement but not fully recovered" on the GRC had a mean change in IKDC-SKF from baseline to 4 months of 16.2 points.

Study III and IV

Factors that orthopaedic surgeons and physiotherapists rate as important to recommend ACLR

In study III, the results showed six factors that $>80 \%$ of orthopaedic surgeons and $>80 \%$ of physiotherapists rated as important for recommending ACLR:

- Young age

- Wishes to return to contact or pivoting sports (at elite or recreational level)

- A physically demanding occupation

- Knee joint instability in sports or activities of daily living (despite adequate rehabilitation training for $>3$ months)

Open-ended question for factors considered important to recommend $A C L R$

Of the orthopaedic surgeons, 56 answered the open-ended question. Of them, 44 reported knee joint instability, often in combination with other factors (e.g. "in relation to activity level" "young age" or "knee joint instability in ADL or working situation") as the most common combination of factors for recommending surgery. Of physiotherapists, 337 answered the open-ended question. Knee joint instability was reported as a single factor or in combination with other factors, by 331 physiotherapists. "Function" was mentioned in combination with other factors, such as "insufficient function despite adequate rehabilitation".

Orthopaedic surgeon's, physiotherapist's and patient's contributions to treatment decisions

In study III, orthopaedic surgeons and physiotherapists appraised that their own, each other's assessments, and the patient's wishes in the decision making to recommend ACLR were very important (table 4). 
Table 4. Result of orthopaedic surgeons and physiotherapists rating for the question: "To what degree do you believe the decision for ACLR is based upon the orthopaedic surgeon's and physiotherapist's assessments, and patient's wishes?". Rating scale: 0-3, anchored; $0=$ "to a very low extent" and $3=$ "to a very high extent". Reported is the number of respondents that had rated 2 or 3.

Orthopaedic surgeon rates: Physiotherapist rates:

\begin{tabular}{lcc}
\hline $\begin{array}{l}\text { The importance of } \\
\text { orthopaedic surgeon } \\
\text { assessment }\end{array}$ & $99 \%$ & $75 \%$ \\
$\begin{array}{l}\text { The importance of } \\
\text { physiotherapists assessment }\end{array}$ & $98 \%$ & $71 \%$ \\
Patient's wishes & $80 \%$ & $80 \%$
\end{tabular}

Compliance to rehabilitation; communication about treatment decision recommendations

- $79 \%$ of orthopaedic surgeons stated that they often sought information about compliance to rehabilitation

- $71 \%$ of orthopaedic surgeons stated that they sometimes or often read the patient's medical record to obtain information about rehabilitation compliance

- $70 \%$ of orthopaedic surgeons stated that they sometimes or often had contact with the treating physiotherapist

- $96 \%$ of orthopaedic surgeons sometimes or often sought information about the rehabilitation outcome by asking the patient

- $78 \%$ of orthopaedic surgeons stated that they sometimes or often obtained information about rehabilitation by reading the patient's medical record

- $81 \%$ of orthopaedic surgeons sometimes or often contacted the treating physiotherapist and asked for information about the patient's compliance to rehabilitation

- $80 \%$ of the physiotherapists stated that when they recommended ACLR, they often communicated their recommendation to the patient

- $67 \%$ of the physiotherapists sometimes or often communicated their recommendation to the orthopaedic surgeon 
Treatment decision after an ACL injury; what decision was made and when?

For the 219 patients included in study IV, the treatment decision was:

- $A C L R$ in the acute phase after injury (0-31 days after injury), $n=33$

- $A C L R$ in the subacute phase after injury (1 to 5 months after injury), $n=85$

- $A C L R$ in the late phase after injury (5 to 12 months after injury), $n=25$

- Non-operative treatment (decision within 12 months after injury, or if no definitive treatment decision was taken), $n=76$

\section{Reason for treatment decision}

In study IV, high activity demands was the main reason for choosing ACLR in the acute phase decision group. Knee joint instability/giving way and high activity demands was the main reason for choosing ACLR in the subacute phase decision. Knee joint instability/giving way was the main reason for choosing ACLR in the late phase decision group.

The main reason for the choice of non-operative treatment was no knee joint instability/no giving way. There were $22(29 \%)$ patients where the choice for nonoperative treatment was based on "other reasons" (study IV, manuscript in progress)

Comparisons of patient-reported factors between ACLR and non-operative groups

In study IV, there were few differences between patients where an ACLR treatment decision had been taken and where a non-operative treatment decision had been taken, regarding pre-injury activity level, patient-reported knee joint instability ratings and function.

- Patients in the non-operative decision group were older than patients in the acute phase decision group $(p<0.031)$ and patients in the late phase decision group $(p<0.001)$

- Patients in the acute phase decision group had a higher pre-injury Tegner score compared to the late phase decision group $(p<0.031)$ and the nonoperative group $(p<0.003)$

- Patients in the subacute phase decision group had a higher pre-injury activity level compared to patients in the non-operative group $(p<0.023)$ 
There were no differences between groups regarding patient-reported knee joint instability ratings (rated at baseline, 4 weeks and 3 months after injury) or IKDCSKF scores (rated at 4 weeks and 3 months after injury). 


\section{DISCUSSION}

This thesis highlights the evaluation of function from the patient's perspective, and provides evidence that the IKDC-SKF is an appropriate patient-reported outcome measure for evaluating symptoms, function and sports participation after $\mathrm{ACL}$ injury. The thesis also summarises the treatment decision process after an $A C L$ injury, from the patient's and the health care personnel's perspectives. Physical activity demands and presence of, or lack of knee joint stability were the factors orthopaedic surgeons, physiotherapists and patients considered important for treatment choice. Yet, patient-reported function and knee joint instability in the early phase after ACL injury did not differ between patients where a decision for ACLR or non-operative treatment had been made, or would be made later. Orthopaedic surgeons, physiotherapists and patients have an important role in the treatment decision process, although the contribution of each part remains clear.

\section{Measurement properties of patient-reported outcome measures}

A key aspect in assessing the measurement properties of a PROM, is to acknowledge that the result of a test for measurement properties is not a fixed result. Tests allow the researcher to draw certain conclusions, but the results are specific for the test environment (population, settings, severity of symptoms etc.) and may not be generalized automatically ${ }^{26}$. In study I of this thesis, the studies included in the systematic review tested the measurement properties of the IKDC-SKF in different populations with different diagnoses, different symptom severities, in different phases of rehabilitation, before or after a surgical intervention, different ages and with different physical activity demands. This may allow a broader generalizability than when one population is tested. Nevertheless, it is important to interpret and apply the results with caution. It is vital to assess the value and appropriateness of a PROM in the specific population in which it will be used.

The results from study I and study II are important for the use of IKDC-SKF. Study I suggests the IKDC-SKF has good measurement properties in several populations. Nevertheless, before using the IKDC-SKF in clinical or research settings, a 
valuation of the evidence for measurement properties of that specific population should be made.

\section{Reliability}

The updated systematic review enhanced the strong positive findings for internal consistency, with a Cronbach's alpha ranging from 0.77-0.97. Internal consistency has been tested in patients with a broad range of diagnoses and symptoms in these studies. The conclusion is that the internal consistency for the IKDC-SKF is well explored and has good results for patients with knee injuries. The Swedish version of the IKDC-SKF ${ }^{121}$ had good results for internal consistency regarding both methodological quality and result (Appendix 1).

Test-retest reliability shows a strong positive score in the systematic review, and the updated review strengthened the conclusion. The Swedish IKDC-SKF had poor methodological quality, due to low sample size (<30 participants). Because of the poor methodological quality, the ICC result of 0.92 for Swedish IKDC-SKF was not added to the systematic review results. Nevertheless, the result indicate that the Swedish version has a positive result for test-retest reliability.

Measurement error was insufficiently evaluated. Only three studies $56,82,126$ had sufficient methodological quality to be assessed. In the updated review seven additional studies were included $15,53,58,67,68,121,124,125$ and the updated review result suggests strong positive findings. The Swedish IKDC-SKF had poor methodological quality for measurement error, due to small sample size, but the result of the testing is consistent with previous findings.

Overall, the methodological quality score for reliability was strong positive, and the results were strengthened in the updated systematic review. Measurement error went from having inconclusive results, to strong positive results. The Swedish version shows good reliability overall, and all results are in line with evidence. Studies of the Swedish IKDC-SKF, with a higher methodological quality could be valuable to further strengthen the reliability of the Swedish version.

\section{Validity}

Structural validity was tested in three studies $52,56,110$ in the systematic review. The results were inconclusive, with one study reporting findings that suggested two dimensions of the form. The overall result still showed more evidence for a one-factor solution, and the updated review supported that, with two studies 
with an excellent methodological score ${ }^{68,121}$. These studies also supported the one-factor solution. The result for structural validity is strongly positive, and it is reasonable to conclude that a one-factor solution and summarization of the score into one overall score could be recommended.

The Swedish version was one of the two studies with excellent methodological score for structural validity, where all items, except item 6 (During the past 4 weeks, or since your injury, did your knee lock or catch?), had a good factor loading. Item 6 has shown lower loading previously, in the development study ${ }^{56}$. In the testing for the Swedish IKDC-SKF all participants had an ACL injury and were waitlisted for ACLR. Thus, the question about locking might have been less of value for this group of patients, because locking is not a primary symptom of $A C L$ injury. However, it is reasonable to retain item 6 because (i) the IKDC-SKF was not specifically developed for $\mathrm{ACL}$ injuries ${ }^{56}$, and (ii) a meniscus injury can manifest in symptoms like catching or locking ${ }^{30}$.

The result of hypothesis testing was assessed in 10 studies ${ }^{12,14,19,20,64,81-83,105,126}$ in the systematic review. There were six additional studies identified that scored poor for methodological quality $2,51,65,70,113,114$, which were excluded from the result assessment.

Studies that evaluated the measurement properties of other studies, and used the IKDC-SKF to compare, and studies that did not aim to evaluate measurement properties were included in the first systematic review. It may be unreasonable to assess methodological quality with the COSMIN checklist when the study was not designed to assess measurement properties of IKDC-SKF. This may be an explanation for the high frequency of poor scoring, hence a methodological consideration for the thesis. It was also the reason to exclude studies from the systematic review update. Nine additional studies $15,53,58,62,67,68,121,124,125$ were added following the updated search, and hypotheses were all confirmed. The former conclusion of conflicting evidence for hypothesis testing changed to strongly positive. The Swedish IKDC-SKF had excellent methodological quality and was tested for ten hypotheses, all confirmed.

In the systematic review, cross-cultural validity included translation validity, reflecting the translation process. The score was intermediate, mainly because no comparisons of similar patient groups in the original language (English) and the target language were made. In the updated review, eight additional studies 
$15,53,57,58,62,67,121,125$ were assessed; two had a good methodological score, three had fair. The low methodological quality in many studies (the Swedish version included) were mainly due to small samples and no differential function item (DIF) testing. In most studies that translated the IKDC-SKF to different languages, the translation process was described in detail, often with reference to Guillemin's work ${ }^{49}$. However, there was no tradition to test DIF, or to report it in accordance to COSMIN guidelines. Therefore, the methodological score for translation and cross-cultural validity was low.

The update for cross-cultural validity strengthened the results, and the overall score was strong positive.

Content validity was assessed in three studies ${ }^{68,124,125}$ in the updated review; two were of excellent methodological quality. There was a strong positive score for content validity for the IKDC-SKF. One study concluded that of both patients and orthopaedic surgeons who completed the form, $>75 \%$ considered the content relevant. All items were rated as comprehensible, and $50 \%$ of the items as essential. One study reported that the IKDC-SKF (among other tested questionnaires) did not cover topics such as fear of re-injury, worries about the future, and expectations regarding sports participation. However, there are other questionnaires more suitable than the IKDC-SKF for measuring psychological concerns regarding return to sport ${ }^{129}$.

Compared to other measurement properties, where an assessment of methodology and result can be direct (e.g. test-retest reliability, where there are clear cut-offs for excellent, good, fair and poor ICC scores), cross-cultural validity and content validity are more arbitrary to assess, and requires extended skills of the assessor. This is a methodological issue that has not been addressed in the literature. Clearer and more specific criteria for cross-cultural and content validity might be useful to ensure that scores are comparable when assessments are completed according to COSMIN criteria.

Criterion validity was assessed in twelve studies $13,20,41,52,56,63,73,81,82,98,110,126$ of good methodological quality. All studies had correlations to the gold standard used (SF36 was common, and also was in the measurement instrument development article ${ }^{56}$ ), but the result score was intermediate, since the correlation was not above 0.7 . Evaluation of criterion validity against a gold standard for PROMs is difficult. For the update, only two more studies were 
assessed ${ }^{27,121}$, one with excellent methodological score (the Swedish version of IKDC-SKF, study II) and one with fair quality. The correlation between the Swedish IKDC-SKF and the physical component summary of the SF36 was 0.73 , which confirms the hypothesis and gives a strong positive result. The findings for criterion validity changed to strongly positive.

\section{Responsiveness}

In the systematic review, responsiveness was given a strong positive score, which was further strengthened in the updated review. In the update, seven studies with methodological score fair ${ }^{15,54,57,121}$, good ${ }^{95}$ and excellent ${ }^{68,92}$ had good result for responsiveness, mainly assessed with measures of area under the curve (AUC) and hypothesis testing.

Some articles used the measure of ES and SRM as test for responsiveness. COSMIN considers ES and SRM of limited value for testing responsiveness ${ }^{24}$. The ES and SRM measure whether the instrument can detect a change, but not whether the change is meaningful to the patient. When testing responsiveness with a criterion approach, the result gives an implication to whether the instrument can detect changes that are clinically relevant, thus ES and SRM should not be used as a sole measures of responsiveness.

More studies evaluated responsiveness with AUC value and hypothesis testing, and fewer reported ES and SRM, compared to the original review. This might indicate that testing for responsiveness is moving towards a trend of less reports in ES and SRM, which would mean a quality improvement in responsiveness testing from PROMs in research ${ }^{24}$. In the updated systematic review, studies that did not evaluate with either AUC or hypothesis testing, but only ES or SRM, were assigned a poor methodology score. In the original review, the methodological score was not affected by whether only ES and/or SRM was used, but the studies that did not use AUC or hypothesis testing did get an inconclusive result score. Because the COSMIN guidelines and criteria are more prominent today ${ }^{42}$, it seems more accepted that correct responsiveness testing should not be (only) with the use of ES and SRM. The result of the updated systematic review, with more studies that have used proper methods, also show that. That is why the decision was taken to give a methodological score of poor in the updated systematic review, for studies that failed to use a proper evaluation method, since it is a methodological flaw, and not a reflection of the result. The overall result is 
the same, since the studies that had evaluated responsiveness in the original systematic review with only ES or SRM, got a result score of inconclusive result, which did not higher or lower the overall result score, and in the updated systematic review, the same study would have gained a poor methodological quality score and thus would not have been included in the result score.

Minimal Clinical Important Difference (MCID) is often considered a measure of responsiveness, although it can be considered to be defined as interpretability, since it is a clinically useful measure ${ }^{87}$. Many studies tested MCID in both the original and updated review, with scores between 9.8 to 13.9 points. Although, the use of MCID scores must be regarded with caution, since a meaningful change in state and score can differ depending on diagnosis, treatment method evaluated, where in a rehabilitation phase patients are ${ }^{8}$, and the score reported must be taken in consideration to the clinical context.

The Swedish version of the IKDC-SKF had an excellent methodological score and the results were good, in both criterion and construct testing for responsiveness, thus confirming the overall strong positive score for responsiveness.

\section{Interpretability}

Although interpretability is not considered to be a measurement property per se, it is important to assess and to report, and provides clinicians with data important for interpreting the scores of PROMs in daily use.

Interpretability was reported mainly in terms of presence of floor and ceiling effect. There was seldom any floor or ceiling effect above $15 \%$, indicating a good result. One study ${ }^{32}$ showed a $30 \%$ ceiling effect, by using a population of patients that had undergone ACLR 2-4 years ago, where such high scores can be expected. A 34\% ceiling effect was found in another study, where children with "previous knee disorders" filled out the questionnaire ${ }^{91}$. Since there was no further description of what the knee disorder was, it is difficult to evaluate the importance of that result.

Muller et al 90 investigated another part of interpretability, by defining the threshold for patient acceptable symptom state (PASS). The PASS is assessed according to whether the patient is satisfied with current knee function. Compared to investigating MCID, PASS indicates not if patients feel better, but if 
they feel well. The IKDC-SKF had a PASS score of 75.9 points, in patients between 1-4 years after ACLR.

The method to define PASS as a meaningful value has been debated, and Roos et al ${ }^{106}$ compared PASS scores to both minimal important change and treatment failure for the same cohort. They found that the PASS value seems to be more adequate as a measure of satisfying result for patients. The PASS score of 75.9 is in line with previous studies that show that a PASS score of 72 on a 0-100 scale should be adequate on a PROM used for young patients after ACLR ${ }^{55}$. In study II in this thesis ${ }^{121}$ the IKDC-SKF mean score was 78.1 at 12 months after ACLR, which should indicate a good result in terms of patient satisfaction.

\section{Choice of treatment after $A C L$ injury}

The desired effect of an ACLR is to gain stability of the knee ${ }^{72}$. Guidelines state that the presence of knee joint instability should be the reason for choosing ACLR $3,9,84,112$. The results of study IV show that the main reasons for a decision of ACLR treatment were instability and/or high activity demands. The combined results of study III and study IV shows that orthopaedic surgeons and physiotherapists follow guidelines when describing the grounds for ACLR recommendation.

\section{Reasons for choice of treatment}

Age was considered to be an important reason for recommending ACLR (study III). It was not expressed as an important reason in study IV by orthopaedic surgeon and patients, but still patients where a decision for ACLR was taken early, were younger than the patients were a non-operative treatment decision was taken. Age could be an indirect reason for fear of knee joint instability in activity, since younger individuals often have higher activity demands, an explanation that also can be found in the literature ${ }^{84}$. It can also be an expression of fear of knee joint instability in future participation in sports activity ${ }^{116}$. During knee strenuous situations, patients with an ACL injury can suffer from giving way symptoms, which can be associated to new injuries $5,16,43$. The core dilemma is that some patients can perform in demanding activities without ACLR, but it is difficult to identify which patients require surgery, and which do not ${ }^{88}$. 
The absence of conclusive evidence regarding the best treatment places health care professionals in a difficult situation. The risk of performing an "unnecessary" $A C L R$, includes the risk for post-operative complications ${ }^{28}$, the costs for surgical procedure and prolonged time for rehabilitation after the surgical procedure. The risk of graft rupture or contralateral ACL injury is higher in young active patients ${ }^{35}$ and if ACLR is conducted early after injury ${ }^{37}$. These risks must be weighed against the risk of suffering giving way episodes with possible new injuries, with a non-operative treatment approach. Although re-injuries seem more frequent after ACLR than non-operative treatment ${ }^{47}$, it could be that patients treated with ACLR often are highly active, and have greater exposure to knee strenuous activities that puts their knee into higher risk situations.

With regard to GRADE score for treatment after ACL injury, there is evidence for successful outcome for both treatment methods. There is a delicate balance between desirable and undesirable treatment consequences. Costs for ACLR outweighs costs for non-operative treatment, and an early ACLR is not more beneficial in terms of costs, compared to a delayed ACLR ${ }^{61}$. With regard to values and preferences, patients often prefer ACLR, which seems to be founded in beliefs that ACLR is a necessary treatment to allow physical activity ${ }^{120}$. Some patients express wishes for non-operative treatment as a more "natural treatment" or because an ACLR is a definitive treatment decision, while a nonoperative treatment can be changed into ACLR later on ${ }^{120}$. Still, evidence for recommendations for either $A C L R$ and non-operative treatment must be considered as weak, and this implies that further research is warranted in that area.

Treatment decision process: patient's, physiotherapist's and orthopaedic surgeon's roles

The treatment decision process after an ACL injury is complex. We have little knowledge of how the treatment decision process after an $\mathrm{ACL}$ injury is perceived by patients and health care personnel. In cases of complex treatment decisions with limited evidence for which treatment is superior, the importance of information of options, possible side effects and risks, and exploration of patient's preferences are enhanced ${ }^{102}$. There is a fine balance between informing the patient without overwhelming her with information. A shared decision making strategy, where health care personnel balance sharing information that the patient requests, in a clear and comprehensible way, with managing the 
emotional responses that might arise, is recommended, but requires a lot from the health care personnel ${ }^{102}$.

The process for choice of treatment after ACL injury is not carefully explored. In this thesis, some aspects of the patient's role in the decision process is reported. Orthopaedic surgeons and physiotherapists rate patient's wishes highly in the treatment decision choice for ACLR (study III), and there were no differences in patients' and orthopaedic surgeons' reasons for choice of treatment (study IV). Patients can tend to rely on health care personnel advice ${ }^{120}$, which emphasizes the importance of further investigation of the treatment decision process. Patients must receive adequate information about the treatment options as well as pros and cons about either treatment, based on evidence and clinical experience, for evidence based health care and shared decision making to be practised.

Patients, orthopaedic surgeons and physiotherapists all have influence on the treatment decision process after an $A C L$ injury. The decision process is not investigated in detail in this thesis. However, assumptions can be made that there is not an equal contribution to the decision by all three actors. In the decision for $A C L R$, the orthopaedic surgeon has the final call, and can decide to not perform the ACLR if necessary, just as the patient must consent to surgery.

The majority of orthopaedic surgeons, sometimes or often, state that they have contact with treating physiotherapist in the treatment decision, regarding rehabilitation and compliance to rehabilitation. Almost all of orthopaedic surgeons also rated the importance of the physiotherapist assessment high. Although, physiotherapists do seem to have lower beliefs in the importance of their own assessment. Only 75\% of the physiotherapists rated their own assessment as important. Physiotherapists often seem to communicate their assessment of treatment recommendation directly to the patient, but not so many stated that they sometimes or often communicate their assessment to the orthopaedic surgeon. This indicates that there could be a discrepancy between physiotherapists and orthopaedic surgeons regarding how they perceive their communication, a phenomena that has been observed in previous studies ${ }^{75}$. 
Physiotherapists seem to experience a lack of communication between caregivers in discussion about surgical treatment and that rehabilitation and surgical decisions often are taken separately ${ }^{131}$. Patients may feel that they are not always heard in the treatment decision process ${ }^{115}$. Physiotherapists often meet the patient more frequently than the orthopaedic surgeon, thus might have more possibilities to listen to the patient's story and communicate patient's wishes further ${ }^{115}$, hence, an improved communication between physiotherapists and orthopaedic surgeons might be beneficial for patients in the decision making after an $\mathrm{ACL}$ injury.

The results from study IV suggest that the orthopaedic surgeon had less influence in the non-operative treatment decision. Some patients had not been at a follow up at the orthopaedic department, thus had not discussed the choice of treatment with an orthopaedic surgeon. We did not analyse information about whether the physiotherapist was more active in advising in these cases, but it may be the case ${ }^{97}$.

In both study III and study IV, respondents from smaller and larger clinics all over Sweden, representing private and public health care have been included. Still, it is important to recognize that there might be different traditions and health care systems both between and within countries ${ }^{60}$, which makes it important to interpret and generalize the results from study III and study IV with care.

\section{Patient-reported factors in relation to choice of treatment}

In study IV, patient reported knee joint instability rating and function (IKDC-SKF) improved during the first 3 months. There were no significant differences between groups in knee joint instability or IKDC-SKF. This indicates that when an early decision for ACLR is made, patient ratings of knee joint instability or function (IKDC-SKF) does not weigh heavily on the treatment decision making. This is supported by the reason for ACLR, which was mainly due to high activity demands. Still it is interesting that patients who decided for ACLR in the late phase did not differ from the non-operatively treated patients in IKDC score and knee joint instability ratings. Perhaps they did not put enough strain on the knee for the first three months after injury to acknowledge knee joint instability? This might imply that when a decision for ACLR is not taken due to high activity demands, several months might be needed to evaluate whether knee function is adequate to sustain non-operative treatment or not. 
The similarity in patient-reported knee joint instability and function also raises questions about whether the right choice of treatment was taken. Instead, the stated reasons for chosen treatment may be simplified and represent a more complex process, which was difficult to describe by both patients and orthopaedic surgeons. When medical decisions are taken in complex situations, the decisions tends to be based on emotional and relational grounds, not only for patients, but also for health care personnel and the reason for these decisions can be more difficult to express ${ }^{31}$. This thesis will not provide answers for the details of the treatment decision process for all involved parts, but the results implicates that the process needs to be further described and explored.

\section{Methodological considerations}

\section{Study I and II}

Study I was a systematic review of mainly methodological studies, and study II was a methodological study. The decision to use the COSMIN guidelines was taken in an early phase of the planning of both studies, and affected the study plan, design and outcome in a direct way. The COSMIN guidelines were used since they are addressing PROMs specifically and exclusively.

The COSMIN guidelines are commonly used for assessment of methodological quality and results of testing of measurement properties. By using a framework specifically developed for patient-reported outcomes, the methodological quality of the assessment can be considered high. Although, in 2013-2014 when the systematic review was conducted, the COSMIN was not as well-known as today, which might be a reason why many studies scored poor on methodological quality. Many studies had been published long before the COSMIN guidelines were developed. The tradition of how to report the translation process and evaluation of validity and reliability, as well as the definitions and terminology of measurement properties, differed and was often inconsistent. By assessing articles that had been published earlier, with the use of newly developed criteria, a possible low methodological score must be interpreted with caution.

At the time for the IKDC-SKF updated review (conducted for this thesis, not published), it was noticeable that more studies referred to the COSMIN guidelines as a theoretical framework in their methodological studies. A common way to report facilitates the interpretation of what has actually been evaluated in the article, and the scoring process for methodological quality. 
During 2018, the COSMIN group published a 10-step instruction guide for how to perform a systematic review of measurement properties of PROMs ${ }^{103}$. These guidelines were not used for the update, due to intentions to be consistent in the methods for both reviews and to enhance the possibilities to add the results from both reviews. Although, this updated checklist will probably be a future important tool to increase the quality the methods of this type of methodological studies. It will hopefully aid in how to report, and also ease the interpretation for clinicians and researchers.

In the original systematic review, the term translation validity was used as a term for cross-cultural validity and content validity. That was a choice made in discussion with the co-author (CT), who also is one of the founders of the COSMIN group initiative. The decision to use the term translational validity was taken to ease interpretation for readers, since the terminology and content of the term cross-cultural validity was defined, but not as commonly used in this area, at that time. For the updated review, cross-cultural validity and content validity was separated, to be more consistent with the checklist but also since the terms often are described in articles today, thus it is easier to interpret and assess.

Since 2013, many papers have been published about translation processes and measurement properties of the IKDC-SKF. For the update, done in 2019, 12 of the 14 assessed articles were articles where the IKDC-SKF was translated into a new language. There is a need to use PROMs of good quality, both in the clinical setting and in research. When a PROM is translated, it is important to ensure the measurement properties of the translation are good ${ }^{24}$.

Although many of the articles in the updated review report that they have used the COSMIN guidelines, many score fair and sometimes even poor for methodological quality. The low scores can be due to circumstances that are difficult to control afterwards. For example, sample size can be poor if there was a lower response rate than expected. But a poor score although good intentions could also be due to difficulties in reporting the result of a standardised assessment in a different forum, e.g. assessing according to COSMIN but reporting as a scientific paper with the structure the specific journal requires (word limitation etc.). Perhaps this type of scientific reports needs to be reported in another standardized way? A standardized report for articles that evaluate measurement properties using the COMSIN guidelines, might ease comparisons between papers, and improve interpretation of results for the reader. It might also facilitate knowledge translation to clinicians and researchers who are not experts in the field of measurement properties. 
Study II was planned to evaluate the measurement properties and translational process of the Swedish IKDC-SKF, by using the COSMIN as a methodical framework. However, we failed to score excellent in all methodological assessments for all measurement properties.

Test-retest reliability and measurement error scored poor methodological quality due to low sample size (<30 patients), which was due to a lower response rate than expected. For test-retest reliability, there was a balance between including responses from patients who returned the questionnaire late and not including responses where too much time had passed, due to the risk that patients had changed in condition. Patients filled out a question if their knee-related condition had changed since they filled out the first questionnaire. If the knee had changed, the patient's response was excluded. The decision not to include responses with more than three weeks interim time contributed to the low sample size for testretest reliability and measurement error. By having two more participants, the methodological score would have been fair. The results for $\mathrm{ICC}_{2,1}$ was high, but the "worst score count system" in the methodological assessment, and decision to exclude the result from studies with poor methodological quality (according to guidelines) meant that the result did not count in the overall result for test-retest reliability.

Assessment criteria always have a cut off, separating "good" from "bad/poor". Although, there are difficulties in assessing, as well as risks of excluding results that are valid, due to how results are presented. That is a problem that should be addressed in the future developments of reports of methodological studies.

\section{Study III and IV}

In study III, the factors/reasons for recommending ACLR were pre-stated. The questionnaire sent to orthopaedic surgeons and physiotherapists was pre-tested by physiotherapists and orthopaedic surgeons presently not active in treating $A C L$ injured patients, but with extended experience in the field. The questionnaire was tested for comprehension, relevance and clarity.

In contrast to testing a PROM, this questionnaire was intended for use in a crosssectional study to describe a phenomenon, and testing responsiveness was not required. Answers to the questions are reported separated and the questionnaire was not intended to result in a score. A test of criterion validity would have been difficult because the questions were study specific and, to our knowledge, had not been used previously. 
Regarding reliability, a test-retest and test for interpretability could have provided useful information about whether there were aspects missing, but it was not practically possible. Because the intention was to reach as many orthopaedic surgeons and physiotherapists who treat patients with ACL injury as possible, a pre-testing of that size necessary would mean that many possible respondents would have already participated, when it was time for the testing. $A$ decision that the pre-testing was enough, was therefore taken.

The intention initially was to grade each factor for importance in the choice to do/recommend ACLR. Although, after data collection, we realized that a score of $0-1$, close to "no surgery" could be interpreted as that the factor was not important in the choice to do/recommend ACLR, but also it could be interpreted as that it was a factor that suggested that a non-operative approach was recommended. Due to that ambiguousness, the decision to only report the result for scoring of 2-3 was taken.

We allowed participants to elaborate in free text, both if there were reasons they considered to be missing and to allow to describe other reasons that might influence the choice of treatment. A decision for using only free text option was taken for study IV. With the results of both the third and fourth study in this thesis, we know that the reason for choosing ACLR or non-operative treatment is more complex than stating one or a few factors that are the most influencing. It is difficult to express reasons for a complex decision into one or a few, and perhaps a qualitative approach could bring further light on this complex issue.

In study IV we used the medical chart information to report exact timing of when an ACLR decision was taken. For the group where a non-operative treatment decision was taken, the exact date for decision was not always registered. As discussed before, the reason for non-operative decision was not as exact as the ACLR decision, and subsequently not the timing either. There were cases where no definitive decision was registered, and overall it seems that there exists a group of patients who steers toward non-operative treatment without outspoken reasons, or a preceding medical decision process.

The question of how orthopaedic surgeons and physiotherapists rated their own, each other's assessment, and the patient's wishes when recommending ACLR, could have been more elaborated. That would have given more information about whose assessment and wishes are important and if there were differences who they considered to have more impact on the decision. Further information about how the decision was taken in non-operative treatment situations would 
have given a more complete picture of the decision process. Future analysis of the treatment decision process, with regards to patient involvement, communication between patient and health care personnel and how information is given and perceived, are planned to be done for both non-operative and ACLR treatment decision processes.

In study IV, pre-injury activity level, knee joint instability rating, and IKDC-SKF were assessed and compared between patients who had chosen or would choose ACLR or non-operative treatment. Patients reported knee joint instability ratings and IKDC-SKF at several times after their injury. Hence, the patient reported factors could be answered either before or after the treatment decision was taken. The results of the patient-reported factors cannot therefore be used for prediction of treatment decision. 


\section{Clinical implications}

This thesis gives the prerequisites for Swedish clinicians to use the IKDC-SKF in clinical context. It also provides evidence that the IKDC-SKF is a well-tested and a suitable tool for assessing symptoms, function and sports participation in patients with ACL injury. The IKDC-SKF has good validity, reliability and responsiveness. The systematic review of measurement properties for IKDC-SKF provides clinicians and researchers a compendium of the measurement properties of the IKDC-SKF.

Orthopaedic surgeons and physiotherapists in Sweden make decisions about treatment for $\mathrm{ACL}$ injured patients, with consideration of best evidence and the patient's wishes.

The complexity of the treatment decision-making process after an ACL injury supports the need for collaboration between orthopaedic surgeons and physiotherapists. Study III shows that both professions value each other's opinions, and share common ground in which reasons they consider important for recommending ACLR. The result that their values are shared, might contribute to enhance collaboration between the professions, a result that most likely would benefit patients.

The result that patient-reported knee joint instability and function did not reflect the choice of treatment chosen, could serve as a reminder to physiotherapists and orthopaedic surgeons, to interpret knee joint instability and function in an early phase with caution, in regards to choice of treatment.

\section{Future research}

The assessment and valuation of the methodological quality of a PROM should be an ongoing procedure. Assessments that are structured, standardized and reported in ways that are easy to interpret are of relevance, and help clinicians and researchers make decisions about which PROM to use. The results of the measurement properties testing for IKDC-SKF, should be completed with further testing of the Swedish version. Future research testing the measurement properties of the IKDC-SKF in patients with other diagnosis, and patients with an $\mathrm{ACL}$ injury that are treated non-operatively, would give information about whether the Swedish version is applicable for these groups.

Future research on the treatment decision process after an $\mathrm{ACL}$ injury is needed for a deeper understanding of how the decision is taken. It would be preferable to gain deeper perspective from health care personnel (orthopaedic surgeons 
and physiotherapists) and the patient's perspective. More information about how patient's receive and perceive information about the treatment options, pros and cons and risks about either treatment should be warranted. This could be gained by a qualitative approach and further explored with a quantitative approach, but should include patients', physiotherapists' and orthopaedic surgeons' perspective.

The course of non-operatively treated patients after an ACL injury is less documented compared to the course after ACLR. There is a need to map the process after an $A C L$ injury that leads to a non-operative treatment, clarify the reasons for choice of treatment further and gain deeper knowledge of the decision process after an ACL injury. 



\section{CONCLUSIONS}

\section{Overall conclusion}

- The IKDC-SKF, including the Swedish version, has good measurement properties and can be recommended for use in patients with an ACL injury, as well as other knee diagnoses.

- After an ACL injury, an early decision for ACLR is based on patients' high activity demands. ACLR decision later after injury is more common in the presence of knee joint instability and dysfunction, which cannot be discriminated by patient-reported knee joint instability and function during the first 3 months after injury. Orthopaedic surgeons' and physiotherapists' assessments are important in the choice of treatment decision, as well as patients' wishes.

\section{Study aim specific conclusions}

- Several studies that have tested the measurement properties of the IKDCSKF showed to have excellent methodological quality, and showed good testing results for measurement properties, assessed with the COSMIN guidelines.

- The Swedish version of the IKDC-SKF has good results regarding measurement properties and interpretability for patients with an $\mathrm{ACL}$ injury.

- According to Swedish orthopaedic surgeons and physiotherapists, ACLR treatment after an $\mathrm{ACL}$ injury should be recommended when patients are young and/or, have high activity demands, have a knee demanding occupation and/or have knee joint instability despite adequate rehabilitation. In the treatment decision after an $\mathrm{ACL}$ injury, orthopaedic surgeons and physiotherapists take each other's assessments and patient's wishes into consideration.

- Treatment choice differs depending on when in time after injury the decision is taken. An early decision for ACLR is more often based upon high activity demands, while later decisions are more often based upon knee joint instability. Non-operative treatment decisions are often based upon 
lack of knee joint instability problems or sufficient knee function. Selfreported knee joint instability and function during the first three months after ACL injury is no different in patients who chose ACLR or nonoperative treatment. 


\section{ACKNOWLEDGEMENTS}

I would like to thank everyone around me that have given me support and positive energy in times when I have been in need of it.

A special thanks to my main supervisor, Joanna Kvist. You have given me so much in terms of knowledge, experience and support. I know that I might have given you some grey hairs, but I hope that you have appreciated our time together as well!

Clare Ardern- You have so much experience, knowledge and talent for research, and I am so grateful that I have had the chance to learn so much from you. I hope we will have the chance to work together some time in the future as well.

Sofi Sonesson- thank you so much for all the time you have spent reading my work and giving constructive criticism. You are phenomenal in structuring and writing, and I hope I will be able to "hang around" to learn more.

Håkan Gauffin- Thank you for all the clinical experience I have gained by examining patients with you! And we have had time for quite a few laughs as well!

Bashir Tajik Edwardsson- I have only one thing to say; I cannot wait for our retirement drinks on the beach $:$ :

Anne Fältström - Thank you for letting me ask all these "silly questions" that you need to ask someone, as a PhD student. And thank you for your patience about all figures and numbers I've mixed up, when we have been co-writers.

Henrik Hedevik- Thank you so much for discussions, statistical advice and excel-help!

Karin Grävare Silbernagel- Thank you for such a warm welcoming to Delaware, and for giving med a wonderful experience at Star! I appreciated it so much.

Siw Carlfjord- Thank you for comments and input while writing paper III.

Caroline Terwee- Thank you for your expert help while writing paper I, and during the course in measurement properties.

Anders Stålman- Thank you for good comments on the manuscript, and discussions from an orthopaedic point of view.

Jonas, Fabian and Saga- Thank you for allowing me to take the time, sometimes from our family time, during these years. You mean the world to me, and I love the three of you so much!

Mom, Dad, Sis- Thank you for your support and for always making me feel that I can do whatever I want. The four of us stick together in good times and bad. 
Thank you Violette and Pernilla from Rörelse \& Hälsa, for allowing me to do my PhD, and also for your great support during these years.

A great thanks to my colleagues at Rörelse \& Hälsa and MIE, for many great discussions and input!

All my colleagues at avdelning Fysio, thank you for discussions, laughs and support!

A great thank you to all physios at Linköping HC and Aktiva Rehab, for all help in the Nacox study, both in recruiting patients and in responding to questionnaires- I appreciate that so much!

Thanks to all patients and respondents in study II, III, and IV. Without your participation this thesis would not exist.

Thank you my dear fika-friends and Nina, for being the best of friends and both listening and giving energy! 


\section{REFERENCES}

1. Adams D, Logerstedt DS, Hunter-Giordano A, Axe MJ, Snyder-Mackler L. Current concepts for anterior cruciate ligament reconstruction: a criterion-based rehabilitation progression. J Orthop Sports Phys Ther. 2012;42(7):601-614.

2. Agel J, LaPrade RF. Assessment of differences between the modified Cincinnati and International Knee Documentation Committee patient outcome scores: a prospective study. Am J Sports Med. 2009;37(11):2151-2157.

3. Ahldén M, Kvist J, Samuelsson K, Eriksson KO, Karlsson J. Individualiserad terapi viktigt vid främre korsbandsskada. Läkartidningen; 2014.

4. Ahmed KM, Said HG, Ramadan EKA, El-Assal MA. Arabic translation and validation of three knee scores, Lysholm Knee Score (LKS), Oxford Knee Score (OKS), and International Knee Documentation Committee Subjective Knee Form (IKDC). Sicot $j$. 2019;5:6.

5. Anderson $\mathrm{AF}$, Anderson $\mathrm{CN}$. Correlation of meniscal and articular cartilage injuries in children and adolescents with timing of anterior cruciate ligament reconstruction. $A m$ J Sports Med. 2015;43(2):275-281.

6. Ardern $\mathrm{CL}$, Grindem H, Ekas GR, Seil R, McNamee M. Applying ethical standards to guide shared decision-making with youth athletes. Br J Sports Med. 2018;52(20):12891290.

7. Beaton DE. Understanding the relevance of measured change through studies of responsiveness. Spine. 2000;25(24):3192-3199.

8. Beaton $D E$, Boers $M$, Wells $G A$. Many faces of the minimal clinically important difference (MCID): a literature review and directions for future research. Curr Opin Rheumatol. 2002;14(2):109-114.

9. Beaufils P, Hulet C, Dhenain M, Nizard R, Nourissat G, Pujol N. Clinical practice guidelines for the management of meniscal lesions and isolated lesions of the anterior cruciate ligament of the knee in adults. Orthop Traumatol Surg Res. 2009;95(6):437442.

10. Beers E, Lee Nilsen M, Johnson JT. The Role of Patients: Shared Decision-Making. Otolaryngol Clin North Am. 2017;50(4):689-708.

11. Beynnon BD, Johnson RJ, Abate JA, Fleming BC, Nichols CE. Treatment of anterior cruciate ligament injuries, part I. Am J Sports Med. 2005;33(10):1579-1602.

12. Bjorklund $K$, Andersson L, Dalen N. Validity and responsiveness of the test of athletes with knee injuries: the new criterion based functional performance test instrument. Knee Surg Sports Traumatol Arthrosc. 2009;17(5):435-445.

13. Boykin RE, McFeely ED, Shearer $D$, et al. Correlation between the Child Health Questionnaire and the International Knee Documentation Committee score in pediatric and adolescent patients with an anterior cruciate ligament tear. $J$ Pediatr Orthop. 2013;33(2):216-220.

14. Briggs KK, Lysholm J, Tegner Y, Rodkey WG, Kocher MS, Steadman JR. The reliability, validity, and responsiveness of the Lysholm score and Tegner activity scale for anterior cruciate ligament injuries of the knee: 25 years later. Am J Sports Med. 2009;37(5):890897.

15. Celik D, Coskunsu D, KiliCoglu O, Ergonul O, Irrgang JJ. Translation and cross-cultural adaptation of the international knee documentation committee subjective knee form into Turkish. J Orthop Sports Phys Ther. 2014;44(11):899-909. 
16. Chen KH, Chiang ER, Wang HY, Ma HL. Correlation of Meniscal Tear with Timing of Anterior Cruciate Ligament Reconstruction in Patients without Initially Concurrent Meniscal Tear. J Knee Surg. 2018.

17. Cimino F, Volk BS, Setter D. Anterior cruciate ligament injury: diagnosis, management, and prevention. Am Fam Physician. 2010;82(8):917-922.

18. Claridge JA, Fabian TC. History and development of evidence-based medicine. World J Surg. 2005;29(5):547-553.

19. Cook C, Hegedus E, Hawkins R, Scovell F, Wyland D. Diagnostic accuracy and association to disability of clinical test findings associated with patellofemoral pain syndrome. Physiother Can. 2010;62(1):17-24.

20. Crawford K, Briggs KK, Rodkey WG, Steadman JR. Reliability, validity, and responsiveness of the IKDC score for meniscus injuries of the knee. Arthroscopy. 2007;23(8):839-844.

21. da Silva TM, Costa Lda C, Garcia AN, Costa LO. What do physical therapists think about evidence-based practice? A systematic review. Man Ther. 2015;20(3):388-401.

22. Dare $D$, Rodeo $S$. Mechanisms of post-traumatic osteoarthritis after $A C L$ injury. Curr Rheumatol Rep. 2014;16(10):448.

23. Davis JC, Bryan S. Patient Reported Outcome Measures (PROMs) have arrived in sports and exercise medicine: Why do they matter? Br J Sports Med. 2015;49(24):1545-1546.

24. de Vet HCW, Terwee CB, Mokkink LB, Knol DL. Measurement in medicine. Cambridge ; New York: Cambridge University Press; 2011.

25. Djulbegovic B, Guyatt GH. Progress in evidence-based medicine: a quarter century on. Lancet. 2017;390(10092):415-423.

26. Dowrick AS, Wootten AC, Murphy DG, Costello AJ. "We Used a Validated Questionnaire": What Does This Mean and Is It an Accurate Statement in Urologic Research? Urology. 2015;85(6):1304-1310.

27. Ebrahimzadeh $\mathrm{MH}$, Makhmalbaf $\mathrm{H}$, Golhasani-Keshtan F, Rabani S, Birjandinejad A. The International Knee Documentation Committee (IKDC) Subjective Short Form: a validity and reliability study. Knee Surg Sports Traumatol Arthrosc. 2015;23(11):3163-3167.

28. Eckenrode BJ, Carey JL, Sennett BJ, Zgonis MH. Prevention and Management of Postoperative Complications Following ACL Reconstruction. Curr Rev Musculoskelet Med. 2017;10(3):315-321.

29. Eitzen I, Moksnes H, Snyder-Mackler L, Risberg MA. A progressive 5-week exercise therapy program leads to significant improvement in knee function early after anterior cruciate ligament injury. The Journal of orthopaedic and sports physical therapy. 2010;40(11):705-721.

30. Englund M, Roemer FW, Hayashi D, Crema MD, Guermazi A. Meniscus pathology, osteoarthritis and the treatment controversy. Nat Rev Rheumatol. 2012;8(7):412-419.

31. Epstein RM, Gramling RE. What is shared in shared decision making? Complex decisions when the evidence is unclear. Med Care Res Rev. 2013;70(1 Suppl):94s-112s.

32. Eshuis R, Lentjes GW, Tegner Y, Wolterbeek N, Veen MR. Dutch Translation and Crosscultural Adaptation of the Lysholm Score and Tegner Activity Scale for Patients With Anterior Cruciate Ligament Injuries. J Orthop Sports Phys Ther. 2016;46(11):976-983.

33. Estabrooks CA. Will evidence-based nursing practice make practice perfect? Can J Nurs Res. 1998;30(1):15-36.

34. Failla MJ, Arundale AJ, Logerstedt DS, Snyder-Mackler L. Controversies in knee rehabilitation: anterior cruciate ligament injury. Clin Sports Med. 2015;34(2):301-312.

35. Faltstrom A. One ACL injury is enough! Focus on female football players. Br J Sports Med. 2017;51(16):1235-1236.

36. Faltstrom A, Hagglund $M$, Kvist J. Patient-reported knee function, quality of life, and activity level after bilateral anterior cruciate ligament injuries. Am J Sports Med. 2013;41(12):2805-2813. 
37. Faltstrom A, Hagglund M, Magnusson H, Forssblad M, Kvist J. Predictors for additional anterior cruciate ligament reconstruction: data from the Swedish national ACL register. Knee Surg Sports Traumatol Arthrosc. 2016;24(3):885-894.

38. Fitzgerald GK, Lephart SM, Hwang JH, Wainner RS. Hop tests as predictors of dynamic knee stability. J Orthop Sports Phys Ther. 2001;31(10):588-597.

39. Florczak KL. Evidence-Based Practice: What's New Is Old. Nurs Sci Q. 2016;29(2):108112.

40. Frobell RB, Roos HP, Roos EM, Roemer FW, Ranstam J, Lohmander LS. Treatment for acute anterior cruciate ligament tear: five year outcome of randomised trial. $\mathrm{Br} \mathrm{J}$ Sports Med. 2015;49(10):700.

41. Fu SN, Chan YH. Translation and validation of Chinese version of International Knee Documentation Committee Subjective Knee Form. Disabil Rehabil. 2011;33(1314):1186-1189.

42. Gagnier JJ. Patient reported outcomes in orthopaedics. J Orthop Res. 2017;35(10):2098-2108.

43. Ghodadra N, Mall NA, Karas V, et al. Articular and meniscal pathology associated with primary anterior cruciate ligament reconstruction. J Knee Surg. 2013;26(3):185-193.

44. Greenhalgh J, Long AF, Flynn R. The use of patient reported outcome measures in routine clinical practice: lack of impact or lack of theory? Soc Sci Med. 2005;60(4):833843.

45. Grevnerts HT, Faltstrom A, Sonesson S, Gauffin H, Carlfjord S, Kvist J. Activity demands and instability are the most important factors for recommending to treat $A C L$ injuries with reconstruction. Knee Surg Sports Traumatol Arthrosc. 2018.

46. Grevnerts $\mathrm{HT}$, Terwee $\mathrm{CB}$, Kvist J. The measurement properties of the IKDC-subjective knee form. Knee Surg Sports Traumatol Arthrosc. 2014.

47. Grindem H, Eitzen I, Engebretsen L, Snyder-Mackler L, Risberg MA. Nonsurgical or Surgical Treatment of ACL Injuries: Knee Function, Sports Participation, and Knee Reinjury: The Delaware-Oslo ACL Cohort Study. J Bone Joint Surg Am. 2014;96(15):1233-1241.

48. Grindem $H$, Wellsandt E, Failla M, Snyder-Mackler L, Risberg MA. Anterior Cruciate Ligament Injury-Who Succeeds Without Reconstructive Surgery? The Delaware-Oslo ACL Cohort Study. Orthop J Sports Med. 2018;6(5):2325967118774255.

49. Guillemin F, Bombardier C, Beaton D. Cross-cultural adaptation of health-related quality of life measures: literature review and proposed guidelines. $J$ Clin Epidemiol. 1993;46(12):1417-1432.

50. Guyatt GH, Oxman AD, Kunz R, et al. Going from evidence to recommendations. Bmj. 2008;336(7652):1049-1051.

51. Haverkamp D, Sierevelt IN, Breugem SJ, Lohuis K, Blankevoort L, van Dijk CN. Translation and validation of the Dutch version of the International Knee Documentation Committee Subjective Knee Form. Am J Sports Med. 2006;34(10):1680-1684.

52. Higgins $L D$, Taylor $M K$, Park $D$, et al. Reliability and validity of the International Knee Documentation Committee (IKDC) Subjective Knee Form. Joint Bone Spine. 2007;74(6):594-599.

53. Huang CC, Chen WS, Tsai MW, Wang WT. Comparing the Chinese versions of two knee-specific questionnaires (IKDC and KOOS): reliability, validity, and responsiveness. Health Qual Life Outcomes. 2017;15(1):238.

54. Huang $\mathrm{H}$, Zhang D, Jiang $\mathrm{Y}$, et al. Translation, Validation and Cross-Cultural Adaptation of a Simplified-Chinese Version of the Tegner Activity Score in Chinese Patients with Anterior Cruciate Ligament Injury. PLoS One. 2016;11(5):e0155463. 
55. Ingelsrud LH, Terwee CB, Terluin B, et al. Meaningful Change Scores in the Knee Injury and Osteoarthritis Outcome Score in Patients Undergoing Anterior Cruciate Ligament Reconstruction. Am J Sports Med. 2018;46(5):1120-1128.

56. Irrgang JJ, Anderson AF, Boland AL, et al. Development and validation of the international knee documentation committee subjective knee form. The American Journal of Sports Medicine. 2001;29(5):600-613.

57. Jacobsen JS, Knudsen P, Fynbo C, Rolving N, Warming S. Reproducibility and responsiveness of a Danish Pedi-IKDC subjective knee form for children with knee disorders. Scand J Med Sci Sports. 2016;26(12):1408-1414.

58. Jia ZY, Zhang C, Zou Y, Huang X, Xu WD. Translation and validation of the Simplified Chinese version of International Knee Documentation Committee Subjective Knee Form. Arch Orthop Trauma Surg. 2018;138(10):1433-1441.

59. Kaeding CC, Leger-St-Jean B, Magnussen RA. Epidemiology and Diagnosis of Anterior Cruciate Ligament Injuries. Clin Sports Med. 2017;36(1):1-8.

60. Kapoor B, Clement DJ, Kirkley A, Maffulli N. Current practice in the management of anterior cruciate ligament injuries in the United Kingdom. Br J Sports Med. 2004;38(5):542-544.

61. Kiadaliri AA, Englund M, Lohmander LS, Carlsson KS, Frobell RB. No economic benefit of early knee reconstruction over optional delayed reconstruction for $A C L$ tears: registry enriched randomised controlled trial data. Br J Sports Med. 2016;50(9):558563.

62. Kim JG, Ha JK, Lee JY, Seo SS, Choi CH, Lee MC. Translation and validation of the korean version of the international knee documentation committee subjective knee form. Knee Surg Relat Res. 2013;25(3):106-111.

63. Kocher MS, Smith JT, Iversen MD, et al. Reliability, validity, and responsiveness of a modified International Knee Documentation Committee Subjective Knee Form (PediIKDC) in children with knee disorders. Am J Sports Med. 2011;39(5):933-939.

64. Kocher MS, Steadman JR, Briggs K, Zurakowski D, Sterett WI, Hawkins RJ. Determinants of patient satisfaction with outcome after anterior cruciate ligament reconstruction. $J$ Bone Joint Surg Am. 2002;84-a(9):1560-1572.

65. Kong DH, Yang SJ, Ha JK, Jang SH, Seo JG, Kim JG. Validation of functional performance tests after anterior cruciate ligament reconstruction. Knee Surg Relat Res. 2012;24(1):40-45.

66. Konstantinos M, Georgios K, Konstantinos S, Georgios T. The Evolution of the Surgical Treatment of Sports Injuries in the 20th Century: A Historical Perspective. Surg Innov. 2016;23(5):538-542.

67. Koumantakis GA, Tsoligkas K, Papoutsidakis A, Ververidis A, Drosos GI. Cross-cultural adaptation and validation of the International Knee Documentation Committee Subjective Knee Form in Greek. J Orthop Traumatol. 2016;17(2):123-129.

68. Kummel D, Preiss S, Harder LP, Leunig M, Impellizzeri FM. Measurement properties of the German version of the IKDC subjective knee form (IKDC-SKF). J Patient Rep Outcomes. 2018;2:31.

69. Kvist J, Gauffin $\mathrm{H}$, Tigerstrand Grevnerts $\mathrm{H}$, et al. Natural corollaries and recovery after acute ACL injury: the NACOX cohort study protocol. BMJ Open. 2018;8(6):e020543.

70. Laboute E, Savalli L, Puig PL, Trouve P, Larbaigt M, Raffestin M. Validity and reproducibility of the PPLP scoring scale in the follow-up of athletes after anterior cruciate ligament reconstruction. Ann Phys Rehabil Med. 2010;53(3):162-179.

71. Lavallee DC, Chenok KE, Love RM, et al. Incorporating Patient-Reported Outcomes Into Health Care To Engage Patients And Enhance Care. Health Aff (Millwood). 2016;35(4):575-582. 
72. Lee YS, Lee OS, Lee SH, Hui TS. Effect of the Timing of Anterior Cruciate Ligament Reconstruction on Clinical and Stability Outcomes: A Systematic Review and Metaanalysis. Arthroscopy. 2018;34(2):592-602.

73. Lertwanich P, Praphruetkit T, Keyurapan E, Lamsam C, Kulthanan T. Validity and reliability of Thai version of the International Knee Documentation Committee Subjective Knee Form. J Med Assoc Thai. 2008;91(8):1218-1225.

74. Logerstedt D, Di Stasi S, Grindem H, et al. Self-reported knee function can identify athletes who fail return-to-activity criteria up to 1 year after anterior cruciate ligament reconstruction: a delaware-oslo ACL cohort study. The Journal of orthopaedic and sports physical therapy. 2014;44(12):914-923.

75. Longstaffe R, Slade Shantz J, Leiter J, Peeler J. Surgeon-Therapist Communication: Do All Members See Eye-to-Eye? Phys Sportsmed. 2015;43(4):381-387.

76. Lysholm J, Gillquist J. Evaluation of knee ligament surgery results with special emphasis on use of a scoring scale. The American Journal of Sports Medicine. 1982;10(3):150154.

77. Markatos K, Kaseta MK, Lallos SN, Korres DS, Efstathopoulos N. The anatomy of the $\mathrm{ACL}$ and its importance in $\mathrm{ACL}$ reconstruction. Eur J Orthop Surg Traumatol. 2013;23(7):747-752.

78. Marx RG, Jones EC, Angel M, Wickiewicz TL, Warren RF. Beliefs and attitudes of members of the American Academy of Orthopaedic Surgeons regarding the treatment of anterior cruciate ligament injury. Arthroscopy. 2003;19(7):762-770.

79. McVeigh F, Pack SM. An exploration of sports rehabilitators' and athletic rehabilitation therapists' views on fear of reinjury after anterior cruciate ligament reconstruction. $J$ Sport Rehabil. 2015;24(2):140-150.

80. Mercuri M, Baigrie $B$, Upshur REG. Going from evidence to recommendations: Can GRADE get us there? J Eval Clin Pract. 2018;24(5):1232-1239.

81. Metsavaht L, Leporace $G$, de Mello Sposito MM, Riberto M, Batista LA. WHAT IS THE BEST QUESTIONNAIRE FOR MONITORING THE PHYSICAL CHARACTERISTICS OF PATIENTS WITH KNEE OSTEOARTHRITIS IN THE BRAZILIAN POPULATION? ReV Bras Ortop. 2011;46(3):256-261.

82. Metsavaht L, Leporace G, Riberto M, de Mello Sposito MM, Batista LA. Translation and cross-cultural adaptation of the Brazilian version of the International Knee Documentation Committee Subjective Knee Form: validity and reproducibility. Am J Sports Med. 2010;38(9):1894-1899.

83. Metsavaht L, Leporace $\mathrm{G}$, Riberto $\mathrm{M}$, et al. Translation and cross-cultural adaptation of the lower extremity functional scale into a Brazilian Portuguese version and validation on patients with knee injuries. J Orthop Sports Phys Ther. 2012;42(11):932-939.

84. Meuffels DE, Poldervaart MT, Diercks RL, et al. Guideline on anterior cruciate ligament injury. Acta Orthop. 2012;83(4):379-386.

85. Mokkink L, Terwee C, Knol D, et al. Cosmin checklist manual. Vol http://www.cosmin.nl/images/upload/File/COSMIN\%20checklist\%20manual\%20v9.pd f. www.cosmin.nl.

86. Mokkink LB, Terwee CB, Knol DL, et al. Protocol of the COSMIN study: COnsensusbased Standards for the selection of health Measurement INstruments. BMC Med Res Methodol. 2006;6:2.

87. Mokkink LB, Terwee CB, Patrick DL, et al. The COSMIN study reached international consensus on taxonomy, terminology, and definitions of measurement properties for health-related patient-reported outcomes. J Clin Epidemiol. 2010;63(7):737-745.

88. Moksnes H, Snyder-Mackler L, Risberg MA. Individuals with an anterior cruciate ligament-deficient knee classified as noncopers may be candidates for nonsurgical rehabilitation. J Orthop Sports Phys Ther. 2008;38(10):586-595. 
89. Mulhall A. Bridging the research-practice gap: breaking new ground in health care. Int $J$ Palliat Nurs. 2001;7(8):389-394.

90. Muller B, Yabroudi MA, Lynch A, et al. Defining Thresholds for the Patient Acceptable Symptom State for the IKDC Subjective Knee Form and KOOS for Patients Who Underwent ACL Reconstruction. Am J Sports Med. 2016;44(11):2820-2826.

91. Nasreddine AY, Connell PL, Kalish LA, et al. The Pediatric International Knee Documentation Committee (Pedi-IKDC) Subjective Knee Evaluation Form: Normative Data. Am J Sports Med. 2017;45(3):527-534.

92. Noorduyn JCA, van de Graaf VA, Mokkink LB, Willigenburg NW, Poolman RW. Responsiveness and Minimal Important Change of the IKDC of Middle-Aged and Older Patients With a Meniscal Tear. Am J Sports Med. 2019;47(2):364-371.

93. Noyes FR, Matthews DS, Mooar PA, Grood ES. The symptomatic anterior cruciatedeficient knee. Part II: the results of rehabilitation, activity modification, and counseling on functional disability. J Bone Joint Surg Am. 1983;65(2):163-174.

94. Noyes FR, Mooar PA, Matthews DS, Butler DL. The symptomatic anterior cruciatedeficient knee. Part I: the long-term functional disability in athletically active individuals. J Bone Joint Surg Am. 1983;65(2):154-162.

95. Ogura T, Ackermann J, Barbieri Mestriner A, Merkely G, Gomoll AH. Minimal Clinically Important Differences and Substantial Clinical Benefit in Patient-Reported Outcome Measures after Autologous Chondrocyte Implantation. Cartilage. 2018:1947603518799839.

96. Olsson O, Isacsson A, Englund M, Frobell RB. Epidemiology of intra- and peri-articular structural injuries in traumatic knee joint hemarthrosis - data from 1145 consecutive knees with subacute MRI. Osteoarthritis Cartilage. 2016;24(11):1890-1897.

97. Osterberg A, Kvist J, Dahlgren MA. Ways of experiencing participation and factors affecting the activity level after nonreconstructed anterior cruciate ligament injury: a qualitative study. J Orthop Sports Phys Ther. 2013;43(3):172-183.

98. Padua R, Bondi R, Ceccarelli E, et al. Italian version of the International Knee Documentation Committee Subjective Knee Form: cross-cultural adaptation and validation. Arthroscopy. 2004;20(8):819-823.

99. Paterno MV, Schmitt LC, Ford KR, et al. Biomechanical measures during landing and postural stability predict second anterior cruciate ligament injury after anterior cruciate ligament reconstruction and return to sport. Am J Sports Med. 2010;38(10):1968-1978.

100. Philpot LM, Barnes SA, Brown RM, et al. Barriers and Benefits to the Use of PatientReported Outcome Measures in Routine Clinical Care: A Qualitative Study. Am J Med Qual. 2018;33(4):359-364.

101. Piontek T, Ciemniewska-Gorzela K, Naczk J, Cichy K, Szulc A. Linguistic and cultural adaptation into Polish of the IKDC 2000 subjective knee evaluation form and the Lysholm scale. Pol Orthop Traumatol. 2012;77:115-119.

102. Politi MC, Lewis CL, Frosch DL. Supporting shared decisions when clinical evidence is low. Med Care Res Rev. 2013;70(1 Suppl):113s-128s.

103. Prinsen CAC, Mokkink LB, Bouter LM, et al. COSMIN guideline for systematic reviews of patient-reported outcome measures. Qual Life Res. 2018;27(5):1147-1157.

104. Ra HJ, Kim HS, Choi JY, Ha JK, Kim JY, Kim JG. Comparison of the ceiling effect in the Lysholm score and the IKDC subjective score for assessing functional outcome after ACL reconstruction. Knee. 2014;21(5):906-910.

105. Reinke EK, Spindler KP, Lorring D, et al. Hop tests correlate with IKDC and KOOS at minimum of 2 years after primary ACL reconstruction. Knee Surg Sports Traumatol Arthrosc. 2011;19(11):1806-1816. 
106. Roos EM, Boyle E, Frobell RB, Lohmander LS, Ingelsrud LH. It is good to feel better, but better to feel good: whether a patient finds treatment 'successful' or not depends on the questions researchers ask. Br J Sports Med. 2019.

107. Rothermich MA, Nepple JJ, Raup VT, O'Donnell JC, Luhmann SJ. A Comparative Analysis of International Knee Documentation Committee Scores for Common Pediatric and Adolescent Knee Injuries. J Pediatr Orthop. 2016;36(3):274-277.

108. Sackett DL, Rosenberg WM, Gray JA, Haynes RB, Richardson WS. Evidence based medicine: what it is and what it isn't. Bmj. 1996;312(7023):71-72.

109. Schindler OS. Surgery for anterior cruciate ligament deficiency: a historical perspective. Knee Surg Sports Traumatol Arthrosc. 2012;20(1):5-47.

110. Schmitt LC, Paterno MV, Huang S. Validity and internal consistency of the international knee documentation committee subjective knee evaluation form in children and adolescents. Am J Sports Med. 2010;38(12):2443-2447.

111. Scurlock-Evans L, Upton P, Upton D. Evidence-based practice in physiotherapy: a systematic review of barriers, enablers and interventions. Physiotherapy. 2014;100(3):208-219.

112. Shea KG, Carey JL, Richmond J, et al. The American Academy of Orthopaedic Surgeons evidence-based guideline on management of anterior cruciate ligament injuries. J Bone Joint Surg Am. 2015;97(8):672-674.

113. Shelbourne KD, Barnes AF, Gray T. Correlation of a single assessment numeric evaluation (SANE) rating with modified Cincinnati knee rating system and IKDC subjective total scores for patients after $\mathrm{ACL}$ reconstruction or knee arthroscopy. Am J Sports Med. 2012;40(11):2487-2491.

114. Siqueira DA, Baraúna MA, Dionísio VC. Functional evaluation of the knee in subjects with patellofemoral pain syndrome (PFPS): Comparison between KOS and IKDC scales. Revista Brasileira de Medicina do Esporte. 2012;18(6):400-403.

115. Smythe E, White SG. Methods of practice: Listening to the story. Physiother Theory Pract. 2017;33(6):462-474.

116. Swirtun LR, Eriksson K, Renstrom P. Who chooses anterior cruciate ligament reconstruction and why? A 2-year prospective study. Scand J Med Sci Sports. 2006;16(6):441-446.

117. Terwee $C B$, Bot $S D$, de Boer MR, et al. Quality criteria were proposed for measurement properties of health status questionnaires. Journal of clinical epidemiology. 2007;60(1):34-42.

118. Terwee CB, Jansma EP, Riphagen II, de Vet HC. Development of a methodological PubMed search filter for finding studies on measurement properties of measurement instruments. Quality of life research : an international journal of quality of life aspects of treatment, care and rehabilitation. 2009;18(8):1115-1123.

119. The American Othopaedic Society for Sports M. 2000 IKDC KNEE FORMS. Vol http://www.sportsmed.org/Research/IKDC Forms/. www.sportsmed.org: The American Othopaedic Society for Sports Medicine.

120. Thorstensson CA, Lohmander LS, Frobell RB, Roos EM, Gooberman-Hill R. Choosing surgery: patients' preferences within a trial of treatments for anterior cruciate ligament injury. A qualitative study. BMC Musculoskelet Disord. 2009;10:100.

121. Tigerstrand Grevnerts H, Gravare Silbernagel K, Sonesson S, et al. Translation and testing of measurement properties of the Swedish version of the IKDC subjective knee form. Scand J Med Sci Sports. 2017;27(5):554-562.

122. Tsoukas D, Fotopoulos V, Basdekis G, Makridis KG. No difference in osteoarthritis after surgical and non-surgical treatment of ACL-injured knees after 10 years. Knee Surg Sports Traumatol Arthrosc. 2016;24(9):2953-2959.

123. van Baalen $S$, Boon $M$. An epistemological shift: from evidence-based medicine to epistemological responsibility. J Eval Clin Pract. 2015;21(3):433-439. 
124. van de Graaf VA, Wolterbeek N, Scholtes VA, Mutsaerts EL, Poolman RW. Reliability and Validity of the IKDC, KOOS, and WOMAC for Patients With Meniscal Injuries. Am J Sports Med. 2014;42(6):1408-1416.

125. van der Velden CA, van der Steen MC, Leenders J, van Douveren F, Janssen RPA, Reijman M. Pedi-IKDC or KOOS-child: which questionnaire should be used in children with knee disorders? BMC Musculoskelet Disord. 2019;20(1):240.

126. van Meer BL, Meuffels DE, Vissers MM, et al. Knee injury and Osteoarthritis Outcome Score or International Knee Documentation Committee Subjective Knee Form: which questionnaire is most useful to monitor patients with an anterior cruciate ligament rupture in the short term? Arthroscopy. 2013;29(4):701-715.

127. van Melick N, van Cingel RE, Brooijmans F, et al. Evidence-based clinical practice update: practice guidelines for anterior cruciate ligament rehabilitation based on a systematic review and multidisciplinary consensus. Br J Sports Med. 2016;50(24):15061515.

128. Webster KE, Feller JA. Tibial rotation in anterior cruciate ligament reconstructed knees during single limb hop and drop landings. Clin Biomech (Bristol, Avon). 2012;27(5):475479.

129. Webster KE, Feller JA, Lambros C. Development and preliminary validation of a scale to measure the psychological impact of returning to sport following anterior cruciate ligament reconstruction surgery. Physical therapy in sport : official journal of the Association of Chartered Physiotherapists in Sports Medicine. 2008;9(1):9-15.

130. Wera JC, Nyland J, Ghazi C, et al. International knee documentation committee knee survey use after anterior cruciate ligament reconstruction: a 2005-2012 systematic review and world region comparison. Arthroscopy : The Journal of Arthroscopic \& Related Surgery : Official Publication of the Arthroscopy Association of North America and the International Arthroscopy Association. 2014;30(11):1505-1512.

131. von Aesch AV, Perry M, Sole G. Physiotherapists' experiences of the management of anterior cruciate ligament injuries. Phys Ther Sport. 2016;19:14-22.

132. Xbase tSnklr. Svenska korsbandsregistret. Årsrapport 2013. Vol http://www.artroclinic.se/scripts/cgiip.exe/WService=skreg/xb info?visa=ars-rapport. www.aclregister.nu: Svenska Korsbandsregistret; 2015.

133. Youden WJ. Index for rating diagnostic tests. Cancer. 1950;3(1):32-35. 


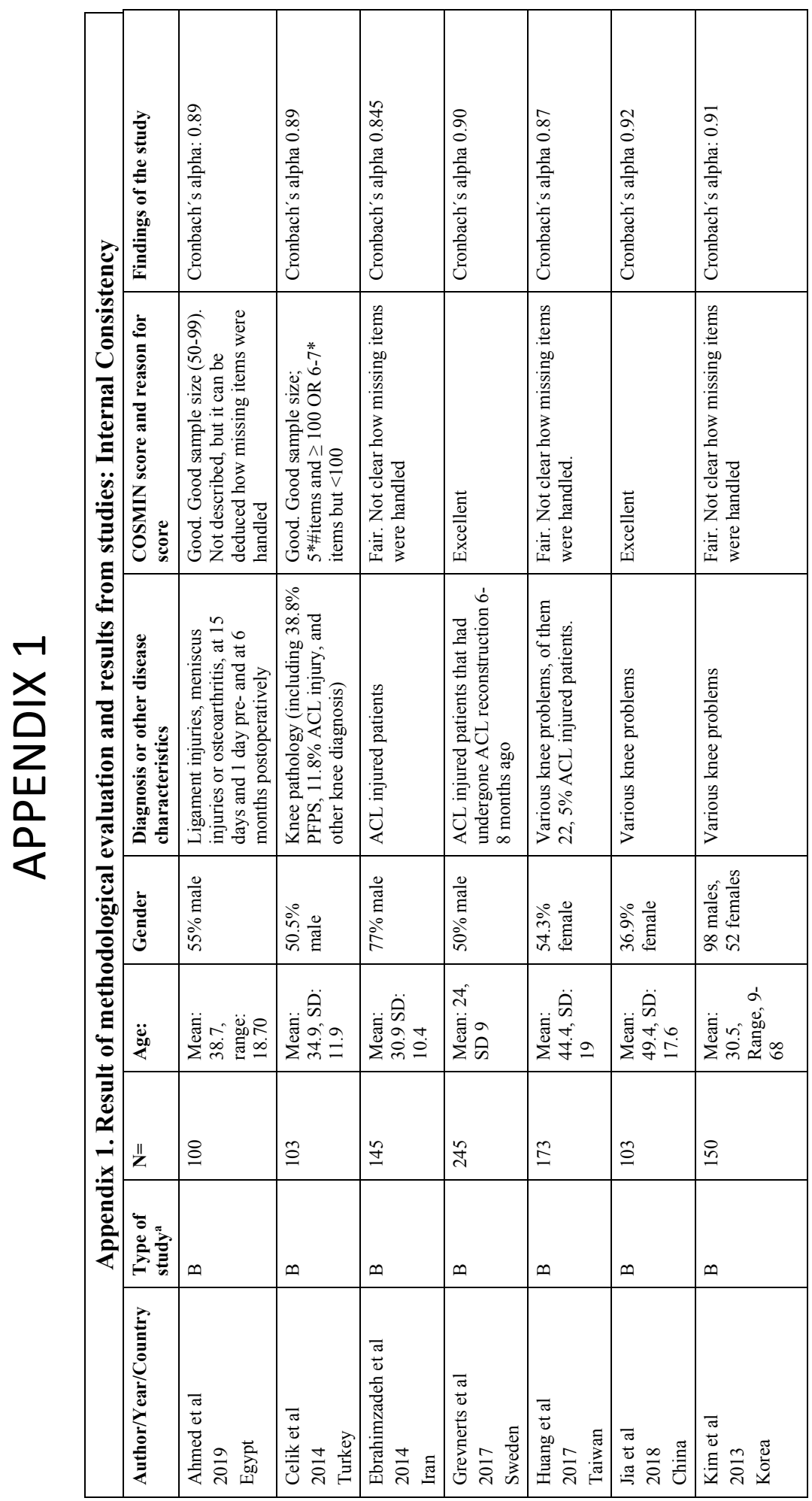



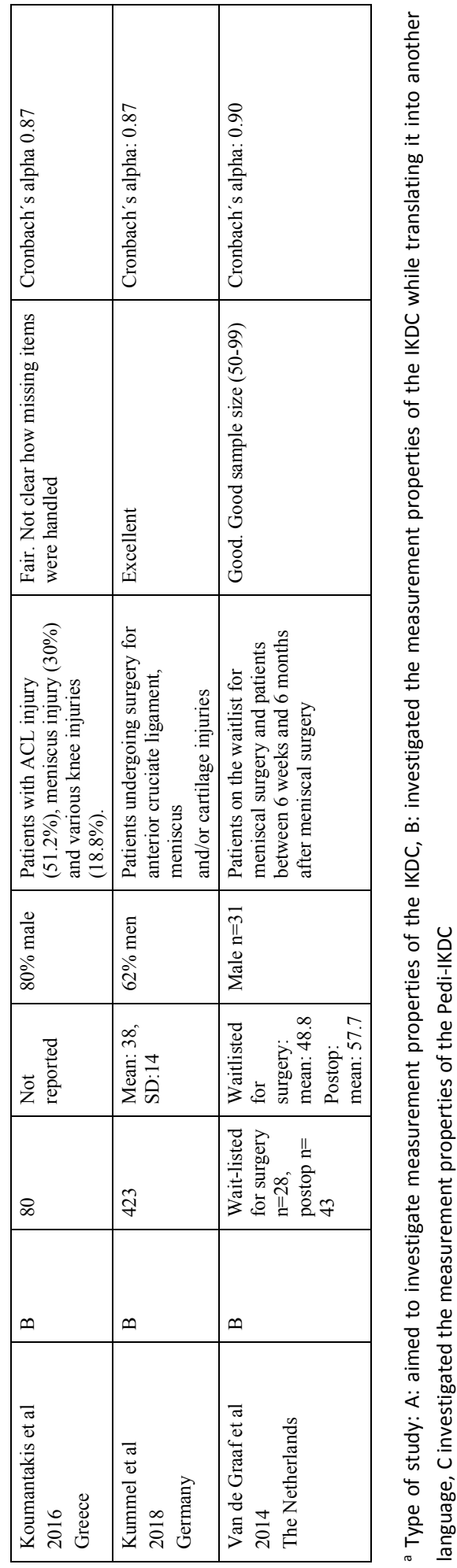


\begin{tabular}{|c|c|c|c|c|c|c|c|c|c|}
\hline : & 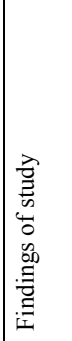 & $\begin{array}{l}2 \\
0 \\
\ddot{0} \\
0\end{array}$ & $\begin{array}{l}\dot{a} \\
\dot{0} \\
\ddot{0}\end{array}$ & 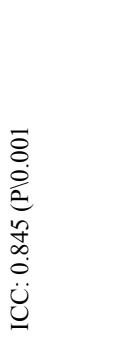 & 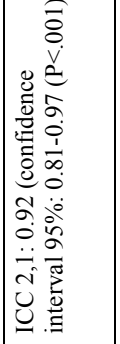 & 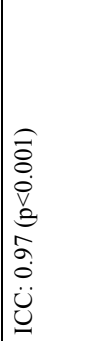 & 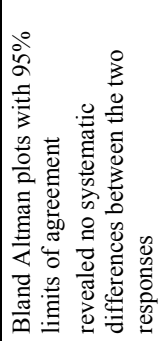 & \begin{tabular}{l}
\multirow{2}{0}{} \\
0 \\
0 \\
0 \\
0
\end{tabular} & 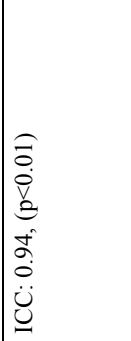 \\
\hline 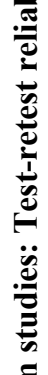 & 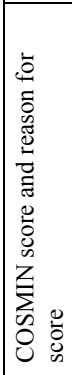 & 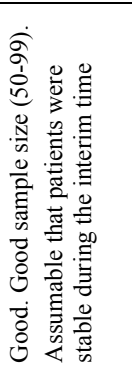 & 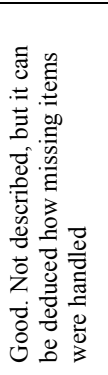 & 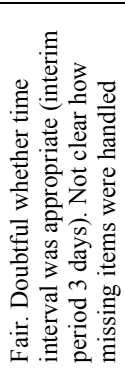 & 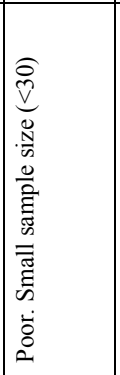 & 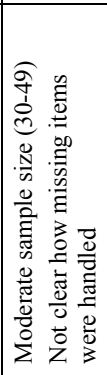 & 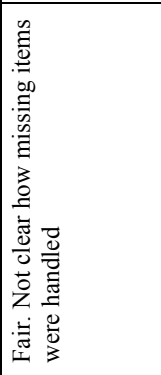 & 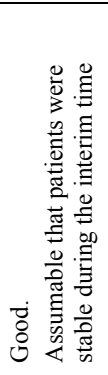 & 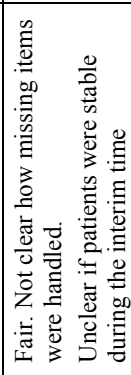 \\
\hline 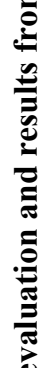 & 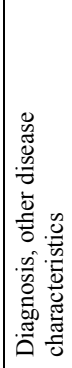 & 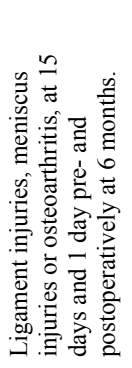 & 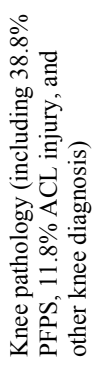 & 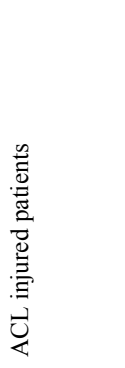 & 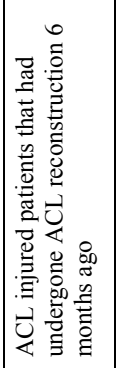 & 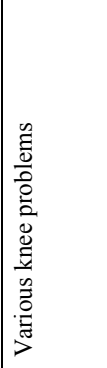 & 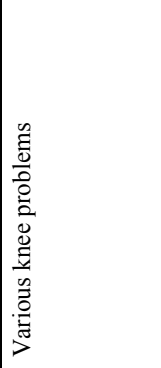 & 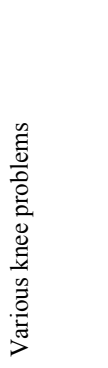 & 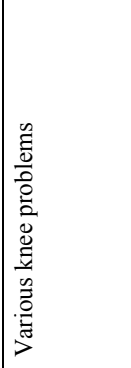 \\
\hline 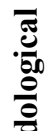 & نั & $\begin{array}{l}\frac{0}{\tilde{g}} \\
\text { 苟 } \\
\text { in }\end{array}$ & $\begin{array}{l}\underset{\Xi}{\Xi} \\
\stackrel{\infty}{\sim} \\
\text { i }\end{array}$ & 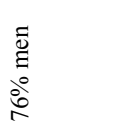 & 总 & 总 & $\begin{array}{l}\infty \\
\widehat{0} \\
0 \\
\infty \\
i\end{array}$ & 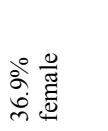 & 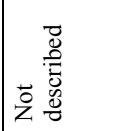 \\
\hline 冚 & 范 & 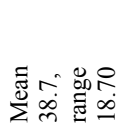 & $\begin{array}{l}\frac{1}{+} \\
\dot{+} \\
\dot{m} \\
\dot{m}\end{array}$ & 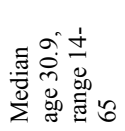 & 总 & 竞 & 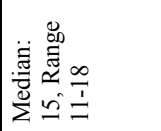 & 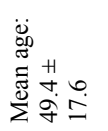 & 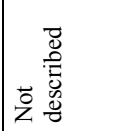 \\
\hline 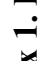 & Z & $\nsubseteq$ & $\stackrel{\infty}{n}$ & If & $\stackrel{\infty}{\sim}$ & $\bar{m}$ & $\approx$ & $\hat{\sigma}$ & $\stackrel{2}{\beth}$ \\
\hline$\frac{0}{2}$ & 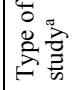 & 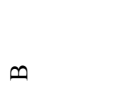 & $\infty$ & $\infty$ & 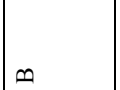 & 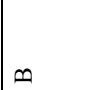 & $\ddot{\infty}$ & 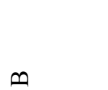 & $\infty$ \\
\hline & 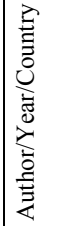 & 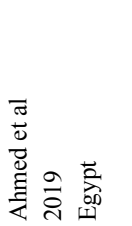 & 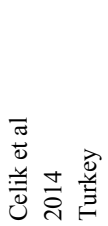 & 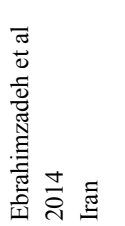 & 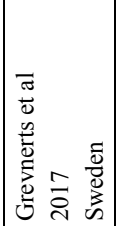 & 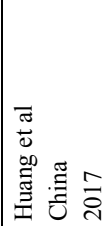 & 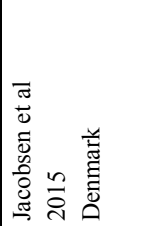 & 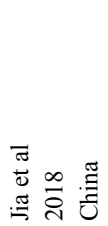 & 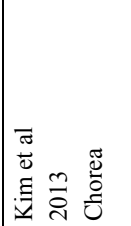 \\
\hline
\end{tabular}




\begin{tabular}{|c|c|c|c|}
\hline 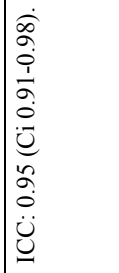 & 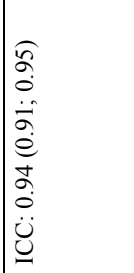 & 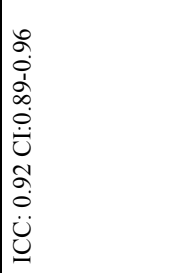 & 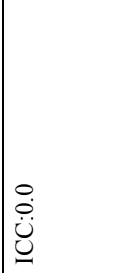 \\
\hline 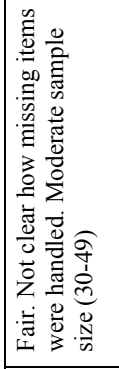 & 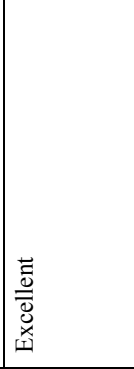 & 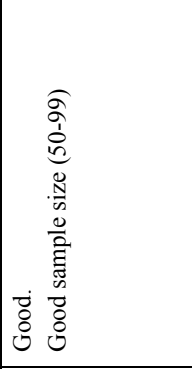 & 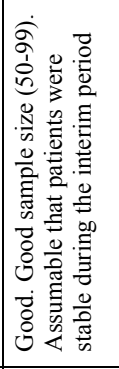 \\
\hline 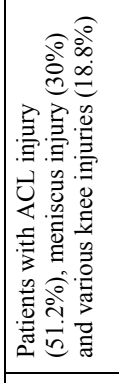 & 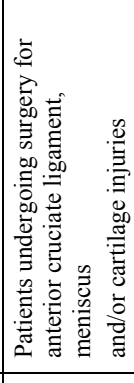 & 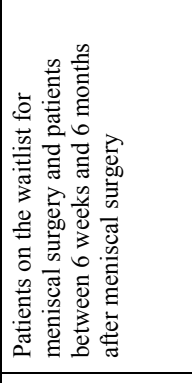 & 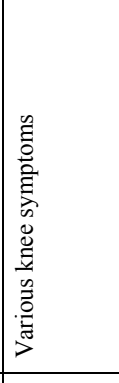 \\
\hline 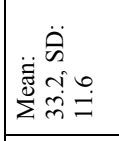 & 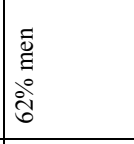 & 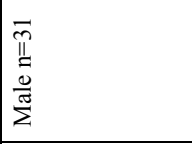 & 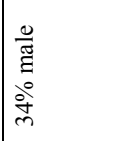 \\
\hline $\begin{array}{l}\stackrel{0}{0} \frac{0}{\tilde{m}} \\
\infty \\
\infty\end{array}$ & 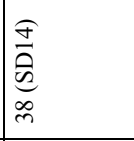 & 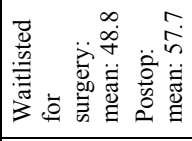 & 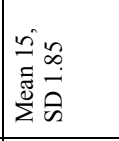 \\
\hline$\approx$ & $\underline{\underline{\infty}}$ & 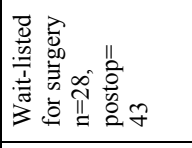 & in \\
\hline$\infty$ & $\infty$ & $\infty$ & $\begin{array}{l}0 \\
\infty\end{array}$ \\
\hline 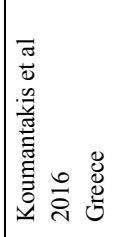 & 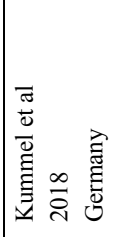 & 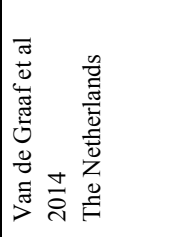 & 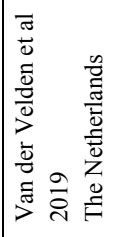 \\
\hline
\end{tabular}

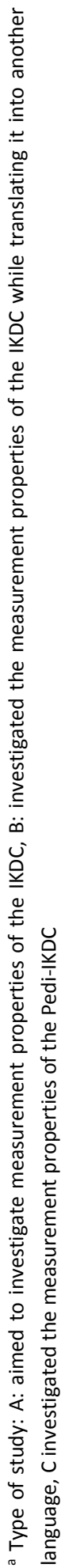




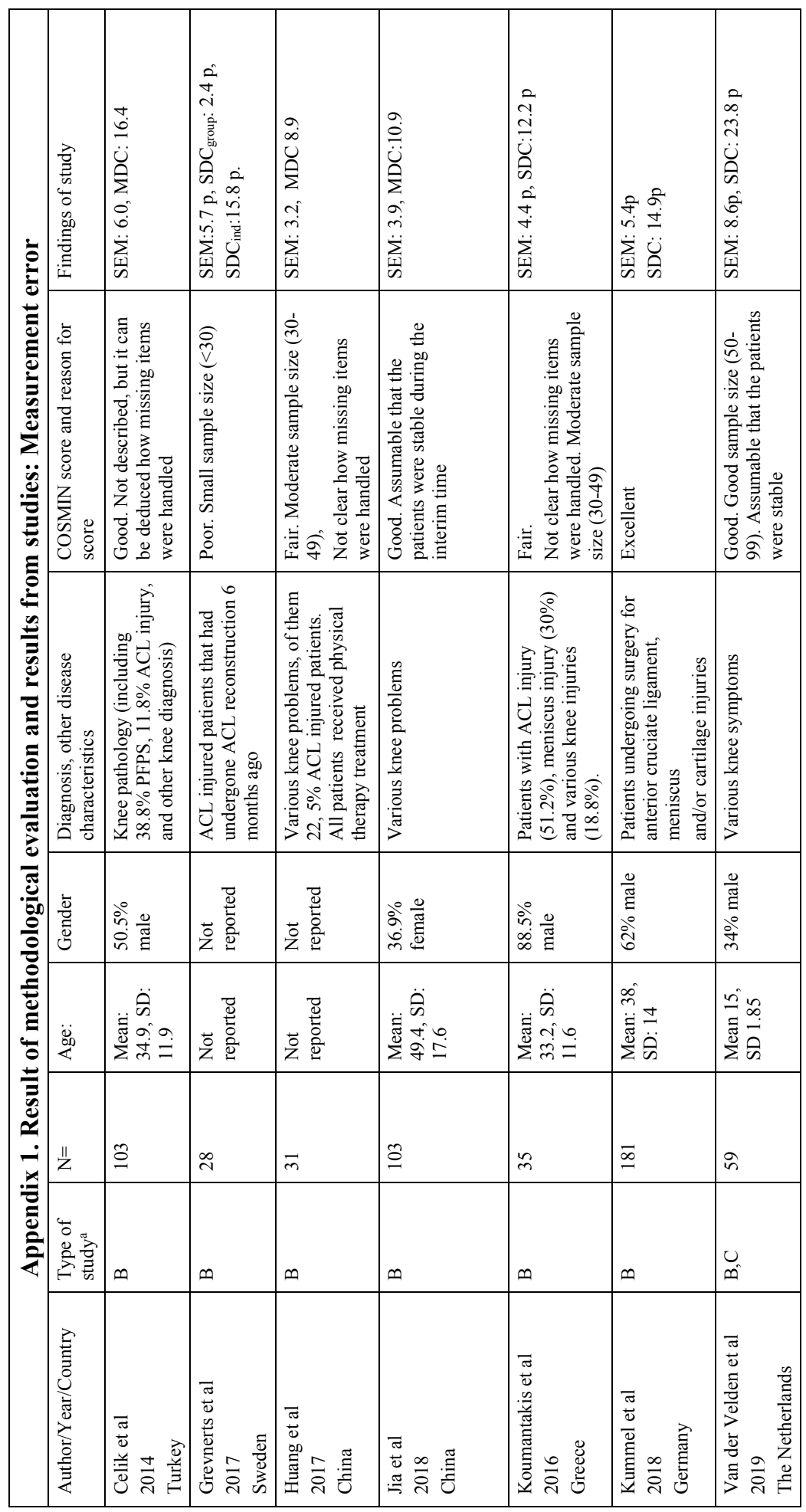




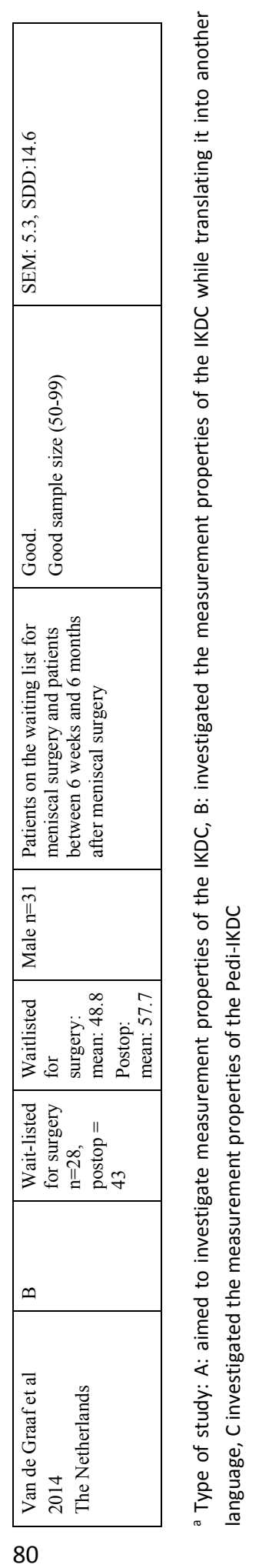




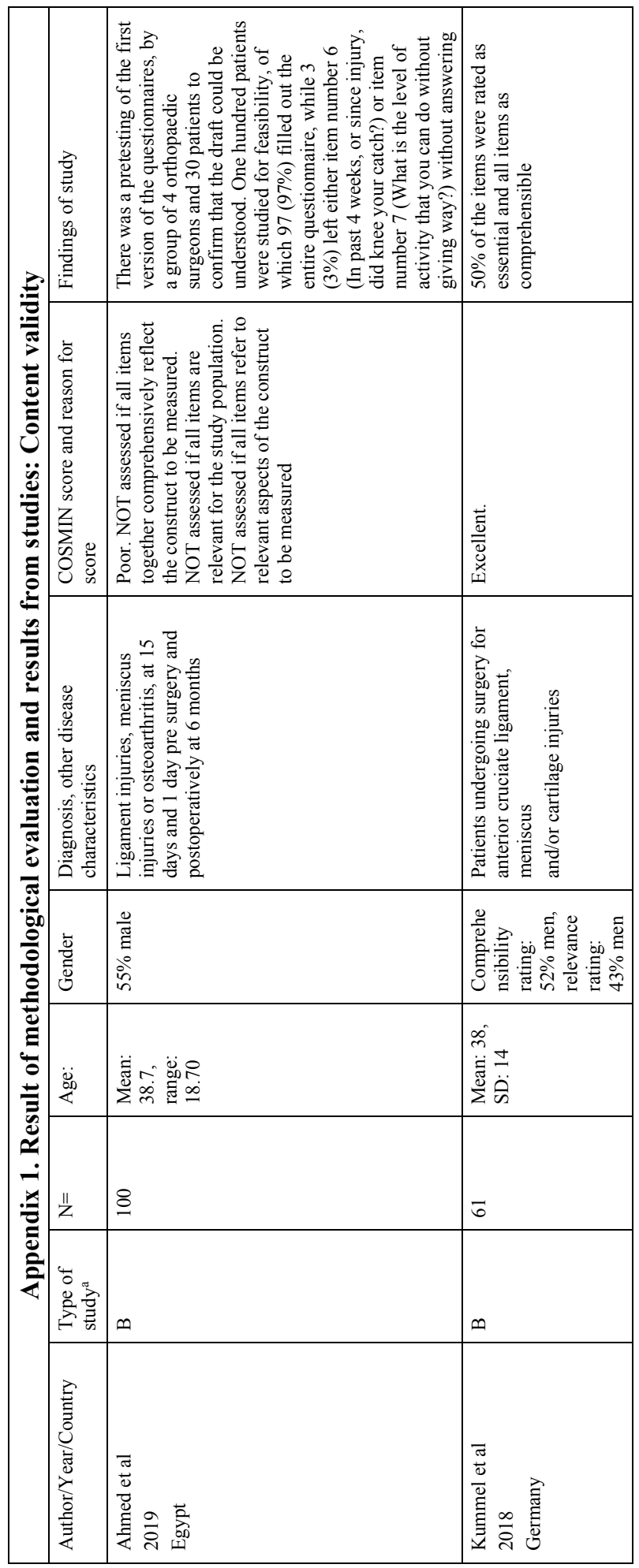



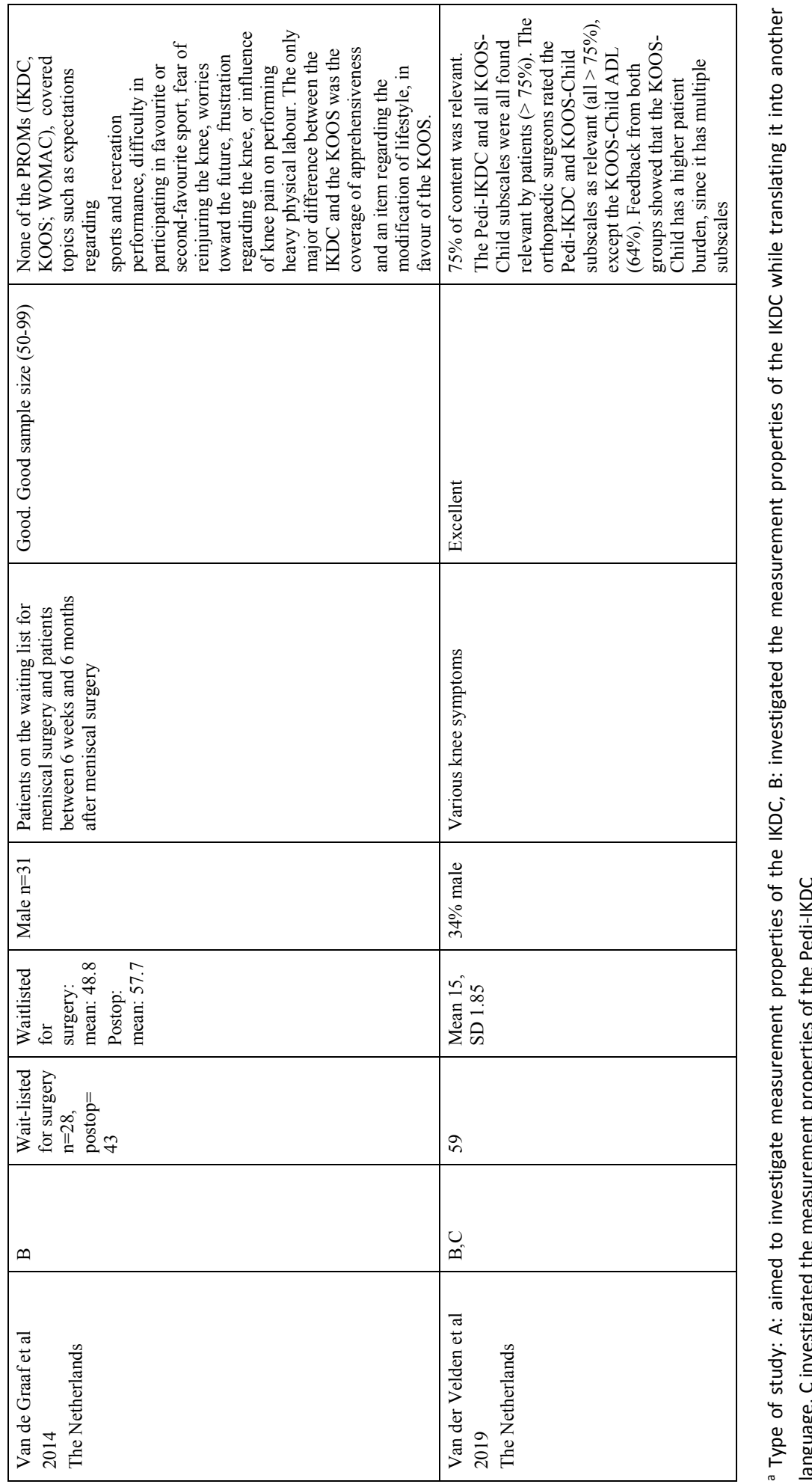


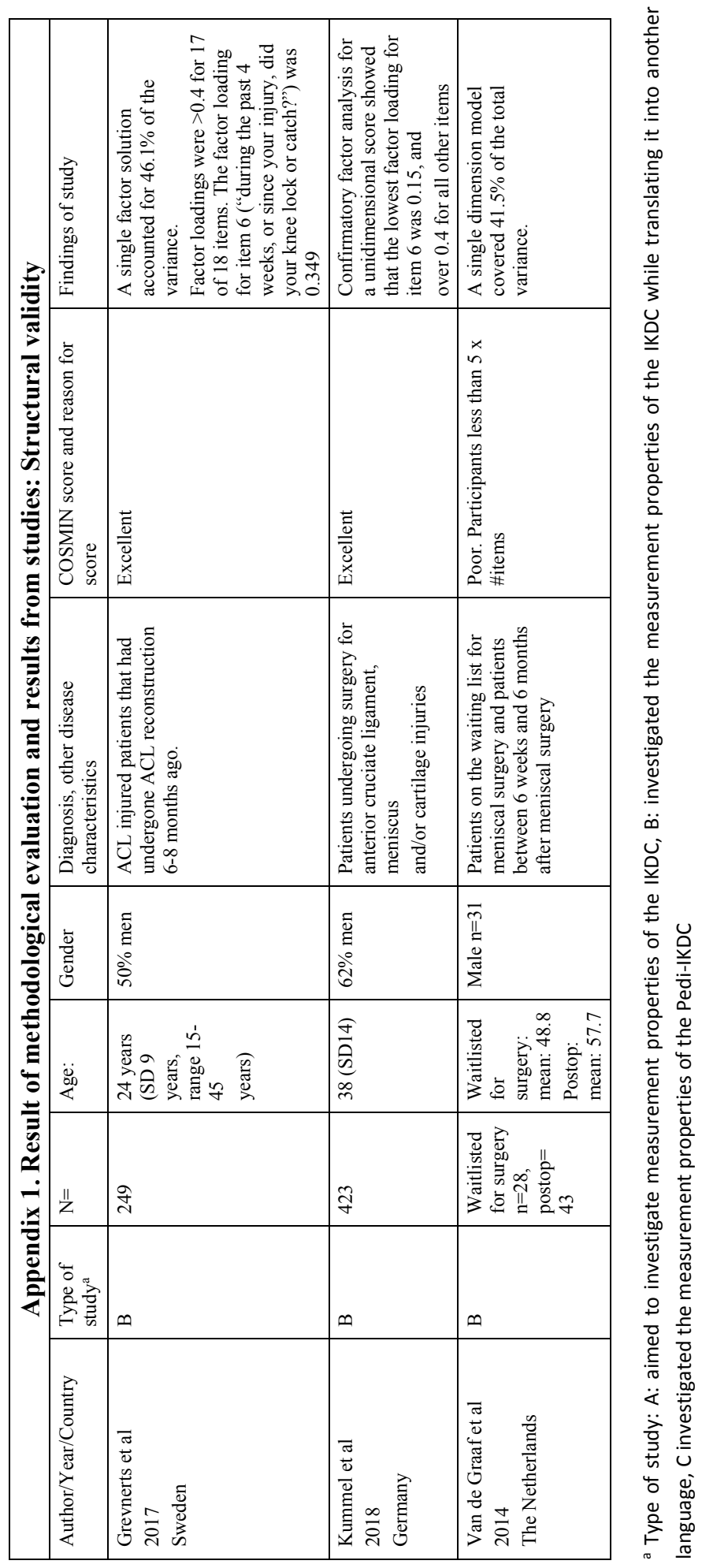




\begin{tabular}{|c|c|c|c|c|c|c|}
\hline \multicolumn{7}{|c|}{ 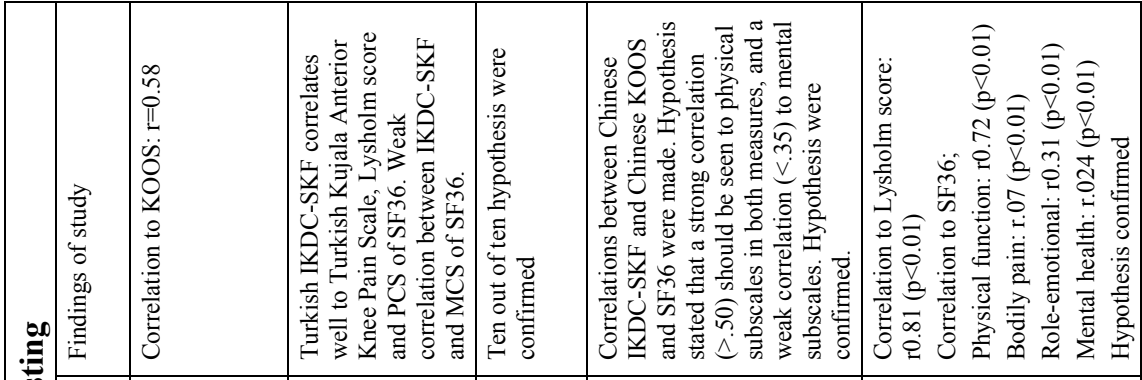 } \\
\hline 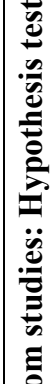 & 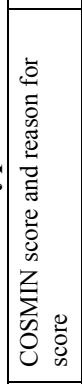 & 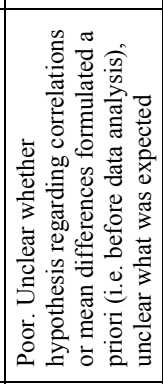 & 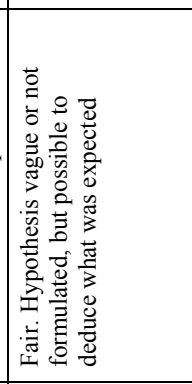 & 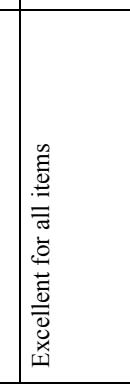 & 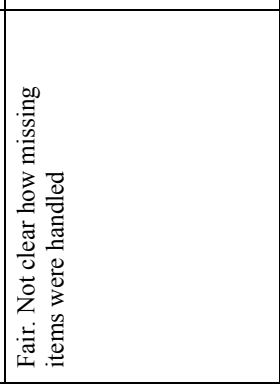 & 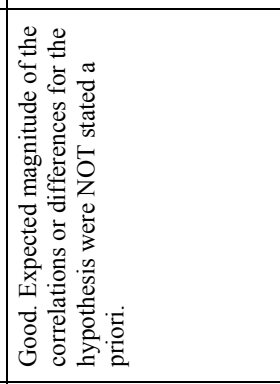 \\
\hline 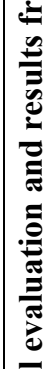 & 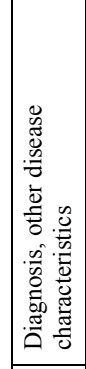 & 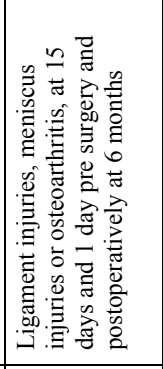 & 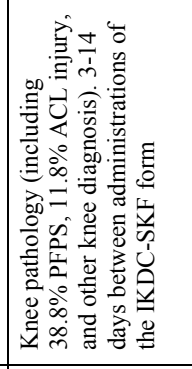 & 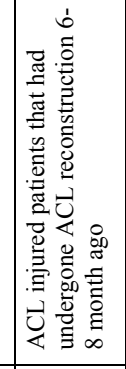 & 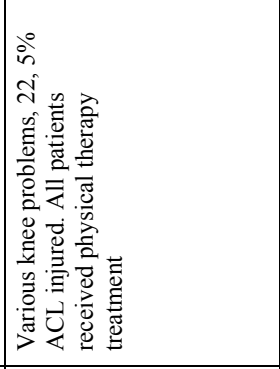 & 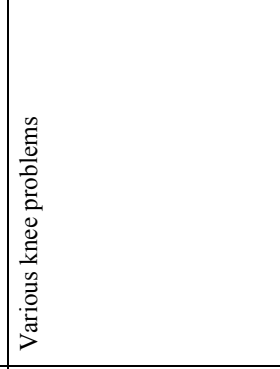 \\
\hline 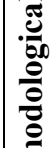 & $\begin{array}{l}\frac{\tilde{g}}{\bar{z}} \\
\text { o }\end{array}$ & 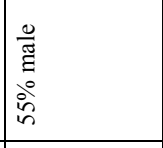 & 品。 & 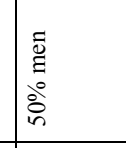 & 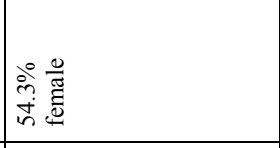 & 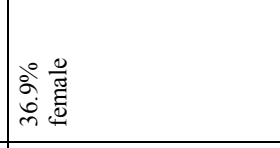 \\
\hline 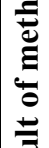 & $\begin{array}{l} \\
\ddot{8} \\
\ddot{4}\end{array}$ & 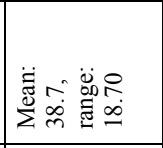 & 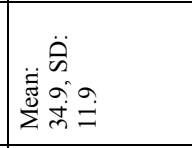 & 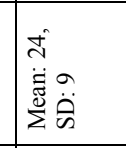 & 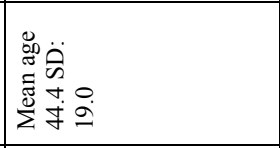 & 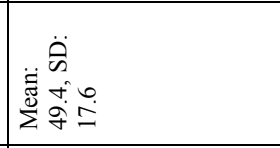 \\
\hline 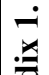 & z & 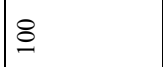 & $\cong$ & ఫे & $\cong$ & $\cong$ \\
\hline & 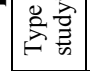 & $\infty$ & $\infty$ & $\infty$ & $\infty$ & $\infty$ \\
\hline & 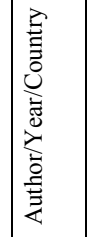 & 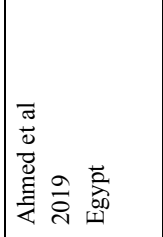 & 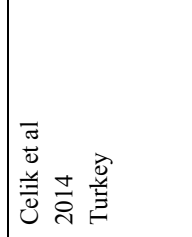 & 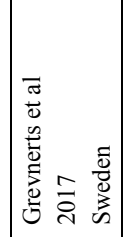 & 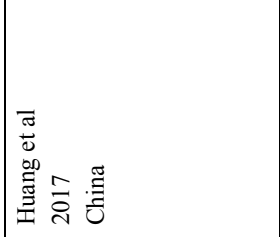 & 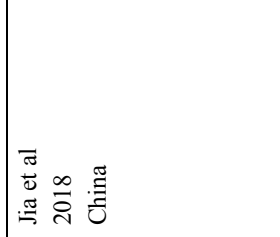 \\
\hline
\end{tabular}




\begin{tabular}{|c|c|c|c|c|}
\hline 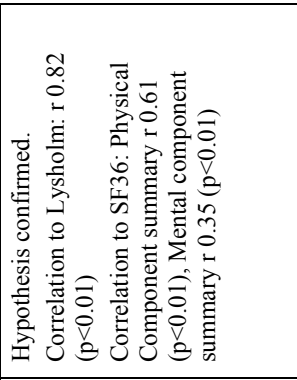 & 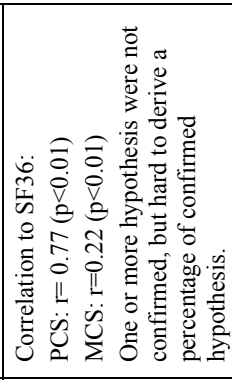 & 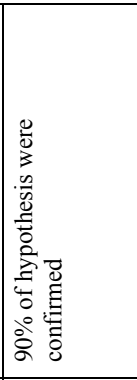 & 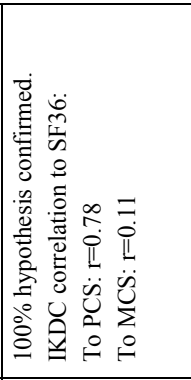 & 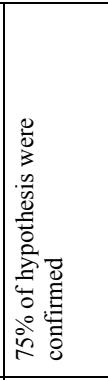 \\
\hline 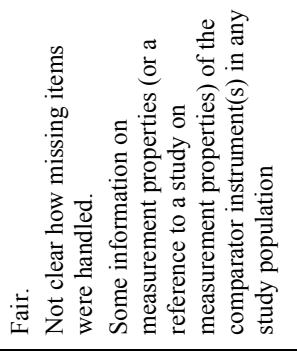 & 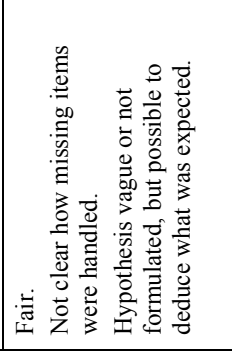 & 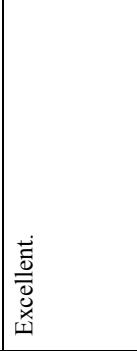 & 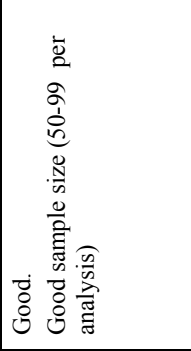 & 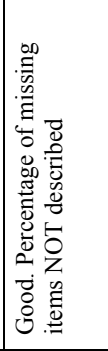 \\
\hline 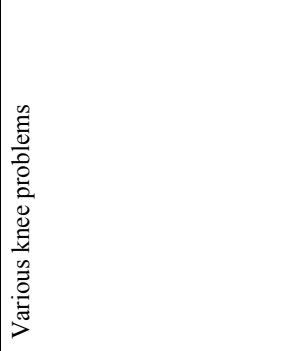 & 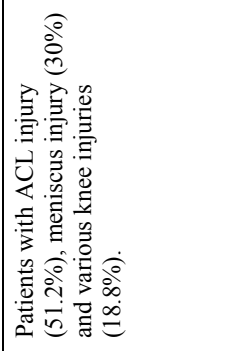 & 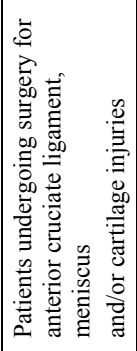 & 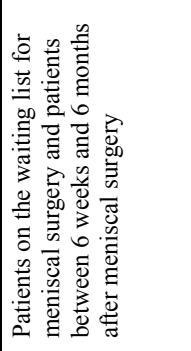 & 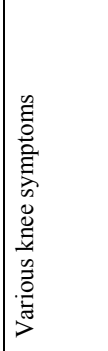 \\
\hline 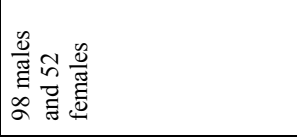 & 离 & 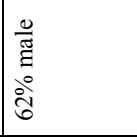 & $\begin{array}{l}\vec{\pi} \\
\mathbb{J} \\
\frac{0}{\pi} \\
\stackrel{\pi}{\Sigma}\end{array}$ & 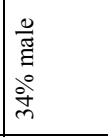 \\
\hline 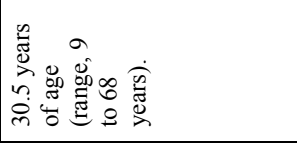 & $\begin{array}{l}\frac{0}{\pi ّ} \\
\stackrel{\Xi}{0} \\
\grave{0} \\
\infty\end{array}$ & 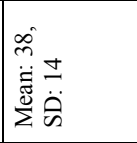 & 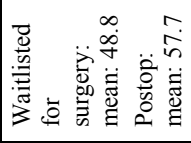 & 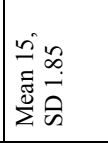 \\
\hline$\stackrel{n}{n}$ & $\infty$ & & 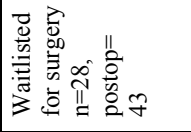 & 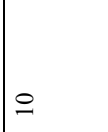 \\
\hline$\infty$ & $\infty$ & $\infty$ & $\infty$ & $\begin{array}{l}0 \\
\infty \\
\infty\end{array}$ \\
\hline 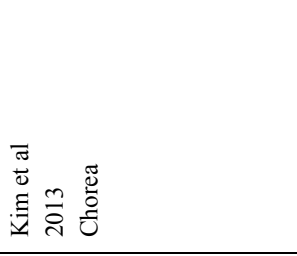 & 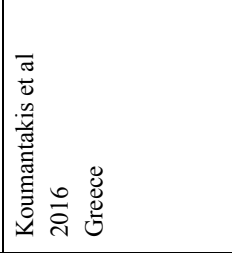 & 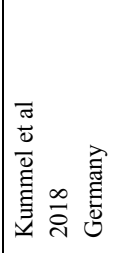 & 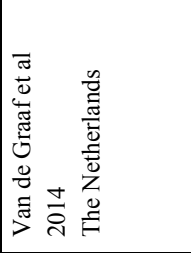 & 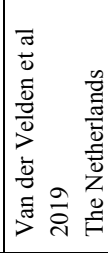 \\
\hline
\end{tabular}




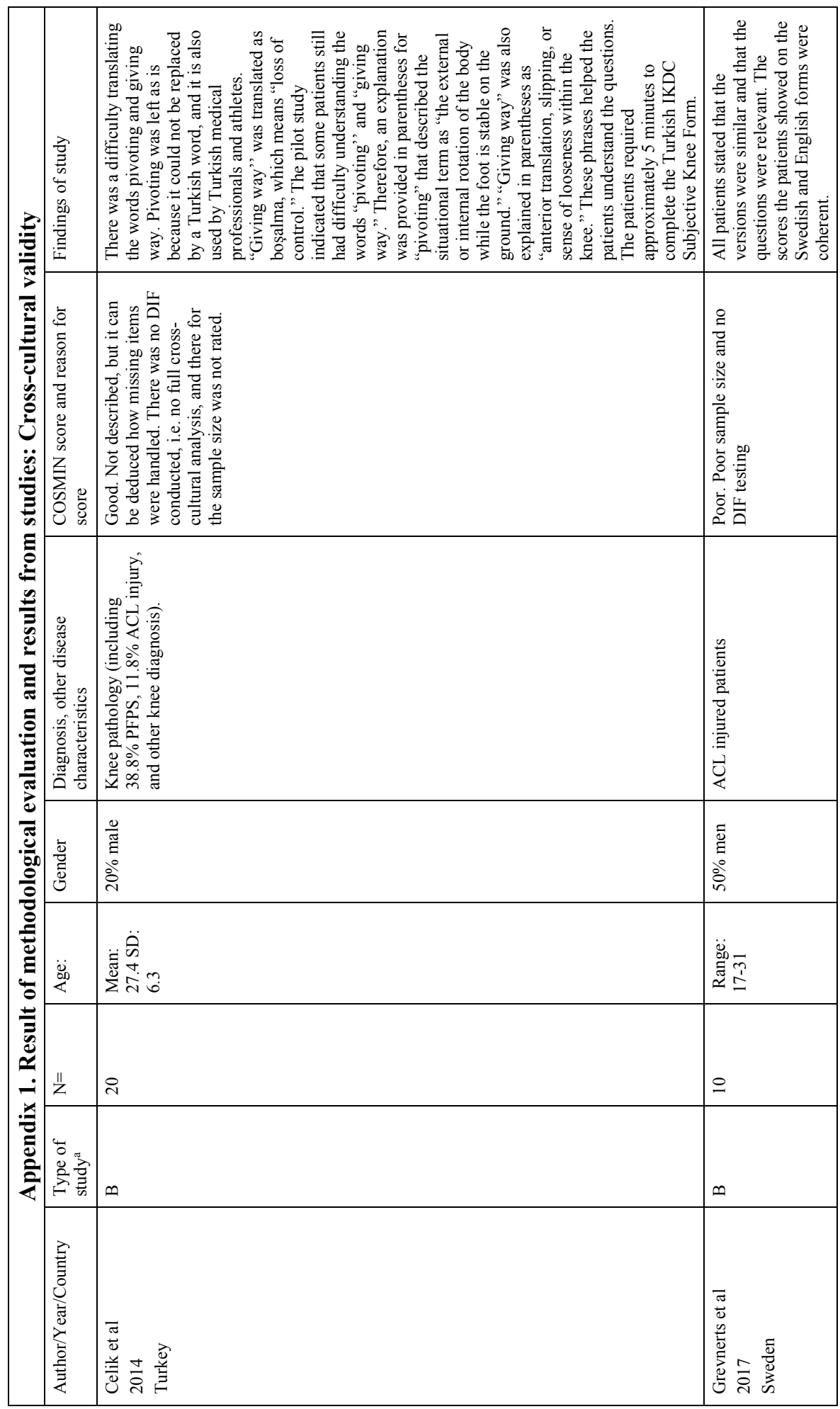




\begin{tabular}{|c|c|c|}
\hline 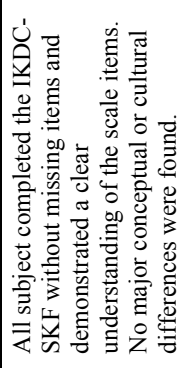 & 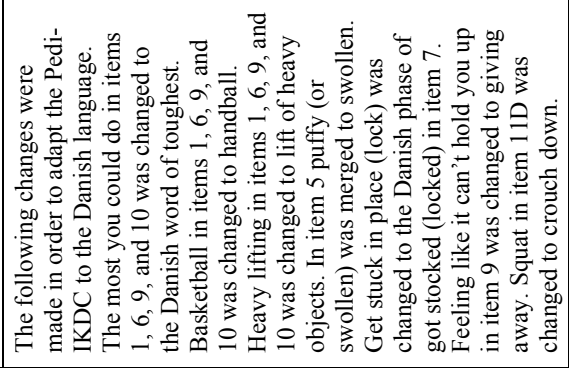 & 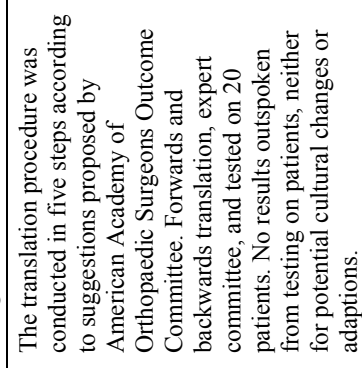 \\
\hline 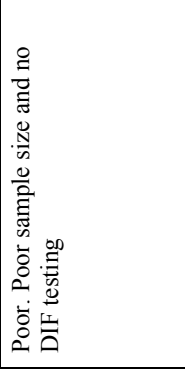 & 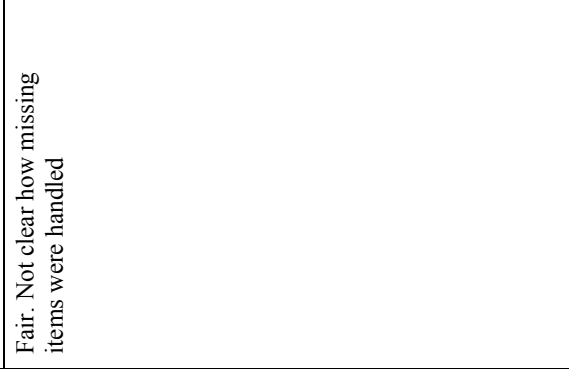 & 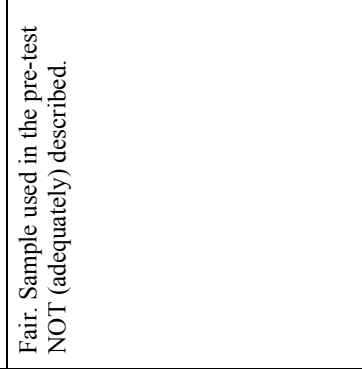 \\
\hline 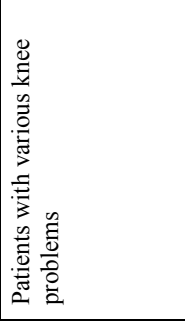 & 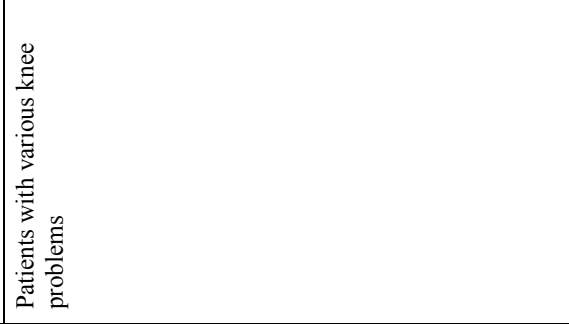 & 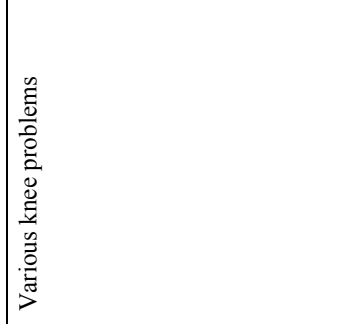 \\
\hline 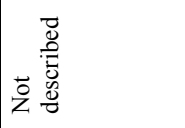 & 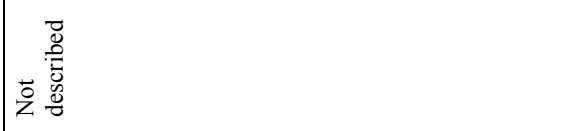 & 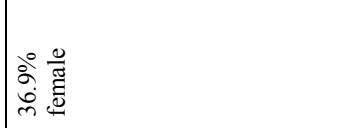 \\
\hline 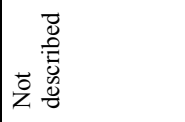 & 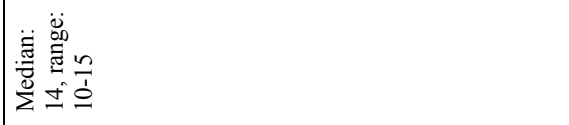 & 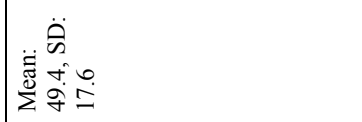 \\
\hline 으 & $\because$ & $\stackrel{\wp}{\varrho}$ \\
\hline$\infty$ & $u^{\cup}$ & $\infty$ \\
\hline 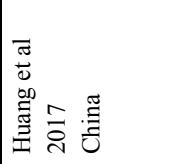 & 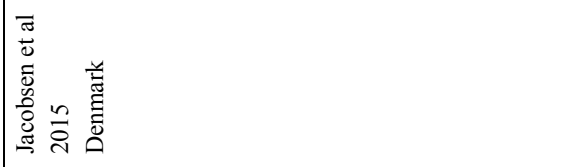 & 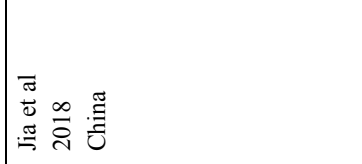 \\
\hline
\end{tabular}




\begin{tabular}{|c|c|c|}
\hline 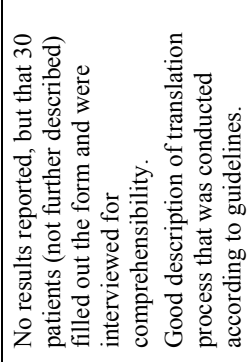 & 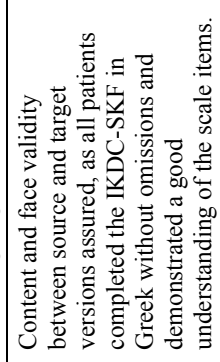 & 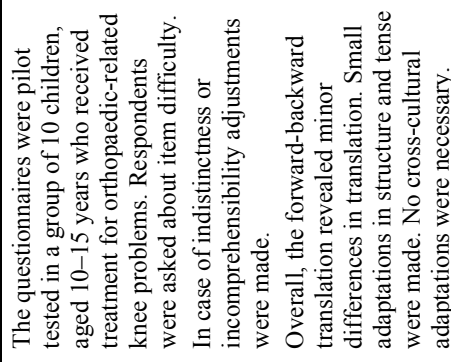 \\
\hline 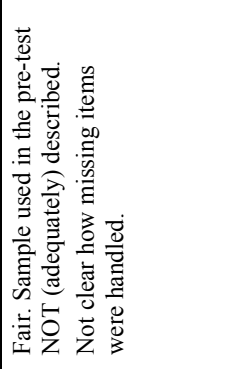 & 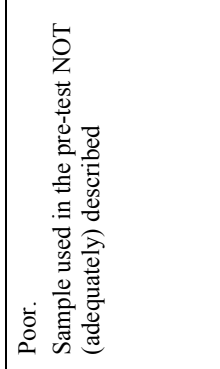 & 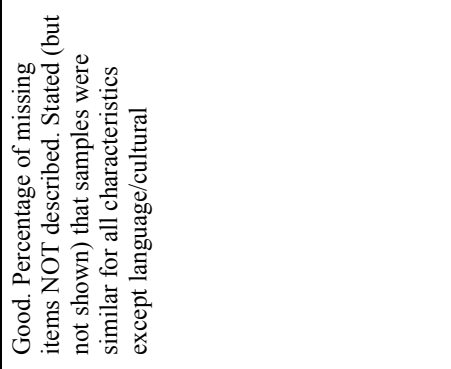 \\
\hline 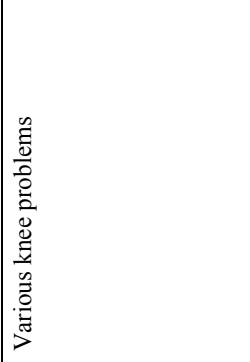 & 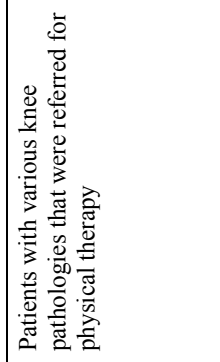 & 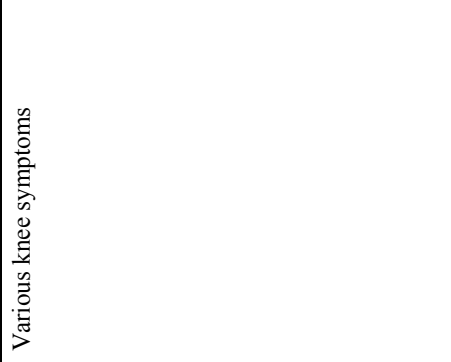 \\
\hline 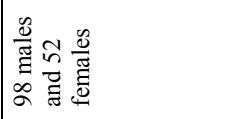 & 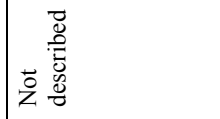 & 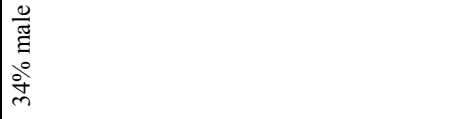 \\
\hline 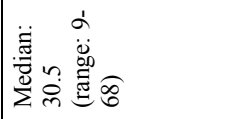 & 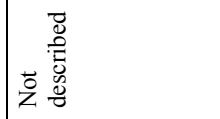 & 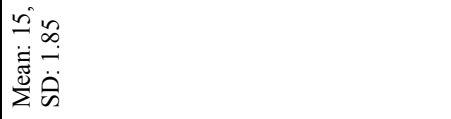 \\
\hline i & i & 은 \\
\hline$\infty$ & $\infty$ & $\begin{array}{l}u \\
\infty\end{array}$ \\
\hline 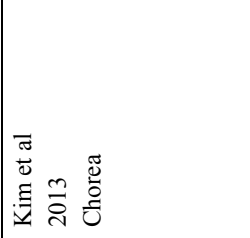 & 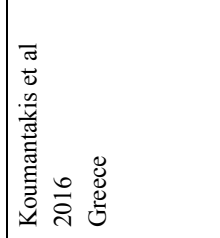 & 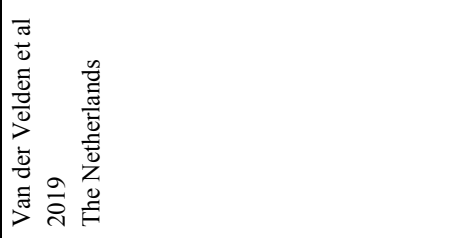 \\
\hline
\end{tabular}

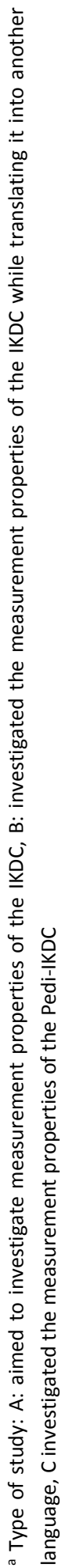




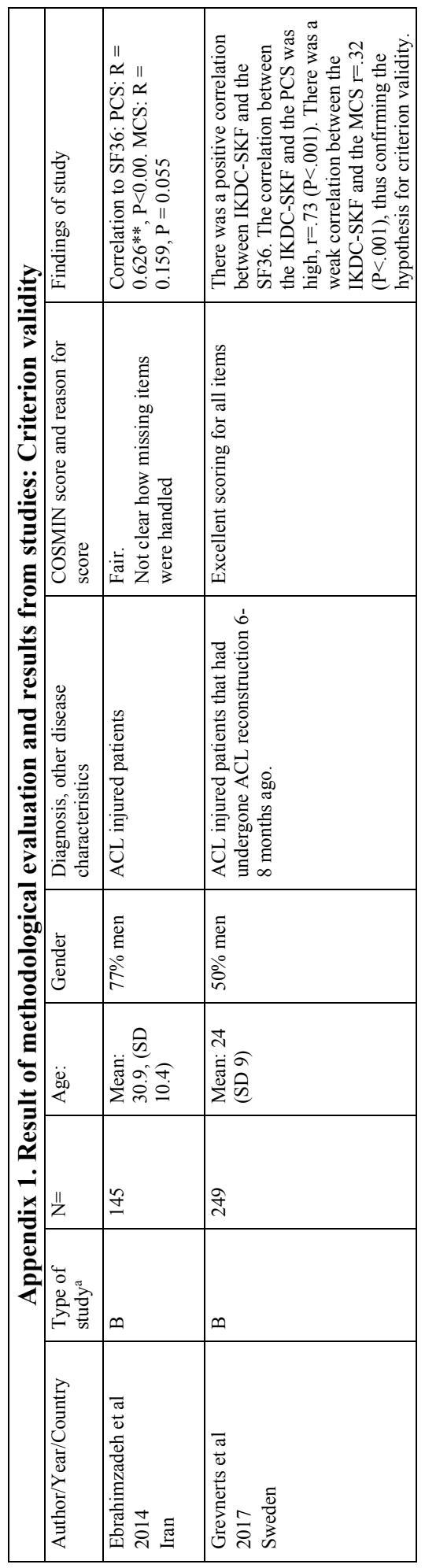

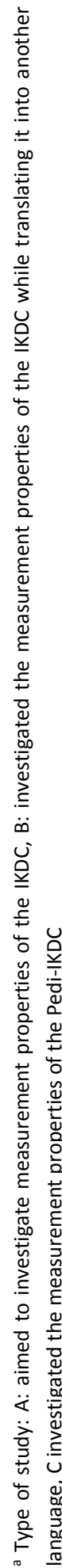




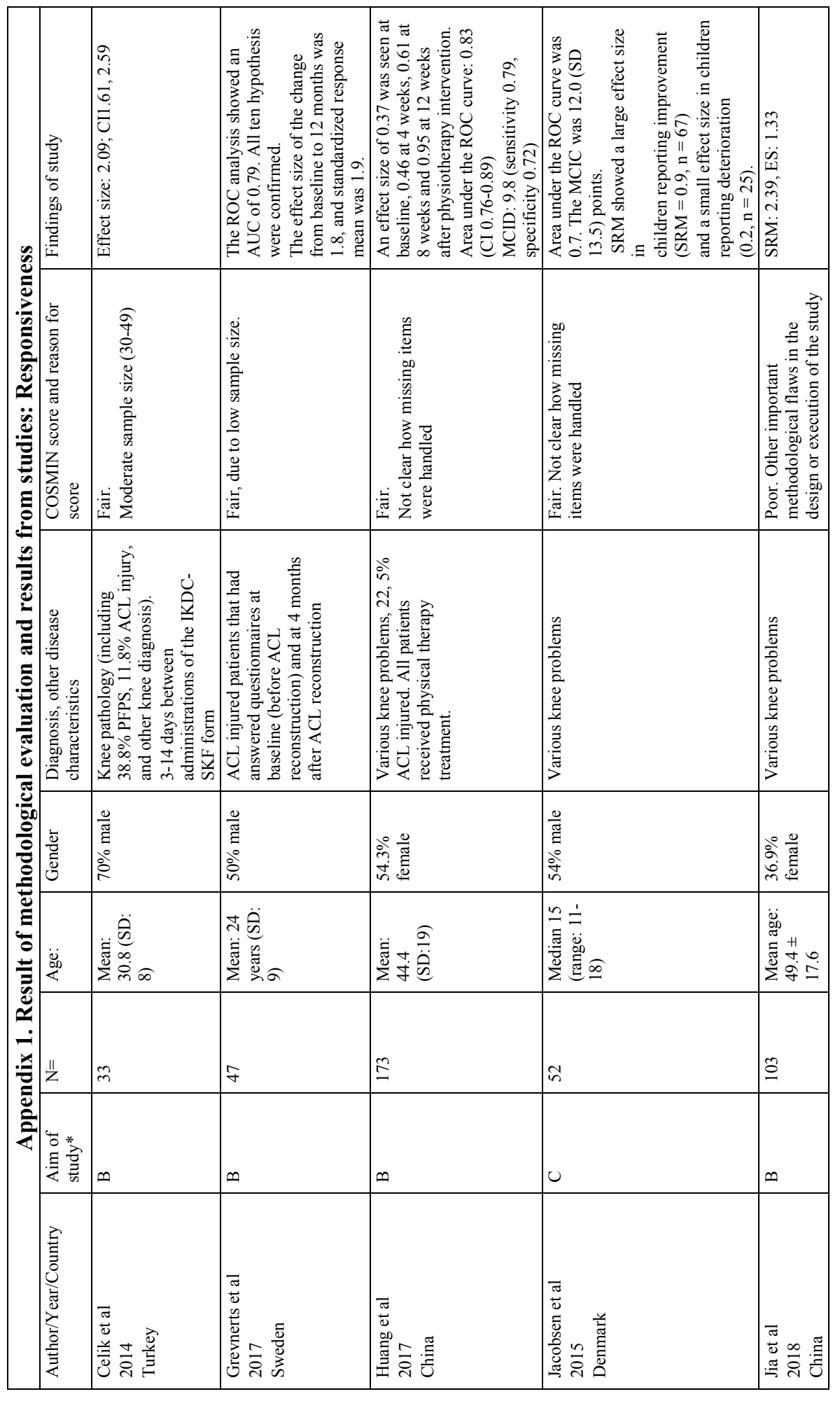



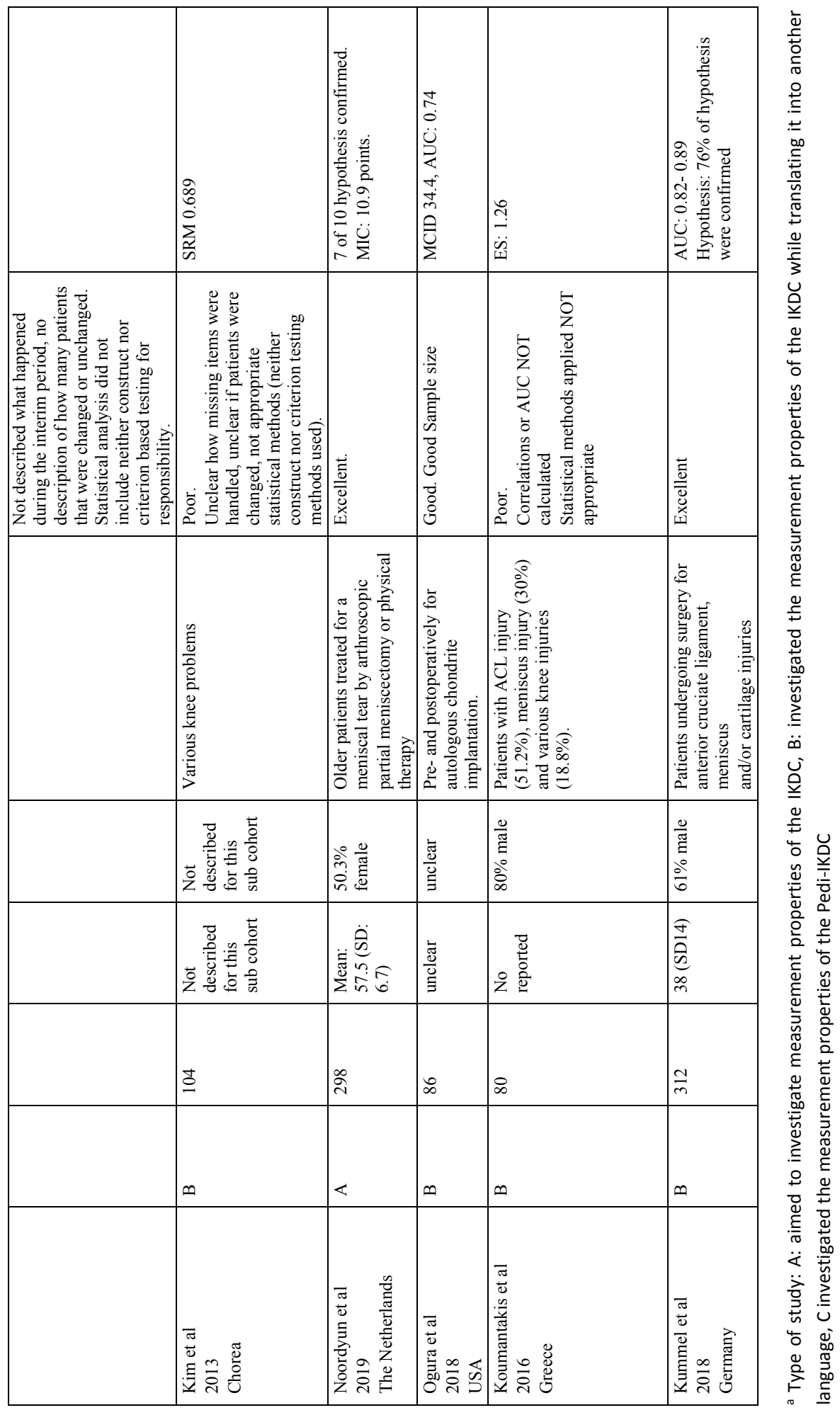


\begin{tabular}{|c|c|c|c|c|c|c|c|c|c|}
\hline & 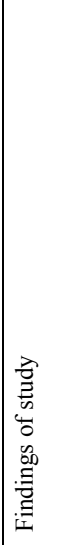 & 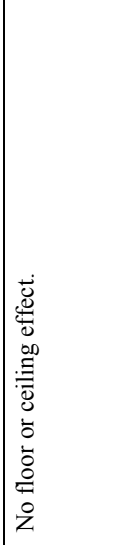 & 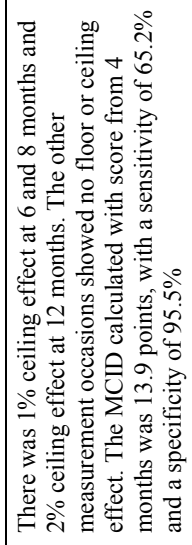 & 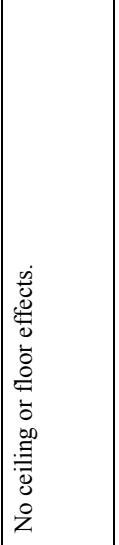 & 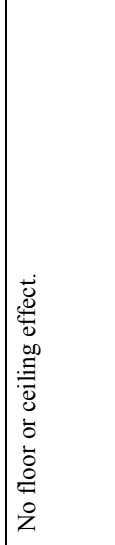 & 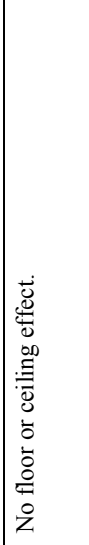 & 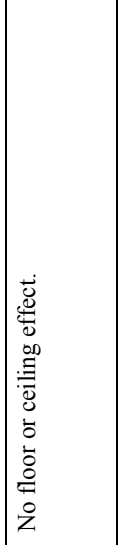 & 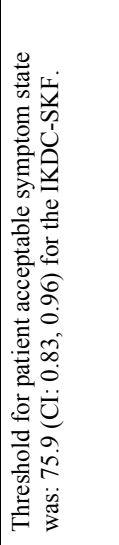 & 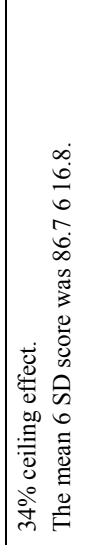 \\
\hline 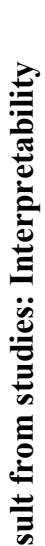 & 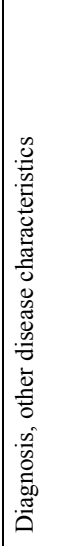 & 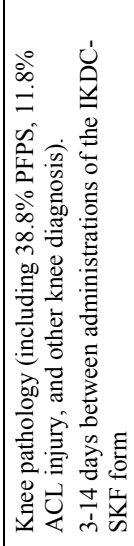 & 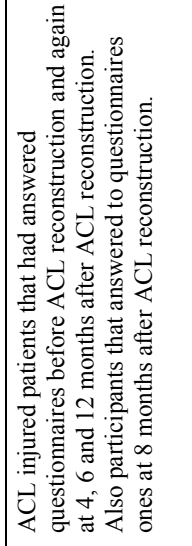 & 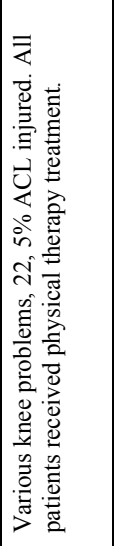 & 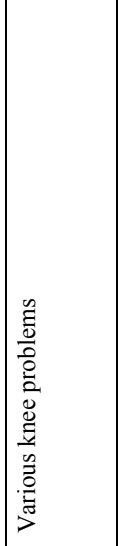 & 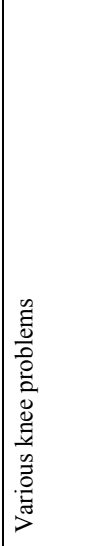 & 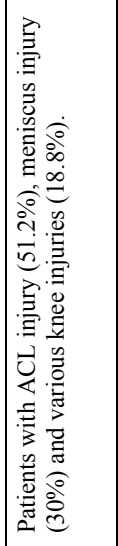 & 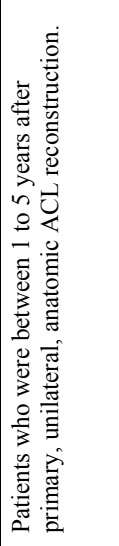 & 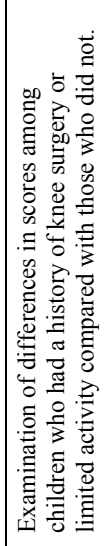 \\
\hline 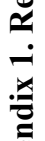 & $\begin{array}{l}\breve{v} \\
\frac{\vec{v}}{\bar{v}} \\
0\end{array}$ & 窇 & 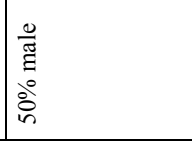 & 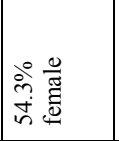 & 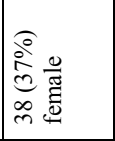 & 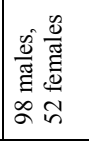 & 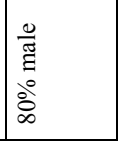 & 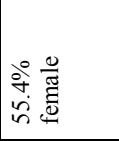 & 它造 \\
\hline$\overline{\frac{2}{4}}$ & 芦 & 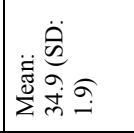 & 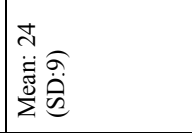 & 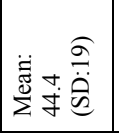 & 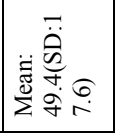 & 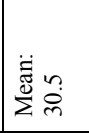 & 离 & 嶑 & 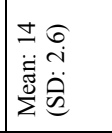 \\
\hline & z & $\cong$ & 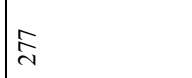 & $\cong$ & $\stackrel{\varrho}{\varrho}$ & $i n$ & $\infty$ & $\overline{\vec{n}}$ & ఫ్లి \\
\hline & 皇害 & $\infty$ & $\infty$ & $\infty$ & $\infty$ & $\infty$ & $\infty$ & $\varangle$ & $\varangle$ \\
\hline & 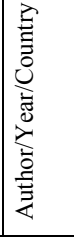 & 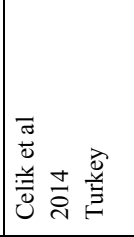 & 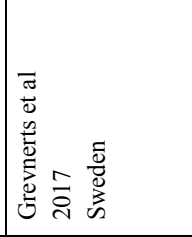 & 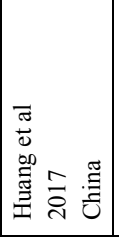 & 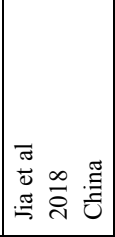 & 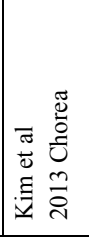 & 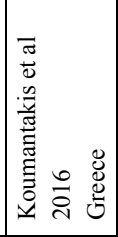 & 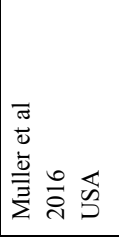 & 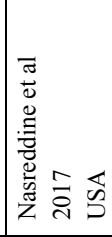 \\
\hline
\end{tabular}




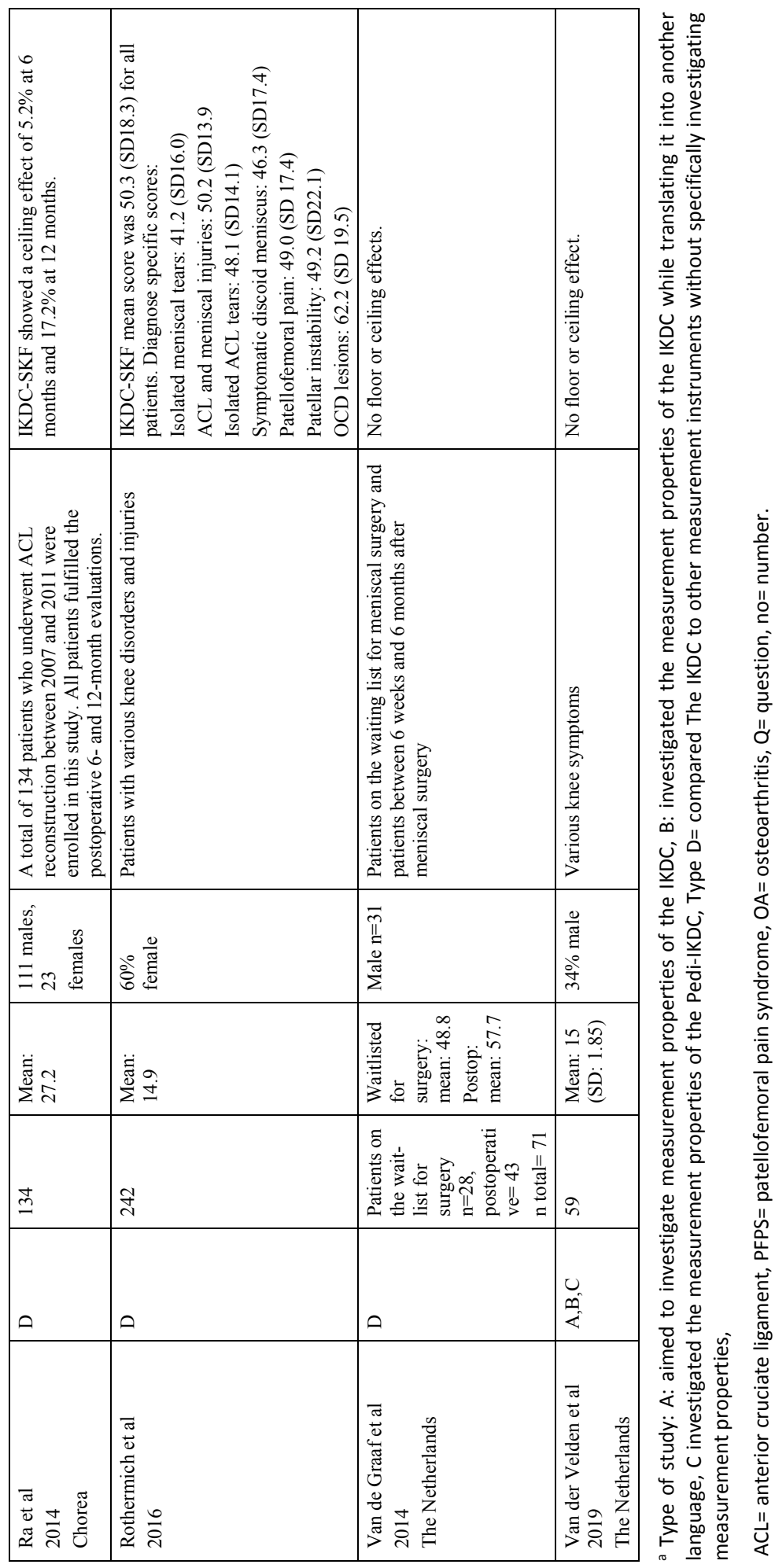




\section{Papers}

The papers associated with this thesis have been removed for copyright reasons. For more details about these see:

http://urn.kb.se/resolve?urn=urn:nbn:se:liu:diva-160918 


\section{FACULTY OF MEDICINE AND HEALTH SCIENCES}

Linköping University Medical Dissertation No. 1706, 2019

Division of physiotherapy, Department of Medical and Health Sciences

Linköping University

SE-581 83 Linköping, Sweden

www.liu.se

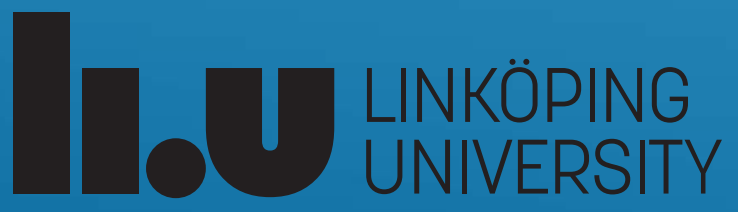

